\title{
EFFECT OF SURFACE ROUGHNESS ON WIND TURBINE PERFORMANCE
}

\author{
A Dissertation \\ by \\ ROBERT SCHAEFER EHRMANN
Submitted to the Office of Graduate and Professional Studies of Texas A\&M University
in partial fulfillment of the requirements for the degree of
DOCTOR OF PHILOSOPHY

\author{
Chair of Committee, Edward B. White \\ Committee Members, Alan Palazzolo \\ Othon K. Rediniotis \\ Thomas W. Strganac \\ Head of Department, Rodney D. W. Bowersox
}

August 2014

Major Subject: Aerospace Engineering

Copyright 2014 Robert Schaefer Ehrmann 


\begin{abstract}
Wind farm operators observe production deficits as machines age. Quantifying deterioration on individual components is difficult, but one potential explanation is accumulation of blade surface roughness. Historically, wind turbine airfoils were designed for lift to be insensitive to roughness by simulating roughness with trip strips. However, roughness was still shown to negatively affect performance. Furthermore, experiments illustrated distributed roughness is not properly simulated by trip strips.

To understand how real-world roughness affects performance, field measurements of turbine-blade roughness were made and simulated on a NACA $63_{3}-418$ airfoil in a wind tunnel. Insect roughness and paint chips were characterized and recreated as distributed roughness and a forward-facing step. Distributed roughness was tested in three heights and five density configurations. The model chord Reynolds number was varied between 0.8 to $4.8 \times 10^{6}$. Measurements of lift, drag, pitching moment, and boundary-layer transition were completed.

Results indicate minimal effect from paint-chip roughness. As distributed roughness height and density increase, lift-curve slope, maximum lift, and lift-to-drag ratio decrease. As Reynolds number increases, bypass transition occurs earlier. The critical roughness Reynolds number varies between 178 to 318, within the historical range. Little sensitivity to pressure gradient is observed. At a chord Reynolds number of $3.2 \times 10^{6}$, the maximum lift-to-drag ratio decreases $40 \%$ for $140 \mu \mathrm{m}$ roughness, corresponding to a $2.3 \%$ loss in annual energy production. Simulated performance loss compares well to measured performance loss on an in-service wind turbine.
\end{abstract}


To my family,

for years of loving support. 


\section{ACKNOWLEDGEMENTS}

I would like to first thank Sandia National Laboratories under contract number 1209202 with David Maniaci as technical monitor. Additional support was received from the Texas A\&M Energy Institute Fellowship sponsored by ConocoPhillips.

Throughout my time at Texas A\&M, countless people guided and affected my research. I would like to thank the project's technical monitors, Matthew Barone and David Maniaci for foresight and leadership during the project. C. P. van Dam and Chris Langel at UC Davis continually challenged me to acquire relevant data. Thank you to my committee members, Dr. Alan Palazzolo, Dr. Othon Rediniotis, and Dr. Thomas Strganac, for offering guidance while completing the experiment. Brian Rodgers and Chris Adcock helped ensure a functional model and successful integration. A special thanks to Todd Williams, Zahir Udovicic, Dave Shelby for an excellently manufactured model. John Kochan, Ric Warren, Doug Kutz, and Alex Herring skillfully led model installation and wind tunnel operations. Lastly, thank you to Rebecca Marianno for being helpful with purchases and a friendly person to talk with.

Numerous colleagues shaped my experimental approach and made research enjoyable. Tom Duncan, Brian Crawford, and David West at the Flight Research Laboratory loaned anemometer and profilometer equipment, greatly aiding in testing. Their test experience was invaluable during the model design phase. A special thanks to Dr. Jason Schmucker, Dr. Robert Downs III, Dr. Nicole Sharp, and Shalom John-

son for inspiring me to be a meticulous experimentalist. Dr. Matthew Kuester and 
Jason Monschke provided continual insight on the transition phenomenon and feedback on my research. The experiment would not have been successful without Robert Long preparing hotfilm equipment and Benjamin Wilcox completing LEWICE simulations. A special acknowledgement to Kristina Loftin who worked tirelessly throughout my time at Texas A\&M. A tremendous thank you to my advisor, Dr. Edward White for challenging and supporting me, shaping me into the scientist I am today. I owe great thanks to the many friends and family who supported and inspired me throughout this endeavor: to my brother, who sparked my engineering interest; my grandfather, who encouraged my love of flight and aircraft; my grandmother, who taught me diligence; my Texas family, who taught what it means to be an Aggie; my parents, who nurtured and guided me into who I am today; and lastly, my Lord and Savior, Jesus Christ, whose unconditional love sustains me. 


\section{TABLE OF CONTENTS}

Page

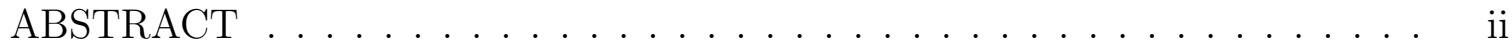

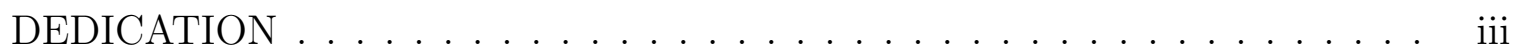

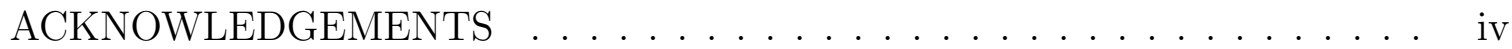

TABLE OF CONTENTS ........................... vi

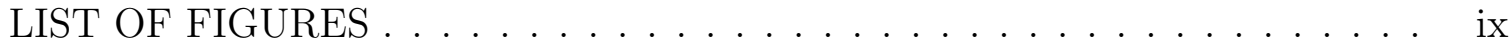

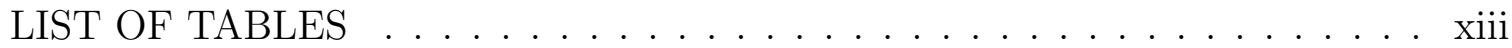

CHAPTER I: INTRODUCTION . . . . . . . . . . . . . . . . . . . 1

I.A. Wind Turbine Power Degradation . . . . . . . . . . . 2

I.B. Roughness Simulation and Description . . . . . . . . 4

I.C. Historical Airfoil Design . . . . . . . . . . . . 8

I.D. Roughness and Boundary Layer Stability . . . . . . . . 11

I.E. Research Objectives ................ 13

CHAPTER II: EXPERIMENTAL DESCRIPTION . . . . . . . . . . . . . . 16

II.A. Wind Tunnel . . . . . . . . . . . . . . . . . . 16

II.B. Model Design . . . . . . . . . . . . . . 18

II.C. Model Installation . . . . . . . . . . . . . . . . 22

II.D. Roughness . . . . . . . . . . . . . . . . 25

II.D.1. Clean Leading Edge . . . . . . . . . . . . . . . . . . . . . . . 28

II.D.2. Zig-Zag Trip Strip . . . . . . . . . . . . . . 28

II.D.3. Paint Roughness . . . . . . . . . . . . . . . . 29

II.D.4. Distributed Roughness . . . . . . . . . . . . . 31

II.E. Measurements . . . . . . . . . . . . . . 35

II.E.1. Pressure . . . . . . . . . . . . 36

II.E.2. Hotfilm Anemometry . . . . . . . . . . . . 40

II.E.3. Infrared Thermography . . . . . . . . . . . . . . 41

II.F. Test Operations . . . . . . . . . . . . . . . 43 
CHAPTER III: METHODOLOGY . . . . . . . . . . . . . . . . . . . 46

III.A. Lift, Moment, and Drag . . . . . . . . . . . . . . 46

III.A.1. Uncertainty . . . . . . . . . . . . . . 51

III.B. Wall Corrections . . . . . . . . . . . . . . . . . 53

III.C. Shaft Deflection Corrections . . . . . . . . . . 55

III.D. Laminar-to-Turbulent Transition . . . . . . . . . . . . 56

III.D.1. Infrared Thermography . . . . . . . . . . . 57

III.D.2. Spectral Content . . . . . . . . . . . . . 59

III.D.3. Intermittency . . . . . . . . . . . . . . . 61

III.D.4. Mean Voltage Variation . . . . . . . . . . . . 63

III.E. Annual Energy Production . . . . . . . . . . . . . . . 65

CHAPTER IV: RESULTS AND DISCUSSION $\ldots \ldots \ldots$. . . . . . . . . . . 69

IV.A. Lift, Moment, and Drag . . . . . . . . . . . . . . 69

IV.A.1. Repeatability . . . . . . . . . . . . 69

IV.A.2. Reynolds Number Dependency . . . . . . . . 71

IV.A.3. Two-Dimensional Steps . . . . . . . . . . . . . 73

IV.A.4. Distributed Roughness . . . . . . . . . . 73

IV.B. Boundary Layer Development . . . . . . . . . . . . . . 79

IV.C. Boundary-Layer Transition Phenomena . . . . . . . . 82

IV.D. Infrared Boundary-Layer Transition . . . . . . . . . 88

IV.E. Critical Roughness Reynolds Number Variation . . . . 94

IV.F. Wind Turbine Performance Loss . . . . . . . . . . . . . 100

CHAPTER V: CONCLUSIONS AND FUTURE WORK . . . . . . . . . . . 105

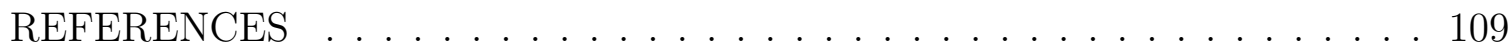

APPENDIX A: AIRFOIL COORDINATES . . . . . . . . . . . . 117

APPENDIX B: AIRFOIL PRESSURE PORTS . . . . . . . . . . . . . 118

APPENDIX C: COMPLIANT CEILING MOUNT . . . . . . . . . . . . . . 119

APPENDIX D: WAKE RAKE PITOT LOCATIONS . . . . . . . . . . . . . 120 
APPENDIX E: BOUNDARY LAYER RAKE POSITIONS . . . . . . . . . . . . 121 APPENDIX F: HOTFILM SENSOR LOCATIONS . . . . . . . . . . . . . . . 122 APPENDIX G: AIRFOIL PERFORMANCE SUMMARY . . . . . . . . . . . . . 123 APPENDIX H: INFRARED THERMOGRAPHY SUMMARY . . . . . . . . . 126 


\section{LIST OF FIGURES}

FIGURE

Page

I.1 Wind turbine blade roughness. . . . . . . . . . . . . . . 2

I.2 Power degradation due to soiling for a megawatt-scale, pitchregulated, variable-speed wind turbine. .......... 5

II.1 Schematic of the Texas A\&M Low-Speed Wind Tunnel. . . . . . . . . 17

II.2 Contour plot of the LSWT turbulence intensity as a function of speed and dynamic pressure. . . . . . . . . . . . . . 18

II.3 NACA $63_{3}-418$ airfoil coordinates. . . . . . . . . . . . . . . 20

II.4 Drawing of the model cross section, illustrating the various components. 21

II.5 Drawing of floor balance mounting setup. . . . . . . . . . . . . . 24

II.6 Drawing of the ceiling mounting system. . . . . . . . . . . . . . . 25

II.7 Example the ExaScan measuring erosion on a blade segment. . . . . . 26

II.8 Image of the chipped paint (a) observed in-service and (b) simulated on wind tunnel model. . . . . . . . . . . . . . . . . 30

II.9 Images of insect roughness on leading edges. . . . . . . . . . . . . . 32

II.10 Simulated accumulated insect distribution with the $30 \%$ cutoff range shown with red cirlces. . . . . . . . . . . . . 33

II.11 Random roughness pattern with $3 \%$ coverage. . . . . . . . . . . 36

II.12 Spanwise drag variation shown relative to wing static pressure ports and standard wake rake location. . . . . . . . . . . . . . 38

II.13 Boundary layer rake (a) side view and (b) front view. . . . . . . . . . 39

II.14 Image of the installed hotfilms and 140-15 roughness. . . . . . . . . . . 41

II.15 Image of the model upper main body with the heating sheet installed. 42 
III.1 Pressure deficit at $\alpha=6^{\circ} \ldots \ldots \ldots \ldots \ldots \ldots$

III.2 Airfoil wake at $\alpha=11^{\circ}$ illustrating separation. . . . . . . . . . . . 50

III.3 IR image of two-dimensional transition front at $45 \%$ chord. . . . . . . 57

III.4 Example of (left) original and (right) corrected IR images. . . . . . . . 58

III.5 Hotfilm spectra at $R e_{c}=1.6 \times 10^{6} \ldots \ldots \ldots \ldots \ldots$

III.6 Hotfilm time series illustrating voltage spikes due to turbulent spots. 62

III.7 Example of hotfilm intermittency calculations. . . . . . . . . . . . . . 64

III.8 Hotfilm voltage variation with angle of attack. . . . . . . . . . . 65

III.9 Map of U.S. wind speed at $100 \mathrm{~m}$ above the ground. . . . . . . . . . 67

IV.1 Repeatability of the clean configuration at $R e_{c}=1.6 \times 10^{6} \ldots \ldots 70$

IV.2 Repeatability of the 140-03 configuration at $R e_{c}=2.4 \times 10^{6} \ldots \ldots 71$

IV.3 Reynolds number variation of the clean configuration. . . . . . . . . 72

IV.4 Lift and drag data for the wavy, forward-facing step. . . . . . . . . . 74

IV.5 Lift coefficient variation with angle of attack for distributed roughness at $R e_{c}=2.4 \times 10^{6} \ldots \ldots \ldots \ldots \ldots$

IV.6 Drag polar at $R e_{c}=2.4 \times 10^{6}$ for numerous configurations $\ldots \ldots$. . . 76

IV.7 Moment coefficient variation with angle of attack at $R e_{c}=$

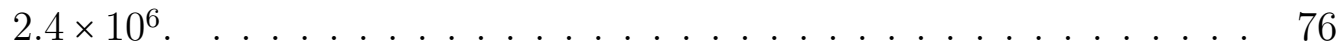

IV.8 Drag polar illustrating roughness height variation at $R e_{c}=$ $2.4 \times 10^{6} \ldots \ldots \ldots \ldots \ldots \ldots \ldots \ldots$

IV.9 Drag polar illustrating the Reynolds number variation for 140-03. . . 79 
IV.10 Boundary layer profiles the for clean configuration at $R e_{c}=$

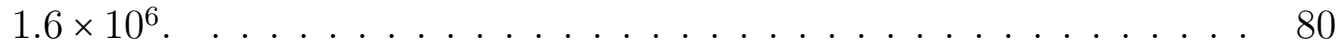

IV.11 Boundary layer profiles at $R e_{c}=1.6 \times 10^{6}$ and $50 \%$ chord. . . . . 82

IV.12 Boundary layer development for the 140-03 configuration. . . . . . . . 83

IV.13 Freelogram for the clean configuration at $R e_{c}=0.8 \times 10^{6} \ldots \ldots . \quad 84$

IV.14 Freelogram for the $140-03$ configuration at $R e_{c}=0.8 \times 10^{6} \ldots \ldots \quad 85$

IV.15 Freelogram for the 200-03 configuration at $R e_{c}=0.8 \times 10^{6} \ldots \ldots$. . 86

IV.16 Freelogram for the $200-03$ configuration at $R e_{c}=1.6 \times 10^{6} \ldots \ldots 87$

IV.17 Freelogram for the straight, forward-facing step configuration at $R e_{c}=0.8 \times 10^{6} \ldots \ldots \ldots \ldots \ldots \ldots \ldots \ldots \ldots \ldots$

IV.18 Infrared boundary-layer transition data at $R e_{c}=2.4 \times 10^{6} \ldots \ldots .90$

IV.19 Infrared boundary-layer transition data at $R e_{c}=3.2 \times 10^{6} \ldots \ldots \quad 91$

IV.20 Infrared boundary-layer transition for multiple $100 \mu \mathrm{m}$ roughness densities at $R e_{c}=3.2 \times 10^{6} \ldots \ldots \ldots \ldots \ldots \ldots \ldots \ldots \ldots \ldots$

IV.21 Infrared boundary-layer transition for multiple $140 \mu \mathrm{m}$ roughness densities at $R e_{c}=1.6 \times 10^{6} \ldots \ldots \ldots \ldots \ldots \ldots$

IV.22 Infrared boundary-layer transition at $\alpha=0^{\circ}$ for multiple configurations. 95

IV.23 Infrared boundary-layer transition for 100-15 at various angles

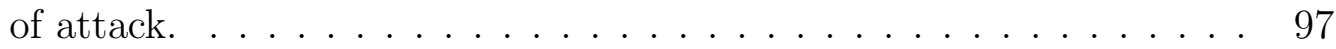

IV.24 Critical roughness Reynolds number variation with airfoil arc

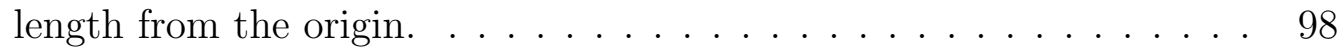

IV.25 Critical roughness Reynolds number variation with angle of attack. . 99

IV.26 Degraded power performance illustrating (a) a representative power curve and (b) percent power loss for multiple configurations. . 102 
FIGURE

IV.27 Measured power loss on a megawatt-scale wind turbine due to insect accumulation compared to predicted power loss from 140-03 simulated insect roughness. . . . . . . . . . . . . . . . . 103

C.1 Drawing of the compliant ceiling mount. . . . . . . . . . . . 119

H.1 IR boundary-layer transition at $R e_{c}=0.8 \times 10^{6} \ldots \ldots \ldots \ldots$

H.2 IR boundary-layer transition at $R e_{c}=1.6 \times 10^{6} \ldots \ldots \ldots \ldots 127$

H.3 IR boundary-layer transition at $R e_{c}=2.4 \times 10^{6} \ldots \ldots \ldots \ldots 128$

H.4 IR boundary-layer transition at $R e_{c}=3.2 \times 10^{6} \ldots \ldots \ldots \ldots \ldots$

H.5 IR boundary-layer transition at $R e_{c}=4.0 \times 10^{6} \ldots \ldots \ldots \ldots$

H.6 IR boundary-layer transition at $R e_{c}=4.4 \times 10^{6} \ldots \ldots \ldots \ldots 131$

H.7 IR boundary-layer transition at $R e_{c}=4.8 \times 10^{6} \ldots \ldots \ldots \ldots$

H.8 IR boundary-layer transition at $R e_{c}=5.0 \times 10^{6} \ldots \ldots \ldots \ldots$ 


\section{LIST OF TABLES}

TABLE

Page

II.1 Model configuration summary. . . . . . . . . . . . . . . 28

II.2 Summary of roughness statistics. . . . . . . . . . . . . . 35

IV.1 Summary of $R e_{k, \text { crit }}$ data at $\alpha=0^{\circ} \ldots \ldots \ldots$. . . . . . 96

IV.2 Wind turbine annual energy production percent loss. . . . . . . . . 101

A.1 Interpolated NACA $63_{3}-418$ coordinates. . . . . . . . . . 117

B.1 Pressure port locations, with $z / c$ of zero at midspan. . . . . . . 118

D.1 Wake rake Pitot pressure locations, with $z / c$ of zero at midspan. . . 120

E.1 Relative positions of the Pitot boundary layer rake probes. . . . . . . 121

F.1 Hotfilm sensor locations. . . . . . . . . . . . . 122

G.1 Airfoil performance summary at $R e_{c}=1.6 \times 10^{6} \ldots \ldots \ldots 123$

G.2 Airfoil performance summary at $R e_{c}=2.4 \times 10^{6} \ldots \ldots \ldots$. . . 124

G.3 Airfoil performance summary at $R e_{c}=3.2 \times 10^{6} \ldots \ldots \ldots \ldots$. . . . 124

G.4 Airfoil performance summary at $R e_{c}=4.0 \times 10^{6} \ldots \ldots \ldots \ldots$ 


\section{CHAPTER I INTRODUCTION}

Wind farms are plagued with underperformance compared to manufacturer predictions. Capacity factors have been overestimated by $10 \%$ to $30 \%$ [1]. However, overprediction is difficult to characterize. Culprits range from nonoptimal siting, misunderstood wind resource, and even political atmosphere. One possible aerodynamic explanation is blade roughness caused by erosion (sand, salt, and hail), foreign

deposits (insects, ice), or coating spallation, illustrated in Fig. I.1. Each harms performance by decreasing the section maximum lift and lift-curve slope and increasing drag [2]. Insect roughness was observed to cause a $25 \%$ decrease in energy production [3]. Similarly, erosion has been observed to result in $20 \%$ or greater loss in energy capture and can affect blades that have been operating for as little as two-to-three years $[4,5]$. Blade erosion now accounts for $6 \%$ of all wind turbine related repairs [6].

While the detrimental effect of roughness is unquestioned, much progress remains to be made in quantifying the magnitude of the effect. Blade designers continue to struggle with minimizing blade sensitivity to roughness. Lastly, operators have no quantitative sense of production loss due to roughness. Therefore, this dissertation aims to quantify annual energy loss for various types of roughness configurations at operationally significant Reynolds numbers. Empirical guidelines for boundary-layer transition will be created. The final data will also serve to validate performance prediction software. 


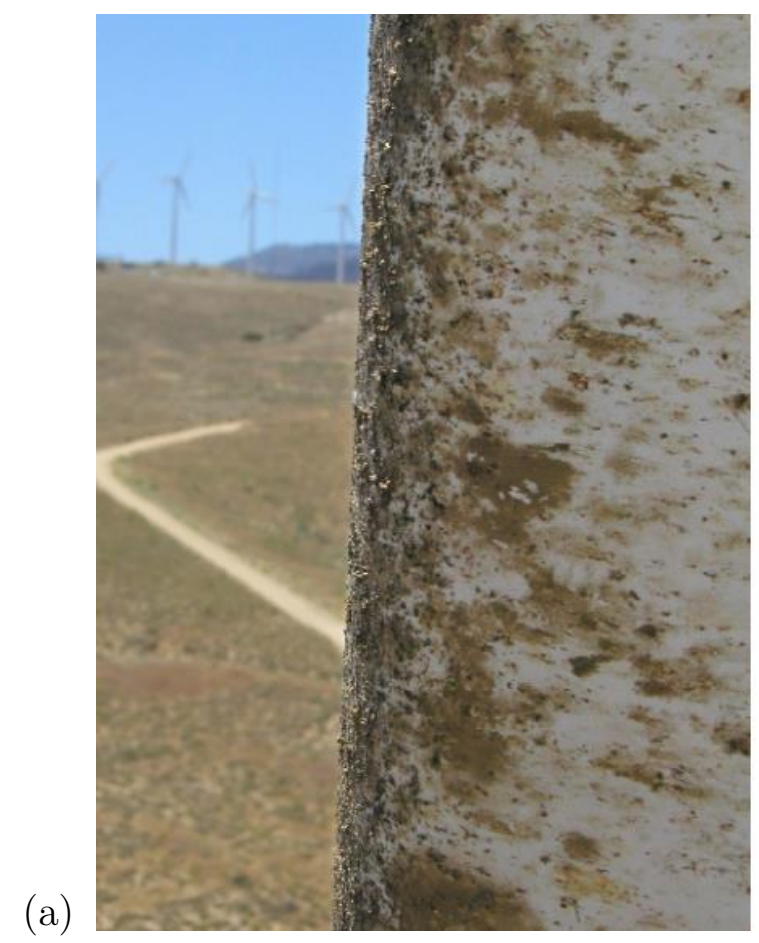

(b)

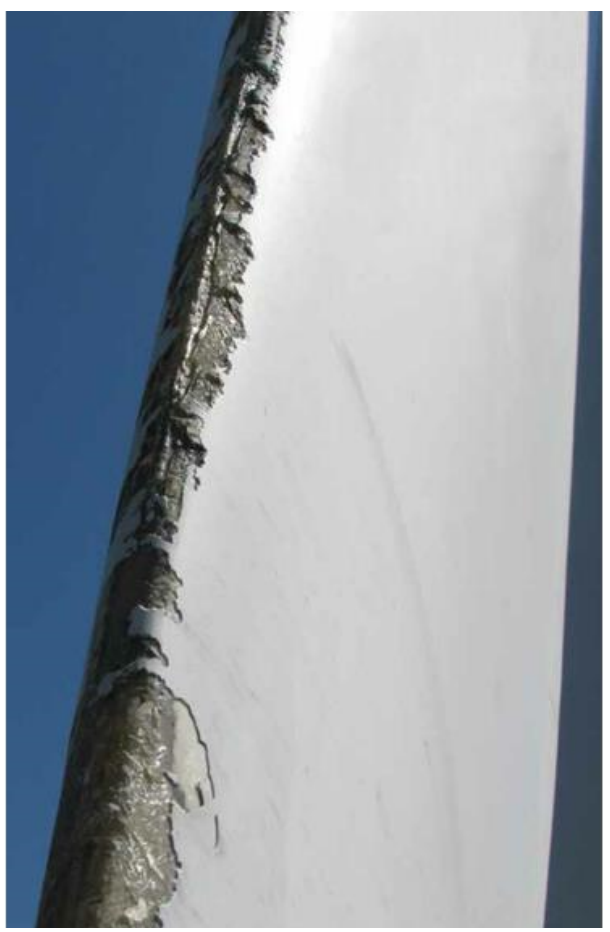

Figure I.1. Wind turbine blade roughness. Roughness here is of (a) insect or (b) erosion type $[5,7]$.

\section{I.A. Wind Turbine Power Degradation}

Few open-literature, quantitative surveys of wind turbine blade roughness exist. Modern manufacturers and wind farm operators hesitate to publish due to brand perception. Much of the available power data is from older, stall-regulated turbines where roughness was a considerable issue. As variable speed, pitch-regulated turbines have become commonplace, the sensitivity to roughness has decreased. However, as blades become thicker, anecdotal evidence is indicating roughness is once again becoming an issue. Roughness is also being revisited as financers demand accurate performance estimates. Despite this, there are few modern references clearly defining and quantifying blade roughness. 
Insect contamination on stall-regulated turbines has been shown to decrease power production on turbines. Moroz and Eggleston studied $120 \mathrm{~kW}$ in San Gorgonio, California [8]. Over 15 days of soiling, turbines observed a $20 \%$ loss in rated power. Malhotra-Bush and Hulls found vertical-axis wind turbines exhibited seasonal roughness sensitivity, correlating to regional rainfall [9]. In dry months, production decreased $25 \%$, resulting in a $7 \%$ decrease in annual energy production (AEP). The Solar Energy Research Institute (later the National Renewable Energy Laboratory, NREL) observed high roughness sensitivity with a $30 \%$ loss in AEP for a $65 \mathrm{~kW}$ turbine [10]. A new airfoil series was designed, improving stalled performance, but a $20 \%$ decrease in AEP remained. Corten measured a $25 \%$ decrease in energy production due to insect roughness on a $700 \mathrm{~kW}$ turbine [3]. The above stall-regulated turbines are sensitive to roughness because rated power is limited with blade stall, which occurs earlier on roughened blades.

As turbines grew larger and pitch mechanisms more reliable, pitch-regulated turbines became standard. Pitch-regulated turbines decrease the blade angle of attack to control rated power. Since rated power is maintained, power deficits only occur in region II, between cut-in and rated power. As a rule of thumb, a modern, pitch-regulated turbine with a fully-turbulent blade compared to a naturally transitioning blade will have a $5 \%$ decrease in annual energy production [11]. To the author's knowledge, no in-service, pitch-regulated, variable-speed power curve in literature indicates a power deficit. The best source is Spruce, who in 2006, measured a maximum decrease of $13 \%$ on "active stall," $1.5 \mathrm{MW}$ turbines [7]. The "active stall" blades were pitched to compensate for reductions in power output due to in- 
sect accumulation. The active blade control is more representative of pitch-regulated operation. However, at high wind speeds, there was a power deficit, uncharacteristic of pitch-regulated operation.

To fill this gap, four years of data from a megawatt-scale, pitch-regulated, variable-speed turbine were analyzed. Power was not observed to decay over the four year period. However, similar to Malhotra-Bush and Hills and Spruce, power decayed during dry months when rain was not cleaning the blades. Data were averaged over wet and dry months, with mean rainfall of 1.7 in and 0.1 in, respectively. At minimum, 9,000 points were averaged for a given period. Data were density corrected and filtered to avoid wake interference. Wind speed was acquired from a meteorological mast ten diameters away. Fig. I.2a illustrates the decayed power curve. Power and wind speed are nondimensionalized by the rated quantities. The percent power loss is shown in Fig. I.2b. The gray area indicates uncertainty based on standard error. At lower wind speeds, there is significant power loss. Between wind speed of 0.5 and 0.9 , it averages $4 \%$. Beyond rated power, the loss is negligible. For an IEC class II mean wind of $8.5 \mathrm{~m} / \mathrm{s}$, the decayed power curve corresponds to a $3.4 \%$ decrease in power.

\section{I.B. Roughness Simulation and Description}

Roughness has shown itself to be a considerable problem for wind turbine performance and airfoils have consistently been designed to combat this. Airfoils were often validated experimentally with grit or trip strips to simulate rough conditions. Trip strips are favored for computational fluid dynamics (CFD) validation because 

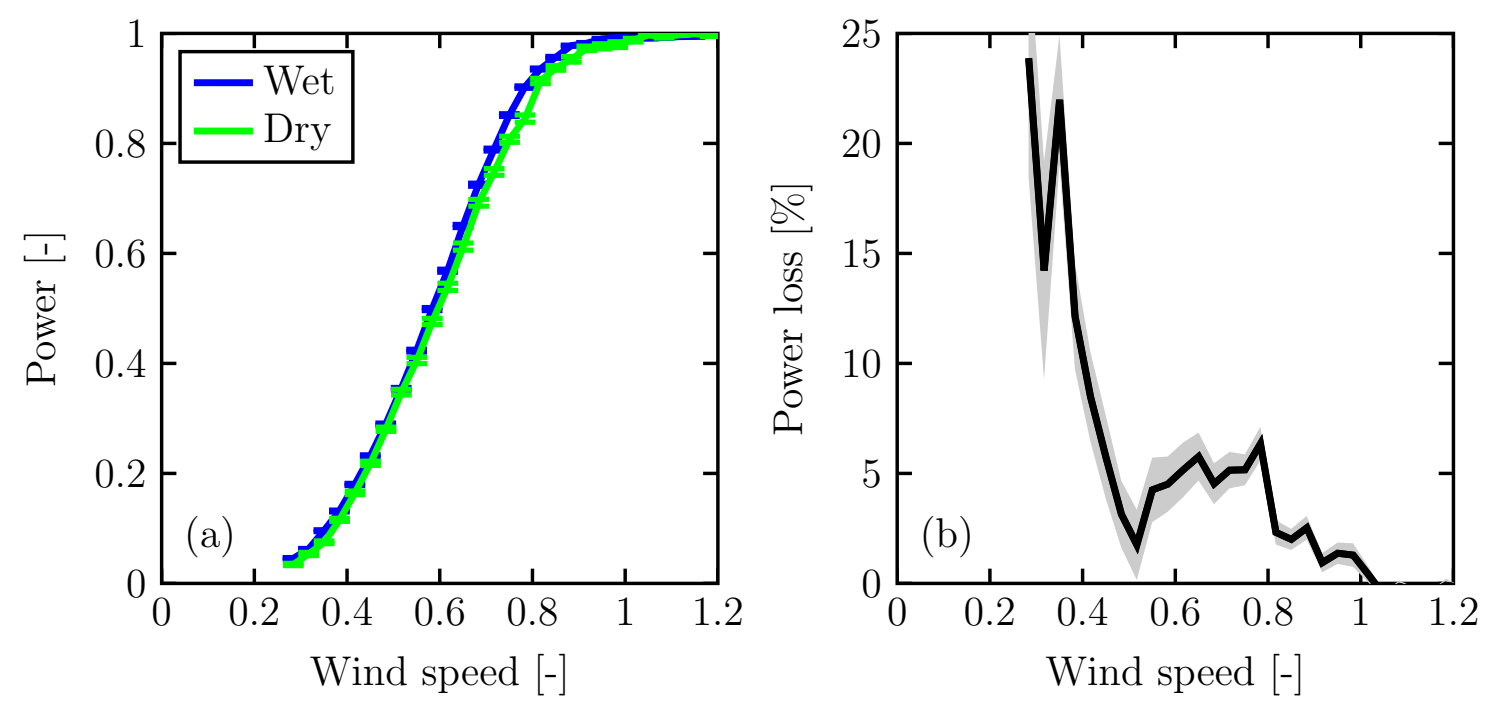

Figure I.2. Power degradation due to soiling for a megawatt-scale, pitchregulated, variable-speed wind turbine.

they force transition to occur at a discrete location. However, White et al., Sareen et al., and Timmer and Schaffarczyk found that a trip strip is not representative of distributed roughness $[2,12,13]$. Grit roughness is more appropriate, but inconsistently defined and applied between references. A summary of the best approaches to roughness simulation on airfoils follows.

An early study of roughness effects was completed on sailplanes by Boermans and Selen [14]. Adhesive backed polyester film was wrapped around sailplane wings to collect insect strikes during flight. These were removed and applied directly to wind tunnel models at $R e_{c}=1.5 \times 10^{6}$, accurately representing the effect of insects on airfoil performance. The insects were also simulated with discrete $330 \mu \mathrm{m}$ tall elements. This failed to properly represent insect roughness at low lift coefficients, but succeeded at higher lift. The insect height was not measured, but from Coleman, $330 \mu \mathrm{m}$ roughness is a low estimate for either house flies or fruit flies [15]. 
Moroz and Eggleston created an insect moulding to represent roughness measured on in-service wind turbine blades [8]. Insect moulding and grit roughness were tested on a NACA 4415 at $R e_{c}=1.0 \times 10^{6}$. Despite careful grit roughness distribution, with high density at the leading edge decreasing aft on the airfoil, grit had consistently higher drag. However, the simulated insect pattern observed a drag minimum similar to the clean configuration. At higher angles of attack, drag coincided with the grit roughness, mirroring Boermans and Selen's results.

White et al. tested a more realistic approach to distributed roughness on a NACA $63_{3}-418$ with a clean, tripped, low- $k$, and high- $k$ leading edge [2]. The low- $k$ and high- $k$ leading edges had a maximum roughness height of $70 \mu \mathrm{m}$ and $1.2 \mathrm{~mm}$, respectively. As expected, the increased roughness decreased maximum lift and increased drag. The tripped leading edge yielded a slightly higher maximum lift and generally lower drag than the low- $k$ leading edge. A significant result was that the trip tape proved to be unrepresentative of roughness.

Many recent papers have qualitatively reviewed the roughness problem on wind turbine blades. Dalili et al. discuss icing, insect roughness, and sand erosion as the major environmental concerns [16]. Insects tend to fly in warm, humid regions in low wind. As turbines become larger, cut-in speeds have been decreasing, increasing the likelihood of insect contamination. Dalili et al. note that a common solution for insect contamination is to wait for rain to clean the blades. Pechlivanoglou et al. more closely investigated the effect of blade roughness on wind turbine performance [17]. Additional blade roughness sources are identified, including sand build-up, salt, water droplets, and manufacturing imperfections. Sand build-up is difficult to characterize 
as no literature is available regarding sand aloft between $20 \mathrm{~m}$ and $150 \mathrm{~m}$. Rainfall is assumed to be of minimal effect since it occurs over relatively short time frames. Literature has not indicated a correlation between rainfall droplets and performance decrease. A panel-method investigation of shape deviations indicated that manufacturing defects, erosion, or sand build-up can have large effects on maximum lift performance. The deviation is highly dependent upon topography, blade geometry, tower height, and weather.

Keegan et al. focused upon erosion caused by rain and hail [18]. Rain can erode gelcoat off of the leading edge in as little as two years. LM Wind and 3M separately designed and tested coatings to protect the leading edge from water impingement. Hail, while infrequent, is more damaging than water droplets. Lastly, Sareen et al. simulated varying degrees of leading edge erosion [12]. It was simulated by observing in-service blades and creating similar patterns in wind tunnel models. They found a $4 \%$ to $24 \%$ decrease in annual energy production. However, the highest Reynolds number tested was $1.85 \times 10^{6}$, lower than modern turbine scales.

Simulating insect roughness has been successful, but only with atypical approaches. Both Boermans and Selen and Moroz and Eggleston indicated different performance for insect roughness compared to grit roughness. Grit roughness was not well represented by trip strips. The surveys indicate general problems and approaches to minimize roughness. However, few details are given regarding roughness height, location, and distribution, making it difficult to simulate and understand how performance is affected by contamination. 


\section{I.C. Historical Airfoil Design}

In 1984, NREL began design of a new wind turbine airfoil series that deviated from traditional aviation airfoils. Airfoils were designed thicker and for lower Reynolds number than standard aircraft airfoils. One primary goal was for the maximum lift coefficient and lift curve slope to be insensitive to roughness [19]. Airfoils were designed with the Eppler Airfoil Design code [20]. Boundary-layer transition was forced and the momentum thickness was increased attempting to simulate distributed roughness. Early series airfoils were validated with wind tunnel testing at Delft University and atmospheric testing [21]. The redesigned airfoils reduced sensitivity to roughness, but still observed a $20 \%$ decrease in power production on the tested turbines [10].

The mid-series airfoils were experimentally validated at The Ohio State University [22]. Grit with a $k / c=0.0019$ was attached in a distinct pattern of varying distribution based on measured wind turbine roughness, where $k$ was the roughness height and $c$ was the model chord. Static and dynamic measurements were made up to $R e_{c}=1.5 \times 10^{6}$. The lift curve slope decreased $9 \%$ while the maximum lift decreased 11\%. Drag increased by $88 \%$.

Later airfoils, such as the S825 and S827, were tested at the NASA Langley Low-Turbulence Pressure Tunnel [23]. The S827 was designed to maximize laminar flow with a pressure minimum at $60 \%$ chord. NACA grit was applied to simulate roughness. NACA grit is defined as $k / c=0.00458$ applied with $5 \%$ to $10 \%$ coverage to $8 \%$ chord on the upper and lower surfaces [24]. Reynolds numbers between $1 \times 10^{6}$ and $6 \times 10^{6}$ were tested. At $R e_{c}=6 \times 10^{6}$, drag increased $200 \%$ due to grit roughness. 
The lift-curve slope decreased 25\%. The Eppler code reasonably predicted the clean configuration, but failed to match the fixed transition lift data.

Both OSU and NASA experiments used sand grain to simulate roughness. As discussed in Section I.A, sand grain is not necessarily representative of insect roughness, but is an improvement over trip strips. The experiments indicated high sensitivity to roughness, suggesting the Eppler code approach to roughness simulation was insufficient. At best, the airfoils were designed for $40 \mathrm{~m}$ to $50 \mathrm{~m}$ diameter turbines and were only $14 \%$ to $26 \%$ thick. The smallest turbine Vestas currently sells is an $80 \mathrm{~m}, 2 \mathrm{MW}$ V80. A need for thicker airfoils insensitive to roughness at higher Reynolds numbers still existed.

The Aeronautical Research Institute of Sweden, Flygtekniska Försöksanstalten (FFA), developed three series of airfoils in the mid-eighties [25]. These were designed similarly to the NREL series using Mark Drela's XFOIL panel method and integral boundary layer code [26]. Unlike the NREL series, the FFA airfoils were developed to be structurally efficient, with up to $50 \%$ thick profiles for the blade root. The airfoils were validated with a $700 \mu \mathrm{m}$ trip strip at $5 \%$ chord. Correlation between simulation and experiment were good for both configurations.

In this same time period, the Delft University of Technology (DUT) noted thicker NACA series airfoils had early transition, severely degrading performance [27]. Therefore, in response to the lack of thick airfoils insensitive to leading edge contamination, DUT designed their own airfoil series. Airfoils ranged from $15 \%$ to $40 \%$ thick. Sensitivity to nose contour and surface contamination was designed to be low. Knowing that wind turbines were continuing to increase scale, the airfoils 
were designed at relevant Reynolds numbers. Moderate design lift coefficients were targeted, acknowledging the airfoil will rarely have ideal, clean performance. The airfoils were designed with RFOIL, an XFOIL derivative, tuned to the NACA 6series airfoils [28]. Validation was achieved with wind tunnel tests using trip strips to simulate roughness.

Timmer found that the thicker, mid-span blade sections at high Reynolds number were more sensitive to roughness than desired [13]. A modified version of the $30 \%$ thick DU-W-300 was tested in a cryogenic wind tunnel to achieve $R e_{c}=10^{7}$. A $400 \mu \mathrm{m}$ trip strip and $250 \mu \mathrm{m}$ grit roughness were compared. The trip strip and grit maximum lift were $16 \%$ and $32 \%$ lower than the clean configuration at $R e_{c}=10^{7}$, respectively. Roughness performance improved as Reynolds number increased. The trip strip failed to simulate roughness properly. The airfoil showed high sensitivity to roughness.

Design on the Risø airfoil series started in the mid-nineties with similar roughness insensitivity goals [29]. The A-series ranged in thickness from $12 \%$ to $30 \%$ and was designed for a $600 \mathrm{~kW}$ turbine. Roughness insensitivity was ensured by locating natural transition at the leading edge near stall. To simulate roughness in XFOIL during the design phase, boundary-layer transition was forced at the leading edge. However, results for the Ris $\varnothing$-A1 airfoil series showed higher-than-expected sensitivity to in-field roughness. The Ris $\varnothing-B 1$ series was designed for megawatt scale, variable-speed, pitch-regulated turbines [30]. Airfoil thickness varied between $15 \%$ and $53 \%$. Airfoils were chosen for high maximum lift, allowing for low-solidity blades. This is uncharacteristic of stall-regulated turbines, which desire a gentle stall which 
is more insensitive to roughness. The series was validated in a wind tunnel with roughness simulated with a trip strip, with maximum lift decreasing between $3.7 \%$ and $27 \%$, depending on location and height of the trip strip.

In summary, airfoil designers were keenly aware of sensitivity to roughness starting with the NACA series and continuing today. The primary design methodology for wind turbine airfoils has been a panel-method coupled with an integral boundary layer solution. Roughness was repeatedly simulated during design by forcing transition at the leading edge, allowing a turbulent boundary layer to develop. If the airfoil performance was insensitive to this, it was deemed insensitive to roughness. Wind tunnel testing validated designs by simulating roughness with trip strips and grit roughness, which in both cases has been shown to be unrepresentative of realistic roughness.

While improvements were made over the baseline airfoil designs, issues have persisted. Airfoils are still sensitive to contamination. As airfoils grow thicker, the sensitivity to contamination increases. Contamination has been poorly simulated in wind tunnel tests. Airfoils were generally designed for lower Reynolds numbers $(\mathrm{kW}$ scale turbines), raising particular concern as roughness becomes more sensitive at higher Reynolds numbers (MW scale turbines). For these reasons, the need for an improved airfoil design approach is evident.

\section{I.D. Roughness and Boundary Layer Stability}

Boundary-layer transition is dependent upon pressure gradient, freestream conditions (velocity, viscosity, turbulence intensity), and surface roughness. Additional 
effects include surface vibrations, boundary layer control, thermal gradients, and sweep and are neglected in this discussion. Freestream turbulence dependence is not discussed in the current research. Numerous nondimensional parameters are used to estimate when transition may occur. Common quantities include $k / \delta_{k}$ and $k / \delta_{k}^{*}$, where $k$ is the roughness height, $\delta$ is the boundary layer thickness, $\delta^{*}$ is the displacement thickness, and subscript $k$ indicates evaluation at the roughness element. Boundary layer thickness is difficult to define and generally avoided. Dryden suggested $k / \delta_{k}^{*}$ as a fundamental parameter, showing transition for various roughness element heights to collapse [31]. Smith and Clutter found this curve to vary if the roughness elements are moved near the leading edge [32]. First suggested by Schiller in 1932, the roughness Reynolds number, $R e_{k}=u_{k} k / \nu$ was preferred by Smith and Clutter, where $u_{k}$ is the velocity at the roughness height, $k$, and $\nu$ is the kinematic viscosity [33]. $R e_{k}$ was found to vary with $k / d$, where $d$ is the diameter of the roughness element $[32,34]$. Based on this data, Tani found the critical roughness Reynolds number to be proportional to $(k / d)^{(2 / 5)}[35]$.

Historical studies of roughness are generally limited to zero-pressure gradient flows. Roughness is characterized into three categories: 2D (trip strips or steps), isolated or arrayed 3D, or distributed 3D. The transition phenomenon is characterized differently for each roughness type. Boundary layers with 2D roughness illustrate forward-moving transition as $R e_{k}$ increases. This begins to occur when $R e_{k}$ is between 40 and 260, with a mean of 125 [32]. Isolated 3D roughness is "more critical" than $2 \mathrm{D}$ roughness, meaning the transition front shows little movement for subcritical $R e_{k}$ [36]. If $R e_{k, \text { crit }}$ is exceeded, transient growth briefly occurs, followed 
closely by bypass transition. Typical critical roughness Reynolds number values for height to diameter ratios near unity range from 600 to 900 for zero pressure gradient flows $[35,36]$. Tani notes that pressure gradient effects are minimal due to the $u_{k}$ term in $R e_{k}$. Distributed roughness had escaped a more formal approach due to difficulties in defining a "typical" surface. Rapid-prototyped patches of distributed roughness were tested on a flat plate by Downs et al. [37]. For supercritical roughness, the transition mechanism was similar to that of isolated 3D roughness. Neither Tollmien-Schlichting (TS)-like profiles nor TS-band disturbance frequencies were observed. This suggests transition for supercritical roughness occurs by the bypass mechanism, similar to Ergin and White [38]. The measurement domain was insufficient to show transition for the subcritical case. If subcritical, the steady transient disturbances would hasten the onset of transition via amplification of TS waves.

\section{I.E. Research Objectives}

Today's wind turbines are megawatt-scale and pitch-regulated with large differences between kilowatt-scale, stall-regulated turbines. While both are sensitive to roughness, little work has been done to quantify roughness performance detriment on modern wind turbines. This has been difficult due to limited quantitative blade roughness data, creating a need to characterize in-service wind turbine blade roughness. Realistic wind turbine roughness at appropriate Reynolds numbers has yet to be tested, with the majority of approaches using grit roughness or trip strips at Reynolds numbers below $2.0 \times 10^{6}$. Most airfoils have been designed for kilowatt-scale wind turbines, assuming trip strips are representative of roughness effects. In a sta- 
bility framework, little is known about the interaction between distributed roughness and forward-facing steps, particularly within pressure gradient flow. Lastly, no high Reynolds number performance and transition data are available to validate CFD simulations.

To address these issues, the following work is presented here: First, roughness on an in-service, megawatt-scale wind turbine is be characterized. This roughness is simulated on a $2 \mathrm{D}$ airfoil model in a wind tunnel. It is tested at $R e_{c}=0.8 \times 10^{6}$ to $4.8 \times 10^{6}$ with clean and multiple rough configurations. Insect roughness and $2 \mathrm{D}$ steps are the primary configurations in this research. Measurements of airfoil lift, drag, moment, and transition are made. The boundary layer development behind the roughness configurations is determined. TS or bypass transition is measured with infrared thermography and hotfilm anemometry. Lastly, AEP is calculated based on the roughened airfoil performance.

Once completed, the research will extend knowledge in multiple ways. Windturbine roughness and erosion for a particular wind farm will be characterized. Performance loss due to roughness will be quantified. Transition characteristics (TS or bypass dominated) for $2 \mathrm{D}$ and/or distributed roughness will be determined. The way in which roughness is characterized with $R e_{k}$ will be verified, with a better understanding of critical values for distributed roughness at a leading edge.

The results will serve industry and future research efforts in numerous ways. Economically, operators can determine if cleaning or repairing the blades is costeffective with performance loss estimates for given roughness types. With performance loss characterized, future operators can improve performance estimates for 
customers, reducing economic risk in the financial backing of a wind farm investment. The operationality of wind turbines may change, with improved active pitch control to compensate for insects. Design of airfoils more insensitive to roughness will come from the UC Davis research. Lastly, the experiment will serve as an extensive validation database for TS and bypass dominated flows with various Reynolds numbers, pressure gradients, and roughness configurations. 


\section{CHAPTER II EXPERIMENTAL DESCRIPTION}

This chapter details the wind tunnel, wind-tunnel model, roughness, and measurement descriptions. In summary, a NACA $63_{3}-418$ was tested in a low-speed wind tunnel at chord Reynolds numbers between 0.8 and 4.8 million. Roughness was placed on the airfoil to simulate paint chips and insect roughness. Lift, drag, moment, and transition phenomena were measured.

\section{II.A. Wind Tunnel}

All testing occurred in the Texas A\&M Oran W. Nicks Low-Speed Wind Tunnel (LSWT). The LSWT is a closed-return tunnel with a $7 \mathrm{ft} \times 10 \mathrm{ft}$ test section, achievable of freestream velocities of $90 \mathrm{~m} / \mathrm{s}$. A schematic of the circuit is shown in Fig. II.1. The test section has $1 \mathrm{ft}$ chamfers, reducing the section area to $68 \mathrm{ft}^{2}$. To correct for boundary-layer growth on its walls, the floor and ceiling diverge 1 in over the $12 \mathrm{ft}$ length of the test section. The pressure difference between static-pressure rings in the settling chamber and test section inlet are used for velocity feedback. A calibration curve is applied to relate this pressure to the effective empty test section dynamic pressure. The calibration is created by placing a Pitot-static probe in the center of the empty test section as a known value. Tunnel temperature is measured with a thermocouple located near the test-side upper chamfer at the test section entrance. Barometric pressure is measured below the test section in the balance room. Two vertical slats vent the test section to atmospheric pressure. A two-axis traverse 
can be mounted at the end of the test section. The LSWT has a six component floor balance located beneath the test section which allows models to be mounted in multiple configurations.

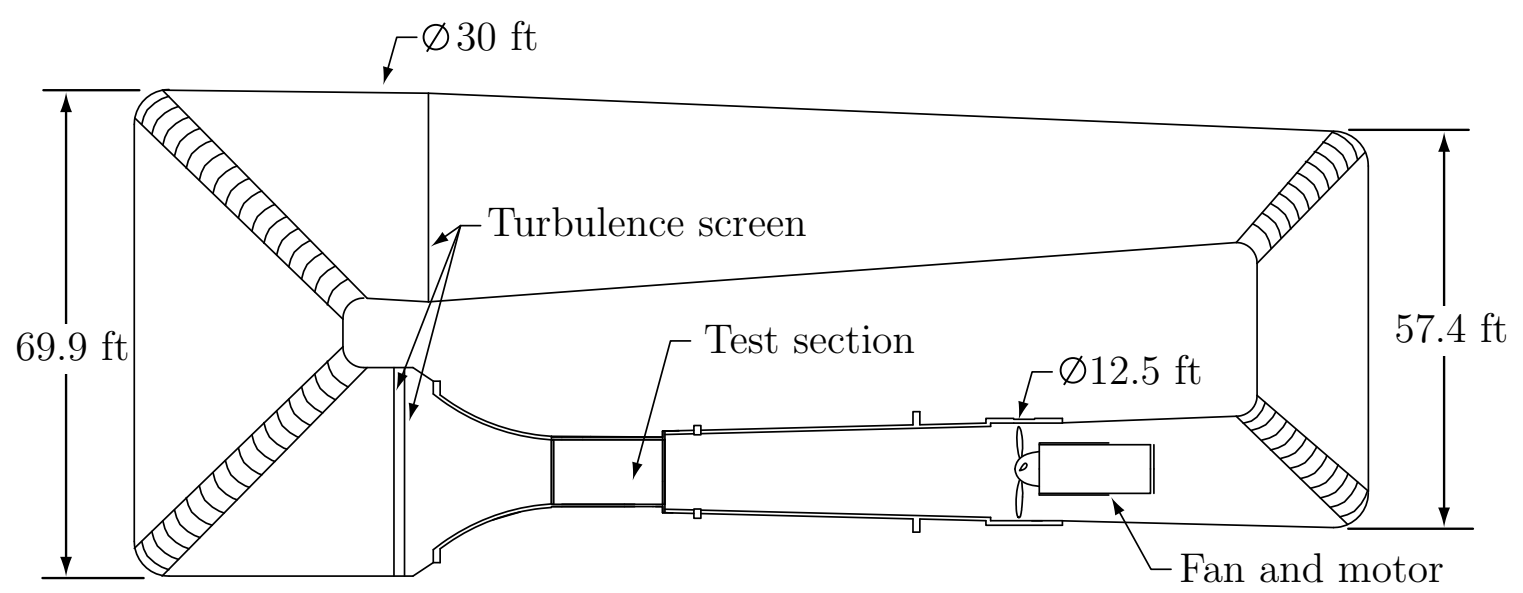

Figure II.1. Schematic of the Texas A\&M Low-Speed Wind Tunnel.

Dynamic pressure is controlled with fan pitch and motor speed. Maximum motor speed is $1200 \mathrm{rpm}$, but the motor is typically operated below $900 \mathrm{rpm}$. Motor speed is generally held constant while pitch is varied to maintain a specified velocity. Hidore extensively characterized the freestream conditions of the LSWT in 2012 [39]. Flow uniformity was found to be within $0.5 \%$ of the mean dynamic pressure above a dynamic pressure of 1 psf. This is within the uncertainty of the Pitot-static measurement, 0.02 psf. Test section turbulence intensity was found to be dependent upon fan-blade pitch (corresponding to dynamic pressure) and motor speed. As Fig. II.2 indicates, the wind tunnel generally has a turbulence intensity of $0.25 \%$. 


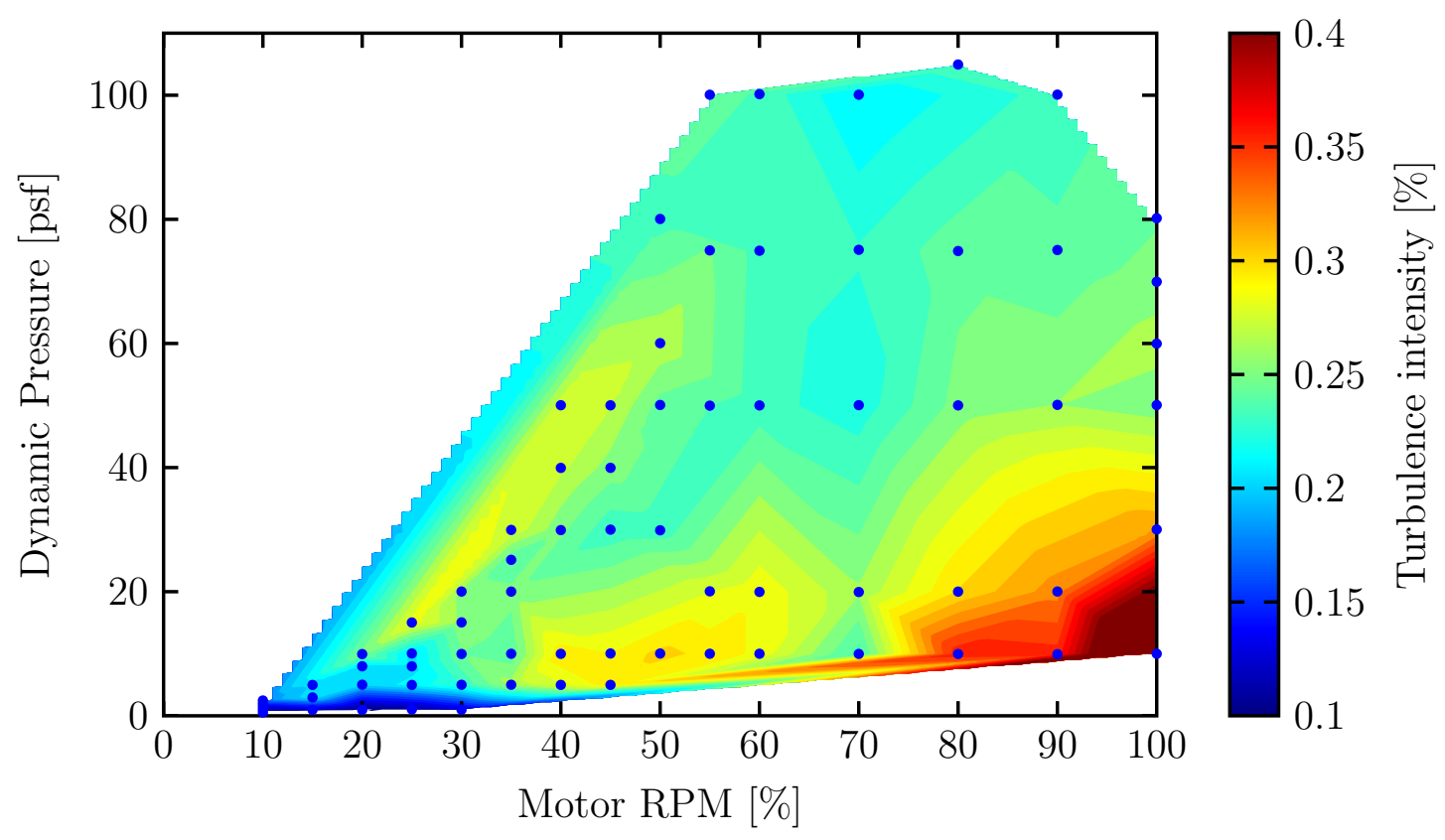

Figure II.2. Contour plot of the LSWT turbulence intensity as a function of speed and dynamic pressure. Blue points indicate where data was acquired [39].

\section{II.B. Model Design}

Choosing an airfoil for roughness testing had two drivers. First, CFD validation is the preliminary purpose of this testing effort, so a well-documented, non-propriety airfoil is required so that data is available for future validation efforts. Second, the airfoil is representative of an outboard section where the majority of power is produced and the most significant erosion was observed. Future testing will include an eroded leading edge, so a thinner airfoil was more appropriate.

A NACA $63_{3}-418$ airfoil was used as the baseline configuration [40]. While originally designed for aircraft flying at high chord Reynolds numbers in the 1940's, the NACA 6-series sections are commonly used on megawatt-scale turbines due to extensive laminar flow and well defined performance characteristics [19]. As early NACA 
series, two-dimensional airfoils were being tested, researchers found that smooth surfaces and favorable pressure gradients could extend the region of laminar flow. However, these airfoils were highly sensitive to roughness, resulting in large drag increases, particularly at off-design lift [40]. The 6-series airfoils were designed with a new approach allowing the pressure distribution to be tailored, thereby delaying transition and improving critical Mach numbers and maximum-lift characteristics [24].

The numbering system for NACA airfoils indicates various design features. The NACA 6-series airfoils are indicated with a leading six-digit. The second digit, 3, indicates the pressure minimum position is at $30 \%$ chord for the basic symmetric section at zero lift. The subscript digit, 3, indicates the range in tenths of lift coefficient above and below the design lift coefficient in which a favorable pressure gradient exists on both upper and lower surfaces. The digit following the dash, 3, indicates the design lift coefficient in tenths. Lastly, the 18 indicates the airfoil thickness-to-chord ratio. The NACA $63_{3}-418$ is designed to operate best between a lift coefficient of 0 and 0.6 , or an angle of attack, $\alpha$, between $-2.9^{\circ}$ to $2.3^{\circ}$, maximizing the amount of laminar flow. While drag is lowest in this region, the maximum liftto-drag ratio, $L / D_{\max }$, occurs at $\alpha=6^{\circ}, c_{l}=1.04$, at $R e_{c}=3 \times 10^{6}[40]$.

Abbott and von Doenhoff specify the NACA $63_{3}-418$ coordinates [40]. These were interpolated to increase resolution before importing into computer-aided design software. Aft of $95 \%$ chord, the trailing edge was thickened, maintaining camber, to $1.9 \mathrm{~mm}$ for manufacturing ease. The thickness was successfully used by White et al. [2]. Coordinates are shown in Fig. II.3 and listed in Appendix A. It is noted that the coordinates from the University of Illinois at Urbana-Champaign Airfoil 
Coordinates Database resulted in $0.02 \%$ chord offset from Abbott and von Doenhoff [41]. This offset was within the manufacturing tolerance, but the original Abbott and von Doenhoff ordinates were still utilized.

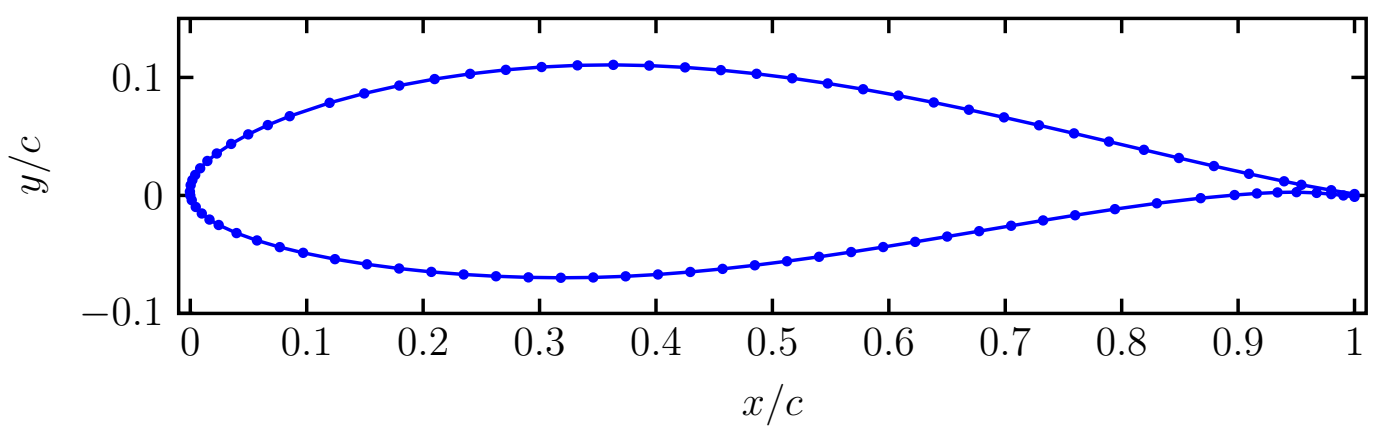

Figure II.3. NACA $63_{3}-418$ airfoil coordinates.

Airfoil chord length was chosen to maximize chord Reynolds number with an acceptable amount of tunnel blockage. The chord is $0.813 \mathrm{~m}$, yielding $4.9 \%$ blockage. The model mounts vertically with a $2.1 \mathrm{~m}$ span (2.6 aspect ratio) and approximately $12 \mathrm{~mm}$ of clearance at the ceiling and floor.

The model has five main components: a leading edge, upper main body, lower main body, trailing edge, and mounting shaft, shown in Fig. II.4. The model is hollow to decrease weight and improve access to pressure ports. The mounting shaft is a 3 in StressProof ${ }^{\circledR}$ steel shaft which runs the spanwise length and is used to mount the model in the tunnel. The remaining model components are manufactured from aluminum, ensuring minimal deflections at maximum load. The lower wing surface mounts to the shaft. For manufacturing ease, the trailing edge was partially manufactured separately. The lower outer mold line (OML) was manufactured first. 
The trailing edge was then bolted to the upper main body. The remaining upper surface OML was machined together, minimizing variation on the sensitive suction side. The completed upper main body and trailing edge are bolted to the lower main body. All bolts are accessed through the lower surface, ensuring a clean suctionside surface. Lastly, the airfoil leading edge is attached. To achieve unique erosion configurations, the model was designed to be modular with a removable leading edge at $15 \%$ chord. Two piano hinges along the upper and lower main body are used to securely attach the leading edge. The hinge pins can be removed through holes in the wind tunnel floor, allowing simple model changes while creating a consistent interface between the leading edge and airfoil main body.

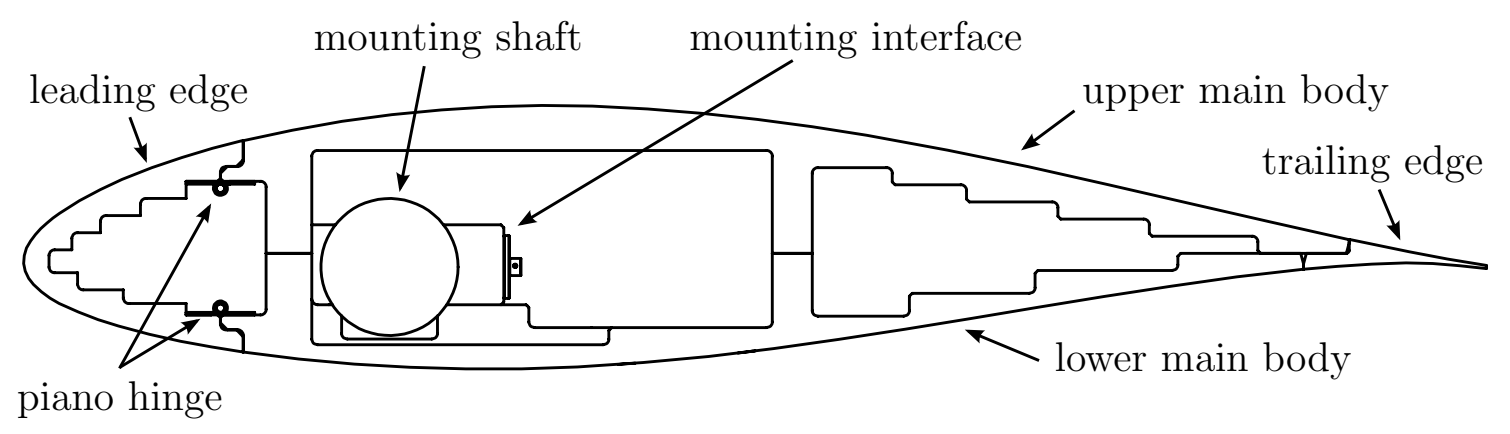

Figure II.4. Drawing of the model cross section, illustrating the various components.

The mounting shaft was designed, instrumented, and calibrated as an internal balance. When compared to static pressure lift, the internal balance varied on average by $2.0 \%$ in the linear lift region. In comparison, drag, on average, varied by $200 \%$ compared to wake rake data. Drag in the linear lift region is 100 times smaller than lift, making an accurate force measurement difficult to obtain. Designing a balance 
with a sufficient factor of safety at high angles of attack and high sensitivity in low drag configurations proved difficult. For this reason, lift and drag were measured with static pressure port and wake-rake measurements, respectively. Details regarding the calculation of shaft deflection are discussed in Section III.C.

Model pressure ports were placed near center span to avoid potential threedimensional effects at stall. Any interference introduced by a neighboring pressure port is avoided by offsetting each pressure port 0.375 in (based on turbulent wedge spreading angle) in the spanwise direction. The pressure port at the airfoil origin is located at essentially midspan, 41.625 in. Ports were drilled with a 0.040 in diameter drill bit and located with a rapid-prototyped jig with alignment holes. Appendix B summarizes pressure tap locations.

\section{II.C. Model Installation}

Multiple installation approaches have been used for two-dimensional airfoil models in the LSWT. First, a $7 \mathrm{ft} \times 7 \mathrm{ft}$ reduced test section was employed for previous testing with Vestas [2]. The additional $1.5 \mathrm{ft}$ on each side allowed a metric yoke to extend from the floor balance around the smaller test section. The model mounted horizontally. The maximum chord Reynolds number was $3.0 \times 10^{6}$. The advantage of the setup was complete attachment to the external balance, allowing integral force and moment data to be directly measured. However, the model had slightly higher blockage at $6 \%$ and the wall liner installation and removal required one week.

Second, a new approach was taken to reduce installation time. The model was mounted vertically in the $7 \mathrm{ft} \times 10 \mathrm{ft}$ test section and cantilevered to the floor balance. 
Mounting the model vertically decreased blockage. This allowed increased chord, thereby increasing chord Reynolds numbers. However, it was quickly determined the cantilevered setup would overload the floor balance rolling moment and side force.

A third approach fixed the upper end of the airfoil with a spherical bearing. The bearing acted as a pin joint, taking no moment and fixing translation in the ceiling plane. Theoretically, the load was split $62.5 \%$ on the floor and $37.5 \%$ on the ceiling, achieving a reduced floor balance load. A second balance was attached to spherical bearing at the ceiling. Combining the floor and ceiling balance output would yield the model integral force and moment. However, it proved difficult to perfectly align. If the model was not mounted normal to the floor balance rotation plane, it would cone while pitching. The floor balance rotation is also slightly eccentric. As a consequence, simply pitching the model caused displacement at the ceiling, overloading both balances.

To overcome the need for near-perfect alignment, the final installation approach remedied the above issues with a compliant ceiling mount. A detailed drawing of the compliant ceiling mount is shown in Appendix C. A spherical bearing is held in place with six, pneumatic cylinders. The cylinders are radially placed around the bearing. The bearing carries no moment and restricts planar translation, while the pneumatic cylinders allow for small, planar deflections from floor balance eccentricity and misalignment. The deflections are limited to less than $15 \mathrm{~mm}$, controlled by varying the cylinder pressure. The compliant ceiling mount shares roughly $37.5 \%$ of the normal and axial load and allows for small, planar displacements, ensuring the floor balance does not overload during rotation. 
Two struts below the test section floor are the main interface between the model and floor balance. A steel saddle bolts to the struts. The model shaft base bolts to the saddle. With the floor balance interface installed, the wind tunnel ceiling is removed and the fully constructed model is lowered into the wind tunnel. The model shaft slides into the shaft base, allowing moments to be transferred from the model to the floor balance. A shoulder bolt positions the shaft height and translates model pitching moment to the floor balance. The floor balance rotates about an axis normal to the floor, effectively pitching the vertically mounted two-dimensional model. The floor balance installation is summarized in Fig. II.5.

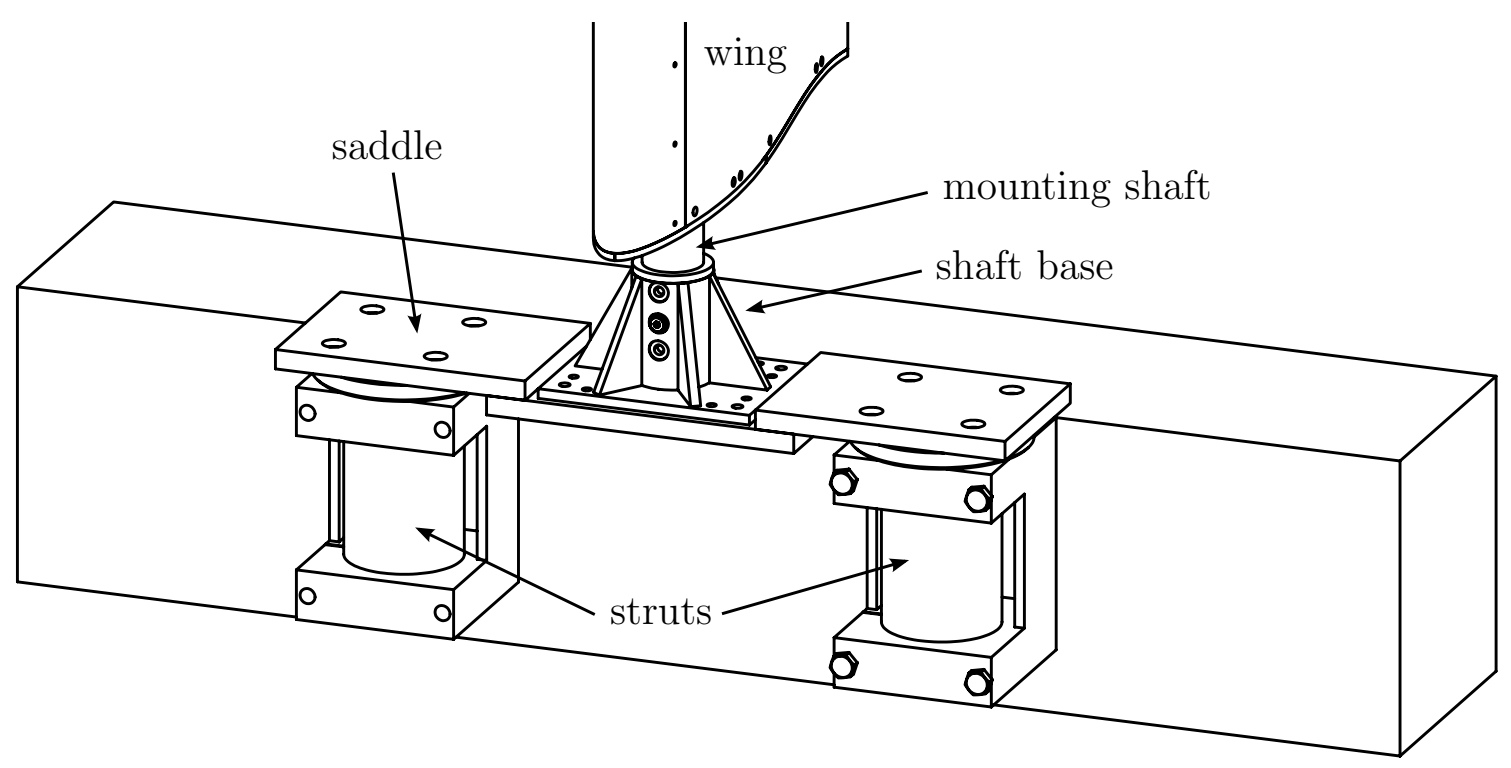

Figure II.5. Drawing of floor balance mounting setup. Wind tunnel floor omitted for clarity.

Before installing the ceiling, the model is centered and made perpendicular to the floor balance rotation plane with set screws in the shaft base. This ensures little 
eccentric motion near the ceiling. The wind tunnel ceiling is installed, followed by the compliant ceiling mount support structure. This structure mounts to the wind tunnel external structure. Lastly, the compliant ceiling mount is lowered onto the model shaft and bolted to the support structure. The pneumatic cylinders are centered around the shaft neutral position and pressurized. The upper model installation is shown in Fig. II.6.

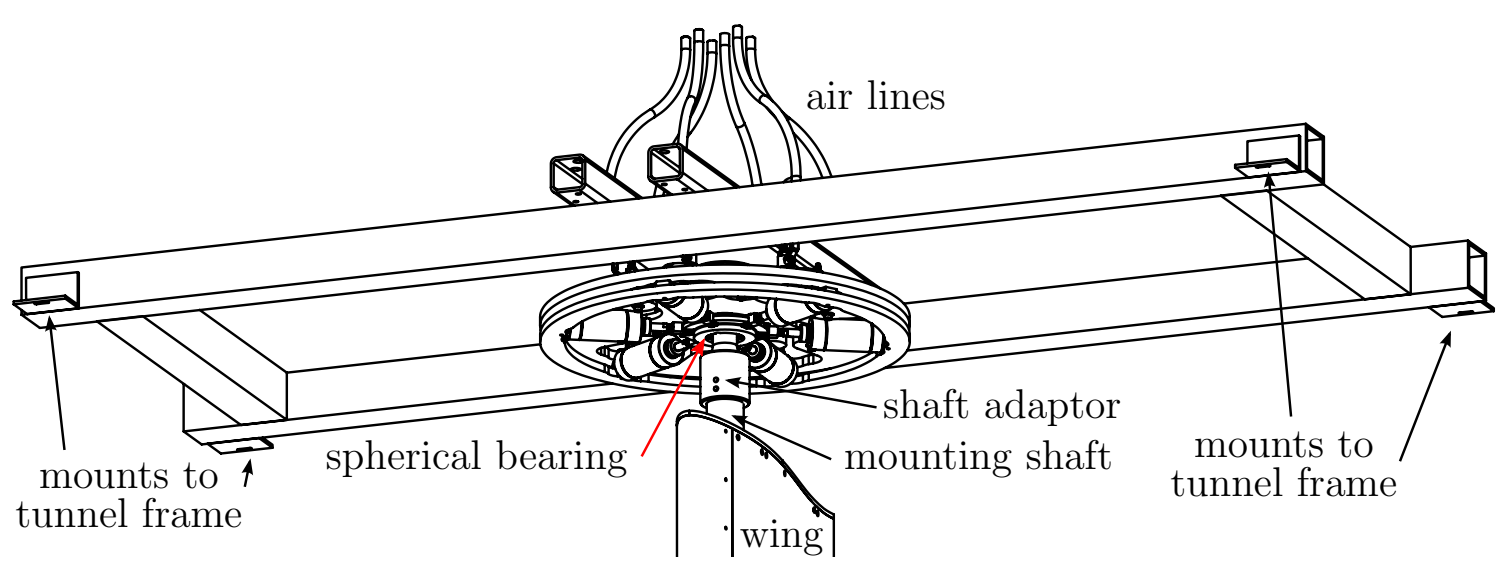

Figure II.6. Drawing of the ceiling mounting system. Wind tunnel ceiling omitted for clarity.

\section{II.D. Roughness}

The parameterization of roughness has been one of the many hurdles encountered in previous investigations. Roughness is often considered as random or a 2D step, ignoring chord or span variation or characteristic lengths. To improve this, blade roughness of three in-service wind turbines was photographed, measured, and documented. Laser scans and castings of the roughness at these locations were then 
made. Large-scale roughness was measured with a Creaform EXAscan, a portable laser scanner with $0.2 \mathrm{~mm}$ resolution, shown in Fig. II.7. Impressions of the smallscale roughness were made with dental alginate. Alginate is non-toxic and flexible, making removal easy, but it is spatially unstable over time. Therefore, lab stone castings of the alginate were made within 24 hours of the original casting. At a later time, the lab stone castings were measured with a Keyence LK-H022 laser displacement sensor. The laser has a $25 \mu \mathrm{m}$ spot diameter with $0.02 \mu \mathrm{m}$ vertical repeatability.

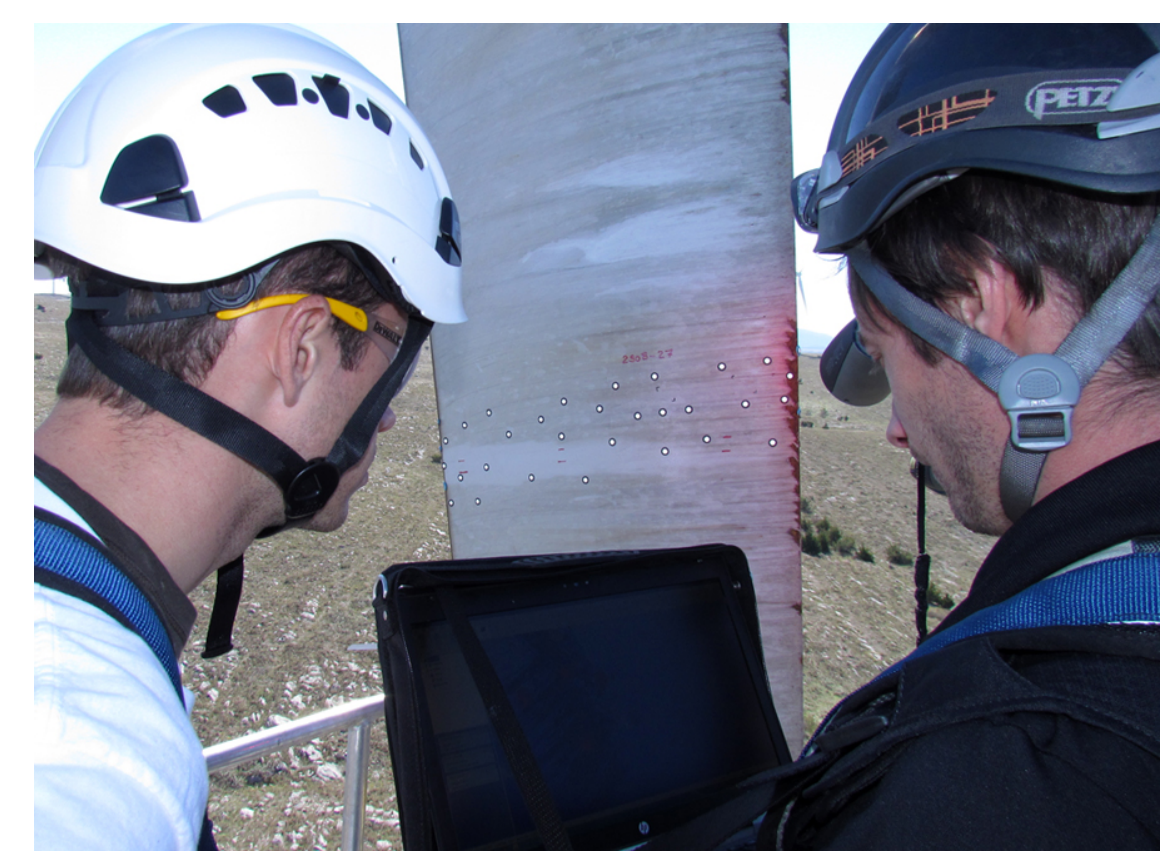

Figure II.7. Example the ExaScan measuring erosion on a blade segment.

Observed roughness types are organized into 2D heavy erosion, 2D inboard steps (from hub to $70 \%$ blade span), random pits, repairs, insects, and paint chips. Only the 2D inboard steps and insect roughness were observed on all blades. The heaviest 
erosion occurs near the blade tip at the highest local blade velocities. Otherwise, there was large variation between occurrence and location of the roughness, despite similar operating conditions. Only the insect and paint roughness has been simulated in the following study. Future work will investigate heavy erosion.

To simulate the wind turbine roughness, the airfoil was tested in four general configurations: clean, two-dimensional step, distributed roughness, and combined roughness. The clean configuration serves as a baseline for the remaining configurations. It is compared to Abbott and von Doenhoff's original data for a NACA $63_{3}-418$ [40]. Three two-dimensional steps are tested: a zig-zag trip strip, a wavy, forward-facing (WFF) step, and a straight, forward-facing (SFF) step. The WFF step is simulates paint which has chipped off the blade leading edge, creating a wavy, forward-facing step. The SFF step is for comparison to the WFF step. The steps are created using contact paper and designed to match the local paint-chip scale, approximately $142 \mu \mathrm{m}$ thick.

Insect accumulation on the leading edge is described as distributed roughness and is simulated with elliptical vinyl decals. It is tested in five deposition coverages, $3 \%, 6 \%, 9 \%, 12 \%$, and $15 \%$ of the surface area and three nominal heights, $100 \mu \mathrm{m}$, $140 \mu \mathrm{m}$, and $200 \mu \mathrm{m}$. The configurations represent different amounts and types of accumulation over time. Roughness is placed between $2 \%$ chord on the upper surface and $13 \%$ chord on the lower surface [42]. An extended configuration starts at $6 \%$ chord on the upper surface, serving as an additional validation case for CFD.

Lastly, the effect of both a straight, forward-facing step and distributed $140 \mu \mathrm{m}$ roughness is tested. Table II.1 summarizes the 15 model configurations. 
Table II.1. Model configuration summary.

\begin{tabular}{cccc}
\hline \hline nominal & 2D step & distributed roughness & combined \\
\hline clean & trip strip & $100 \mu \mathrm{m}, 3,9,15 \%$ & SFF \& $140 \mu \mathrm{m}, 3 \%$ \\
& straight FF & $140 \mu \mathrm{m}, 3,6,9,12,15 \%$ & \\
& wavy FF & $200 \mu \mathrm{m}, 3 \%$ & \\
& & $140 \mu \mathrm{m}, 3 \%$ extended & \\
\hline \hline
\end{tabular}

\section{II.D.1. Clean Leading Edge}

The nominal aluminum leading edge has a surface roughness of $R_{a}=1.0 \mu \mathrm{m}$ and maximum peak-to-valley of $R_{t}=9.3 \mu \mathrm{m}$. The surface is finished with an abrasive cleaning pad. The model was carefully designed to minimize the gap between the leading edge and airfoil main body. The final result was a $590 \pm 75 \mu \mathrm{m}$ wide gap. The depth could not be measured due to stylus interference.

Upon initial installation, drag was generally higher than anticipated. A piece of tape applied over the leading edge seam was found to decrease the drag, suggesting leakage at the seam affected performance. The tape is $19 \mathrm{~mm}$ wide and $55 \pm 3 \mu \mathrm{m}$ thick. When covered, the gap is smoothed, with depth approximately equal to the tape thickness. At $R e_{c}=4 \times 10^{6}$ and $\alpha=4^{\circ}$, the $R e_{k}=59 \pm 7$. Smith and Clutter found on average, a 2D step with $R e_{k}<125$ would have no effect on transition [32].

\section{II.D.2. Zig-Zag Trip Strip}

An effective two-dimensional trip strip must be sufficiently tall to trip at all Reynolds numbers and angles of attack. Based upon Smith and Clutter, $R e_{k, \text { crit }}$ ranges from 40 to 400 for two-dimensional steps [32]. Smith and Clutter define crit- 
ical transition to occur when the roughness transition Reynolds number is $95 \%$ of the clean transition Reynolds number. As two-dimensional roughness causes transition to move forward by amplifying the TS instability, Smith and Clutter's larger $R e_{k, \text { crit }} \approx 400$ will be more likely to represent the desired bypass transition path.

The trip strip was placed at $2 \%$ and $5 \%$ chord on the upper and lower surfaces. Location was chosen to trip the majority of the airfoil upper surface at low angles of attack. The upper trip at $2 \%$ chord is behind the pressure minimum after $\alpha=5^{\circ}$ in a large adverse pressure gradient, possibly encouraging separation. The lower trip is placed further aft at $5 \%$ chord ensuring the stagnation point does not move behind the trip.

Within the low-drag performance range at $R e_{c}=0.8 \times 10^{6}$, the required roughness height for a $R e_{k, \text { crit }} \approx 400$ is $k_{\text {crit }} \approx 350 \mu \mathrm{m}$. The available zig-zag trip strip has a $60^{\circ}$ pattern, with a wavelength and peak-to-peak amplitude of $6 \mathrm{~mm}$ and $9 \mathrm{~mm}$, respectively. It is nominally $500 \mu \mathrm{m}$ tall, with an installed height of $460 \pm 2 \mu \mathrm{m}$. It is manufactured by Glasfaser Flugzeug-Service. While the trip strip is appropriately scaled at low Reynolds numbers, it is too thick at higher Reynolds numbers. A thin boundary layer and thick trip strip potentially yield early separation. However, the tripped performance was used for comparison only, so a single trip strip was employed.

\section{II.D.3. Paint Roughness}

Another roughness type being investigated is two-dimensional forward-facing steps from chipped paint. This roughness is characterized as paint which has eroded 
or chipped off the leading edge of the blade, shown in Fig. II.8a. This yields a forwardfacing step on both the suction and pressure sides of the blade. The spanwise and chordwise locations of the two-dimensional paint step are inconsistent. The average step height is $150 \pm 25 \mu \mathrm{m}$. The paint is assumed to chip off in constant thicknesses for this testing. Steps near the leading edge will likely cause transition while steps further aft may or may not. Hence, the further aft step at $10 \%$ chord is investigated.
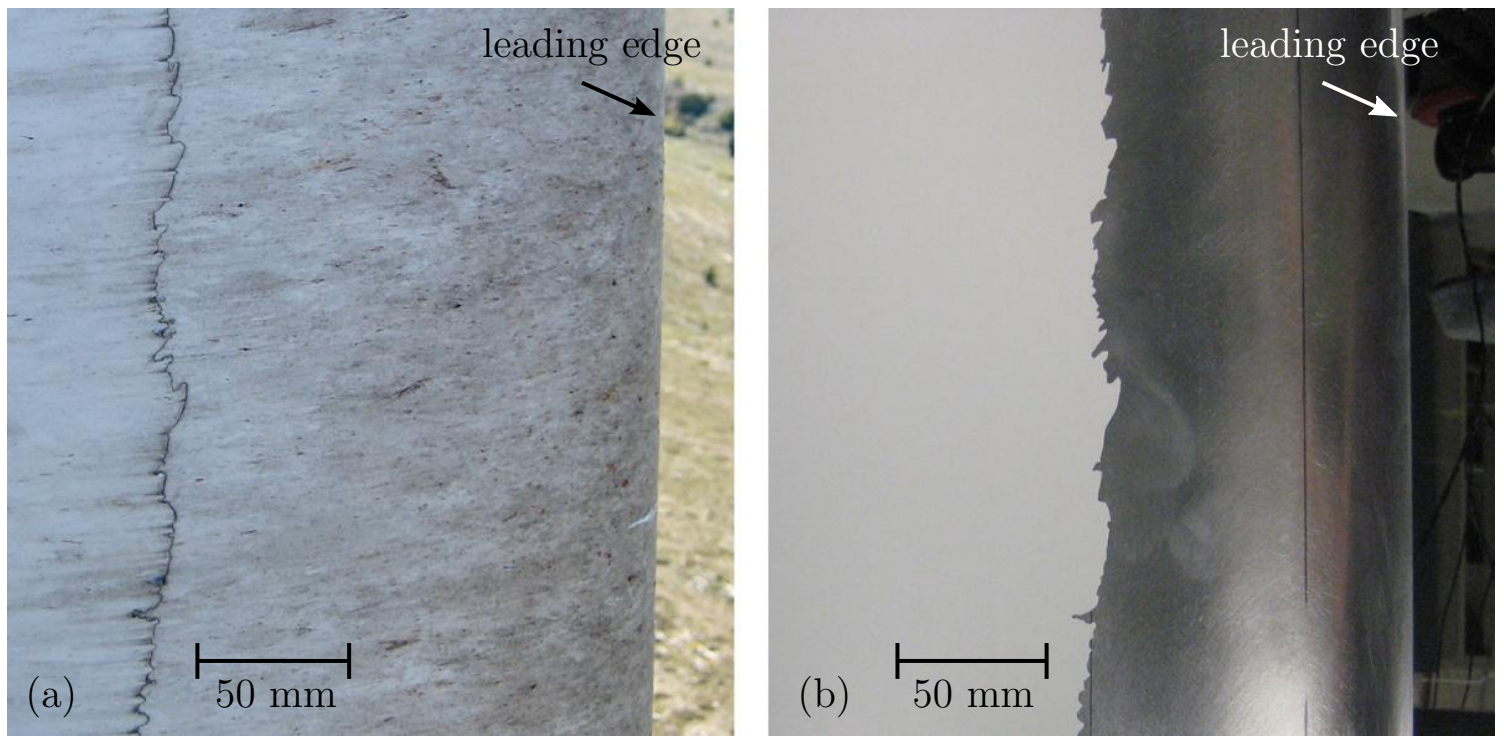

Figure II.8. Image of the chipped paint (a) observed in-service and (b) simulated on wind tunnel model. Flow is from right to left in both images.

Figure II.8a illustrates an example of two-dimensional paint roughness at 10\% chord. The local step height of the paint is $142 \pm 16 \mu \mathrm{m}$. Because the step is smaller than the boundary layer thickness, $R e_{k}$ is matched rather than $k / c$. Assuming general operating conditions for a wind turbine, $R e_{k}$ at a $10 \%$ chord location was calculated to be $R e_{k}=186$. Experimental $R e_{k}$ both higher and lower than the measured value 
are desired, so the simulated roughness height is designed to match $R e_{k} \approx 186$ at a model $R e_{c}=2.4 \times 10^{6}$. This results in a desired roughness height of $134 \mu \mathrm{m}$ for the wind tunnel model.

The paint roughness is simulated by laying contact paper from $10 \%$ to $60 \%$ chord on the suction side of the model. Installed, the contact paper measured $157 \pm 6 \mu \mathrm{m}$, $17 \%$ thicker than the nominal step height. The final result was an $R e_{k}=246 \pm 27$ at $R e_{c}=2.4 \times 10^{6}$ and $\alpha=4.75^{\circ}$. The leading edge of the contact paper has a profile cut into it, shown in Fig. II.8b, simulating the profile of one sample of observed paint roughness. Since the boundary layer is thinner on the operational wind turbine than in the designed test, the roughness profile must also be scaled. The roughness pattern is scaled in both spanwise and chordwise directions by the local displacement thickness for the operational wind turbine at $R e_{c}=5.2 \times 10^{6}$ to the wind tunnel model at $R e_{c}=4.0 \times 10^{6}$, scaling the paint roughness by 1.15 .

As a control, a straight, forward-facing step was also tested at $10 \%$ chord. The same height contact paper was installed with a straight profile at the leading edge.

\section{II.D.4. Distributed Roughness}

Randomly distributed roughness may be characterized by a variety of roughness elements. For wind turbines, insect roughness is deemed a distributed roughness, as it is neither a two dimensional nor an isolated three-dimensional surface element [37]. Insect roughness is a foreign deposit, adding to the airfoil outer mold line. Insects generally impact the blade within the first $15 \%$ of the chord. Examples of insect roughness on in-service blades are shown in Fig. II.9. Figure II.9a shows extreme 
insect roughness from Spruce [7], which had accumulated on the blade over four dry months. Figure II.9b is from the current study. The insect roughness appears extremely sparse. Profilometer scans validate this, indicating the insect roughness to be minimal. Additional image investigation suggested that the blades, while dirty, generally had low roughness. One possible explanation for minimal insect roughness is rainfall. One month prior to measurement, the region had 5.4 in of rain, potentially cleaning the blades of most or all insect accumulation.
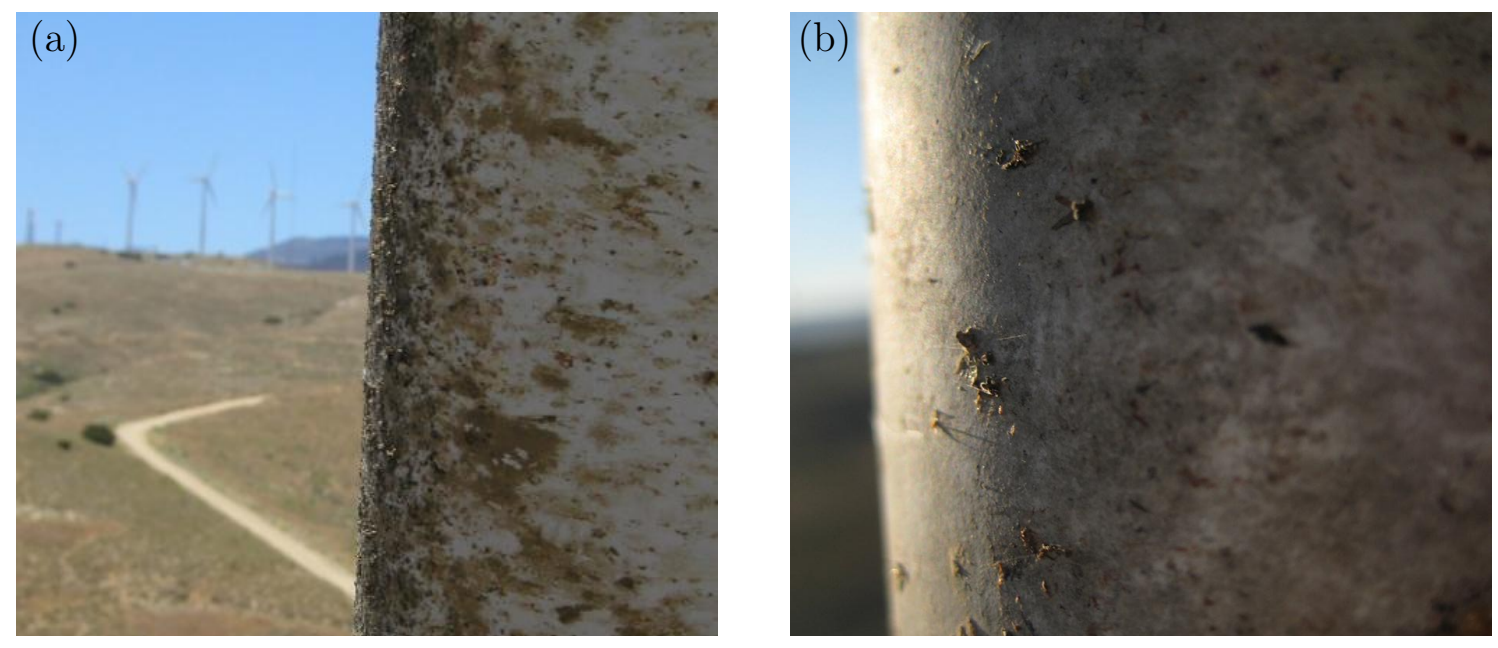

Figure II.9. Images of insect roughness on leading edges. (a) Heavy insect roughness from Spruce and (b) minimal insect accumulation from the current research [7].

Due to minimal insect roughness, NASA LEWICE (LEWis ICE accretion program) was implemented to better estimate the location of insect impingement [43]. LEWICE calculates the inviscid flowfield around an airfoil, and then determines ice particle trajectories in a Lagrangian framework. Applying a standard insect drag coefficient, frontal area, and mass to the particles, impingement locations can be cal- 
culated [42]. A profile normalized by insect mass accumulation is shown in Fig II.10. Cut-in conditions for an 80 meter wind turbine were reproduced on a NACA $63_{3}-418$ at $6^{\circ}$ angle of attack and $85 \%$ span. The simulation found the majority of strikes occuring near the stagnation point with accumulation extending much further on the pressure side compared to the suction side. Since the primary goal of this research is CFD validation, a simple roughness configuration needs to first be validated before moving on to a variable insect distribution. A randomly distributed insect roughness pattern was chosen. The LEWICE results are used to determine the roughness application range. Using 30\% normalized mass accumulation as a cutoff, the roughness distribution extends from $2 \%$ chord on the upper surface to $13 \%$ chord on the lower surface. An additional test case for CFD validation includes roughness extending to $6 \%$ chord on the upper surface.

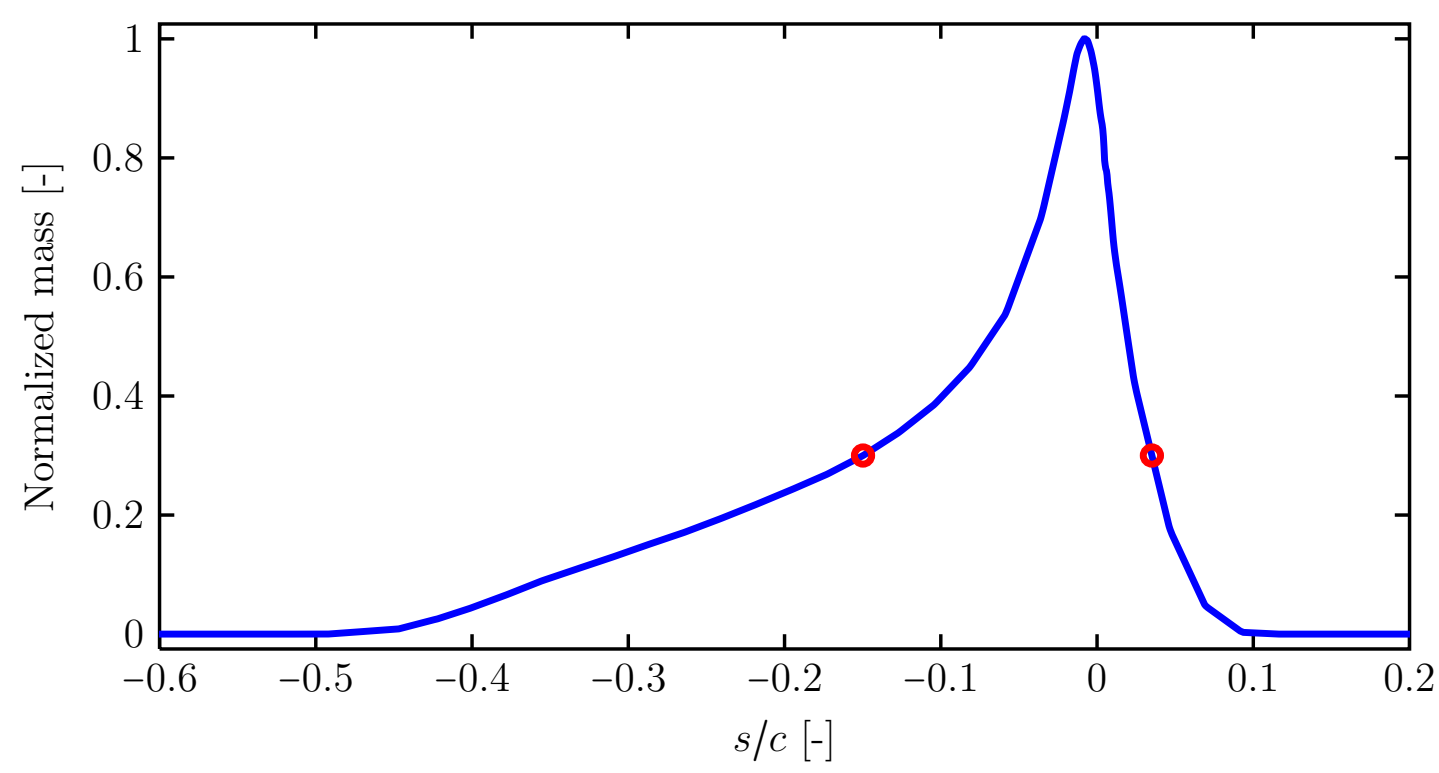

Figure II.10. Simulated accumulated insect distribution with the $30 \%$ cutoff range shown with red cirlces. 
As discussed in Section I.B, trip strips and sand-grain roughness are unrepresentative of actual insect roughness. Trip strips effectively cause transition, but are not distributed or properly scaled. Sand-grain roughness is difficult to apply in a repeatable manner and lacks robustness throughout a test. Instead, roughness was simulated with vinyl decals. Decals offer a repeatable position and height. One drawback is their aspect ratio, roughness height to diameter $k / d$, is smaller than insect or sand-grain roughness. However, insects erode over time, decreasing their aspect ratio. Again, the main objective of the study is to validate CFD transition simulations, so choosing relevant heights was most important.

The roughness pattern is created by randomly distributing points within a $152 \mathrm{~mm} \times 152 \mathrm{~mm}$ area. Each point represents a circle center with a normally distributed radius of $1.2 \pm 0.15 \mathrm{~mm}$ based on manufacturing limitations. Circle boundaries may extend beyond the bounding area, while circle centers will not. If a circle happens to intersect another circle, an ellipse is circumscribed around the two circles such that its area is minimized. If any object remains overlapped, it is removed. Objects are randomly removed to create different coverage densities.

Assuming all the elements are circles, roughness statistics are summarized in Table II.2. Due to limited in-service roughness measurements, roughness heights were chosen based on CFD validation purposes and historical values [15]. As installed, they were measured to be $102 \pm 2 \mu \mathrm{m}, 139 \pm 3 \mu \mathrm{m}$, and $199 \pm 2 \mu \mathrm{m}$. These are abbreviated as 100, 140, and 200 throughout. By varying Reynolds number and angle of attack, various roughness Reynolds numbers can be tested based on the two locations, three heights, and five densities. 


\section{Table II.2. Summary of roughness statistics.}

\begin{tabular}{ccc}
\hline \hline coverage & radius $[\mathrm{mm}]$ & density $\left[\mathrm{qty} / \mathrm{m}^{2}\right]$ \\
\hline $3 \%$ & $1.40 \pm 0.36$ & 4,570 \\
$6 \%$ & $1.45 \pm 0.37$ & 8,579 \\
$9 \%$ & $1.44 \pm 0.37$ & 13,020 \\
$12 \%$ & $1.45 \pm 0.37$ & 17,116 \\
$15 \%$ & $1.45 \pm 0.37$ & 21,168 \\
\hline \hline
\end{tabular}

The $3 \%$ coverage roughness pattern is shown in Fig. II.11. The red square bounds the nominal pattern while the red rectangle at right bounds the extended roughness pattern. The pattern is shown to repeat in the spanwise direction. Negative airfoil length indicates the lower surface while positive is the upper surface. Because the roughness pattern is much wider than the boundary layer thickness, it can be repeated in the spanwise direction with no consequence. In some cases, this yields periodic transition fronts which removes concern about spanwise uniformity. The extended configuration is created by repeating the pattern in the chordwise direction.

\section{II.E. Measurements}

Numerous measurements are completed on the model, including lift, drag, moment, boundary layer profiles, transition, and hotfilm spectra. Lift and moment are measured by integrating surface static pressure measurements. Drag is calculated by measuring the velocity deficit with a wake rake. A boundary layer rake yields boundary layer profiles. Transition location is measured with infrared thermography, mean hotfilm voltage, hotfilm intermittency, and hotfilm spectra. 


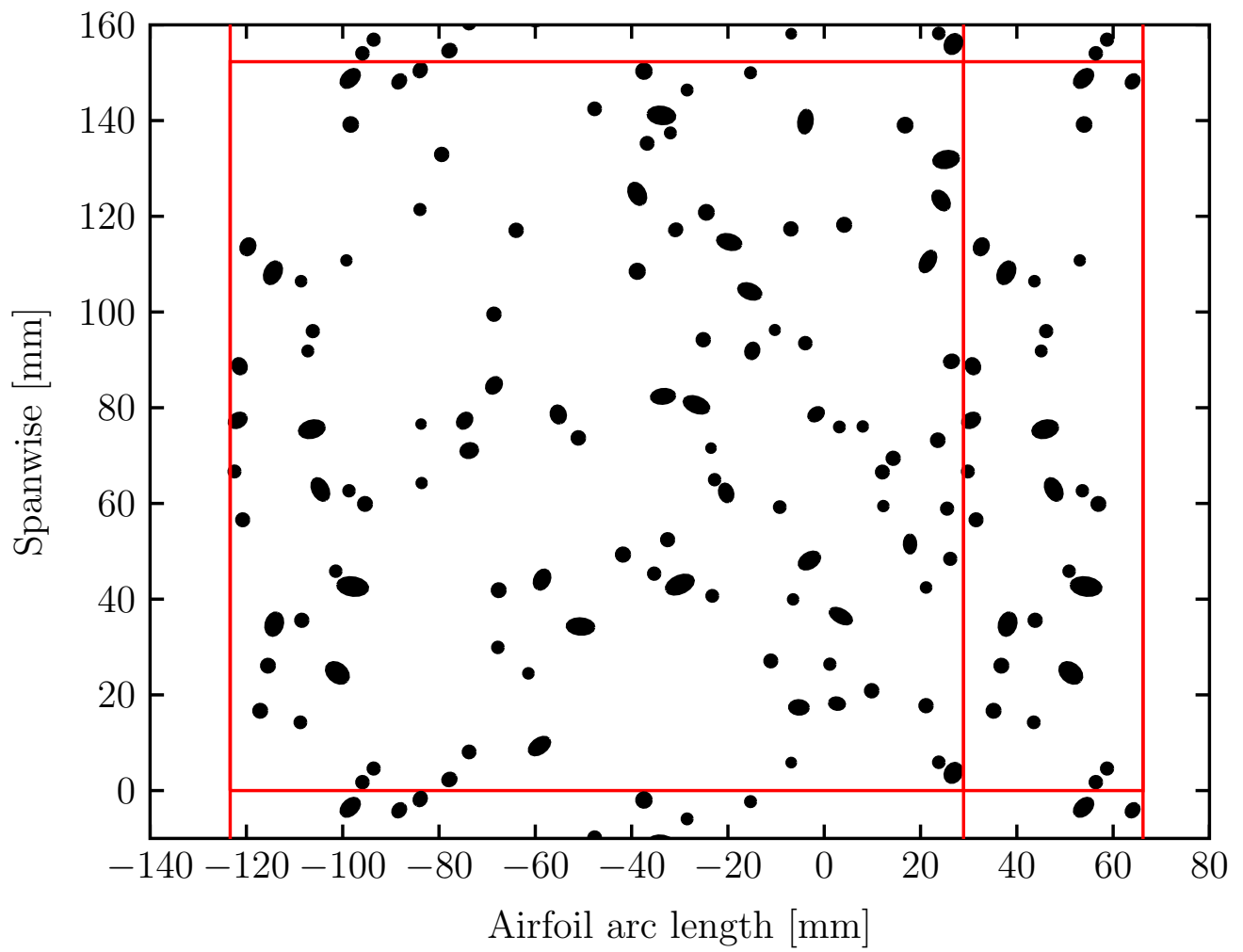

Figure II.11. Random roughness pattern with $3 \%$ coverage. The red square indicates a single roughness pattern, which is repeated in the spanwise direction. The extended configuration is bounded by the narrow rectangle at right.

\section{II.E.1. Pressure}

The pressure difference between static-pressure rings in the settling chamber and test section inlet are used for velocity feedback. A calibration curve is applied to relate this pressure to the effective empty test section dynamic pressure. The calibration is created by placing a Pitot-static probe in the center of the empty test section as a known value. The dynamic pressure transducer has an uncertainty of $\pm 1 \mathrm{~Pa}$. Barometric pressure is measured below the test section in the balance room with an uncertainty of $11.5 \mathrm{~Pa}$. 
Wing static pressure is measured using two 32 port pressure scanners. A 5 psi unit is used for leading edge ports while a 1 psi unit is used in the aft region, with accuracies of $\pm 17 \mathrm{~Pa}$ and $\pm 7 \mathrm{~Pa}$, respectively. Wing static pressure is referenced to a static pressure ring on a Pitot-static probe, located at the test section inlet. The total and static pressure from the Pitot-static are also measured on each scanner for redundancy. A third, $20 \mathrm{inH}_{2} \mathrm{O}$ pressure scanner, with a $\pm 5 \mathrm{~Pa}$ accuracy, is utilized for wake rake and boundary layer rake measurements. Because there is no tunnel temperature control and no temperature correction is applied, the pressure scanners are recalibrated every two hours. Uncertainty due to temperature drift is taken considered. The 5 psi unit technical specification indicates up to $\pm 21 \mathrm{~Pa} /{ }^{\circ} \mathrm{C}$ and $\pm 7 \mathrm{~Pa} /{ }^{\circ} \mathrm{C}$ due to thermal zero and span error, respectively. The 1 psi unit technical specification indicates up to $\pm 14 \mathrm{~Pa} /{ }^{\circ} \mathrm{C}$ and $\pm 2 \mathrm{~Pa} /{ }^{\circ} \mathrm{C}$ due to thermal zero and span error, respectively. The $20 \mathrm{inH}_{2} \mathrm{O}$ unit technical specification indicates up to $\pm 10 \mathrm{~Pa} /{ }^{\circ} \mathrm{C}$ and $\pm 2 \mathrm{~Pa} /{ }^{\circ} \mathrm{C}$ due to thermal zero and span error, respectively. On cold days, temperature may drift $5^{\circ} \mathrm{C}$ between calibrations. Use of the sprinkler system on warm days better controls the tunnel temperature. The wing pressure scanners lag the tunnel temperature, as they are effectively insulated the wing. The drag pressure scanner is more exposed and sensitive to tunnel temperature variation.

The wake rake was placed $0.9 c$ downstream of the wing trailing edge. The minimum suggested distance is $0.7 c$ [44]. The wake rake has 25 Pitot probes and three static probes. The Pitot probe locations are summarized in Appendix D. The three static probes are located at $-0.39,0$, and $+0.39 z / c$, where zero $z / c$ is located at tunnel midspan. 
Drag was found to vary depending on wake position. Generally, the flow behind the pressure ports is turbulent, increasing drag. Secondary flow structures near the wall also increase drag. Therefore, the wake rake is placed 18 in above the model centerline (24 in from the wall), resulting in a consistent drag measurement. Drag variation with wake position is shown in Fig. II.12 for the model at a $6^{\circ}$ angle of attack. Drag varies in a repeatable way for different Reynolds numbers. The spanwise variation is approximately 7 drag counts, where one drag count is 0.0001 of drag coefficient. The mean measurement uncertainty, shown with errorbars, is 6.4 counts and 4.4 counts for 1.6 and $3.2 \times 10^{6}$ chord Reynolds numbers, respectively.

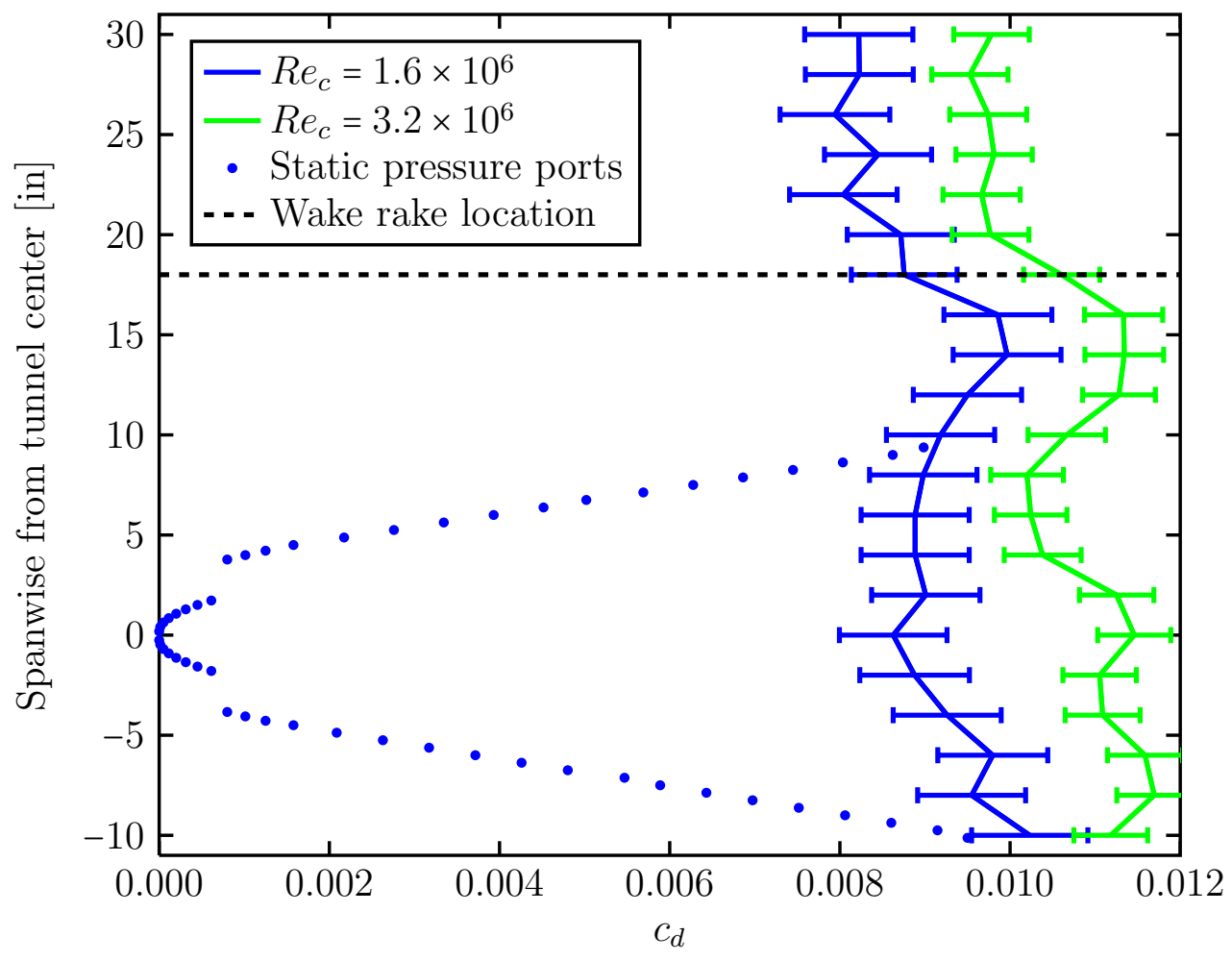

Figure II.12. Spanwise drag variation shown relative to wing static pressure ports and standard wake rake location. 
A boundary layer rake was placed at 30\%, 40\%, 50\%, and 60\% chord locations, shown in Fig. II.13, yielding boundary layer profiles. A summary of the 19 Pitot tube locations is in Appendix E. The positions assume the first Pitot is flush with the wall, a Preston tube. For some installations, the first two Pitot tubes were flush with the wall. A static pressure probe is attached for a local static pressure measurement. However, static pressure interpolated from the local pressure taps is more accurate and used instead. The boundary layer rake was attached with aluminum tape, flush with the model surface. At high dynamic pressure, the rake had a tendency to tip back, changing the measurement locations. At low angles of attack, the boundary layer is thin, making well resolved pressure measurements difficult. Therefore, wake rake measurements should be viewed somewhat skeptically. Despite these disadvantages, the data indicates separation well. With care, transition may also be indicated.
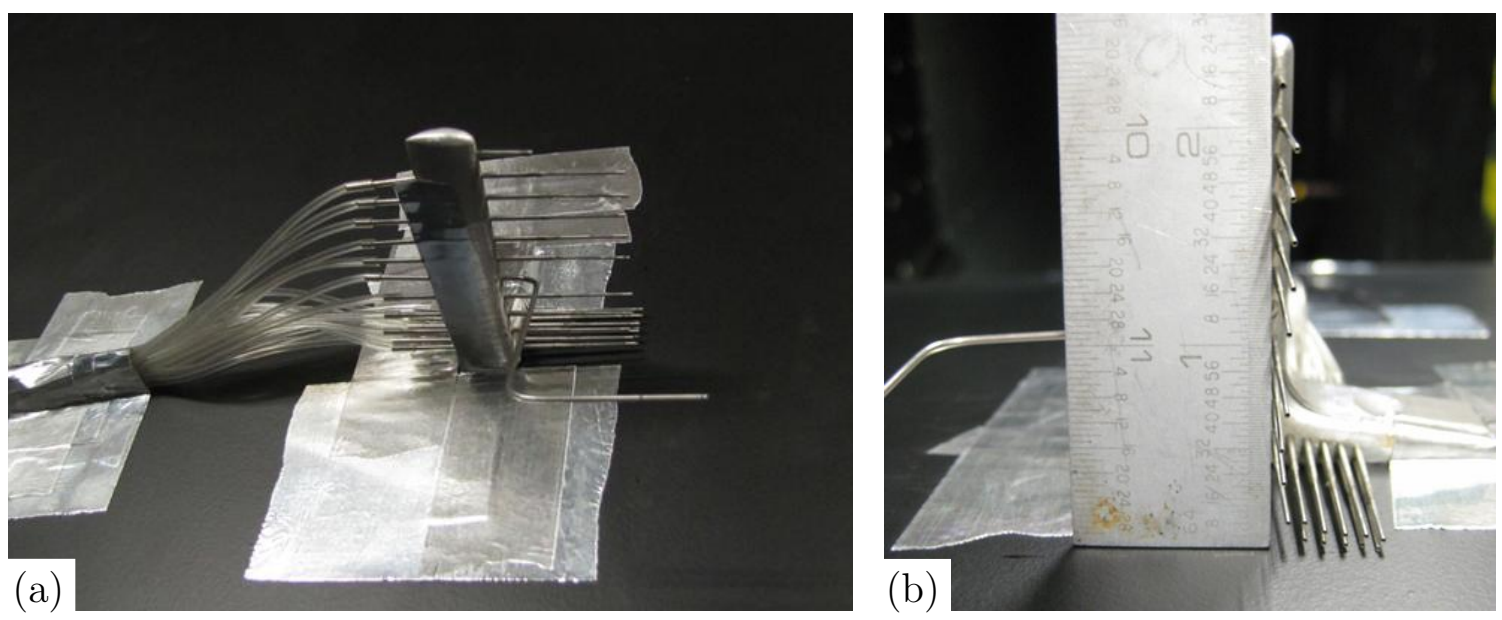

Figure II.13. Boundary layer rake (a) side view and (b) front view. 


\section{II.E.2. Hotfilm Anemometry}

Hotfilm anemometry was implemented to measure transition flow phenomena. A hotfilm consists of a polyimide substrate film, low resistance copper leads, and nickel sensor elements. The sensor element is approximately $0.2 \mu$ thick, $100 \mu$ wide, and $1.45 \mathrm{~mm}$ long. A single Senflex ${ }^{\circledR} 93021$ hotfilm was applied to the model. The hotfilm has 28 sensors, varying from $20 \%$ to $41 \%$ chord. Only eight sensors were utilized due to limited channels. Six single-element SF0303 sensors were added to broaden the sensor range from $4 \%$ to $56 \%$ chord. Final sensor locations are summarized in Appendix F. Sensors on the 93021 hotfilm were inline with one another at 38\% span. The single element sensors were offset, shown in Fig. II.14, avoiding turbulent wedges from neighboring element substrates. The installed hotfilm substrate and adhesive are $128 \pm 4 \mu \mathrm{m}$ thick. A $R e_{c}=4 \times 10^{6}, \alpha=4^{\circ}$, and $15 \%$ chord location correspond to an $R e_{k}=304 \pm 23$, sufficient to trip transition. For this reason, data quality varied with Reynolds number and location.

The sensors were attached to an A.A. Lab Systems AN-1003 constant temperature anemometer (CTA). The CTA circuit has low thermal inertia yielding excellent frequency response. In the first entry, the CTA was bandpass filtered with a Kemo VBF44 between $1 \mathrm{~Hz}$ and $10 \mathrm{kHz}$. The signal was sampled at $75 \mathrm{kHz}$ with $2^{16}$ samples collected. In the second entry, the CTA was unfiltered and sampled at $31.25 \mathrm{kHz}$ with $2^{16}$ samples collected. The filtered data varied little from the unfiltered data. The unfiltered data contained the mean voltage, useful to indicate transition location. Measuring the near-wall frequency content allowed two additional transition phenomena to be indicated. The signal spectral content illuminates the growth of the 


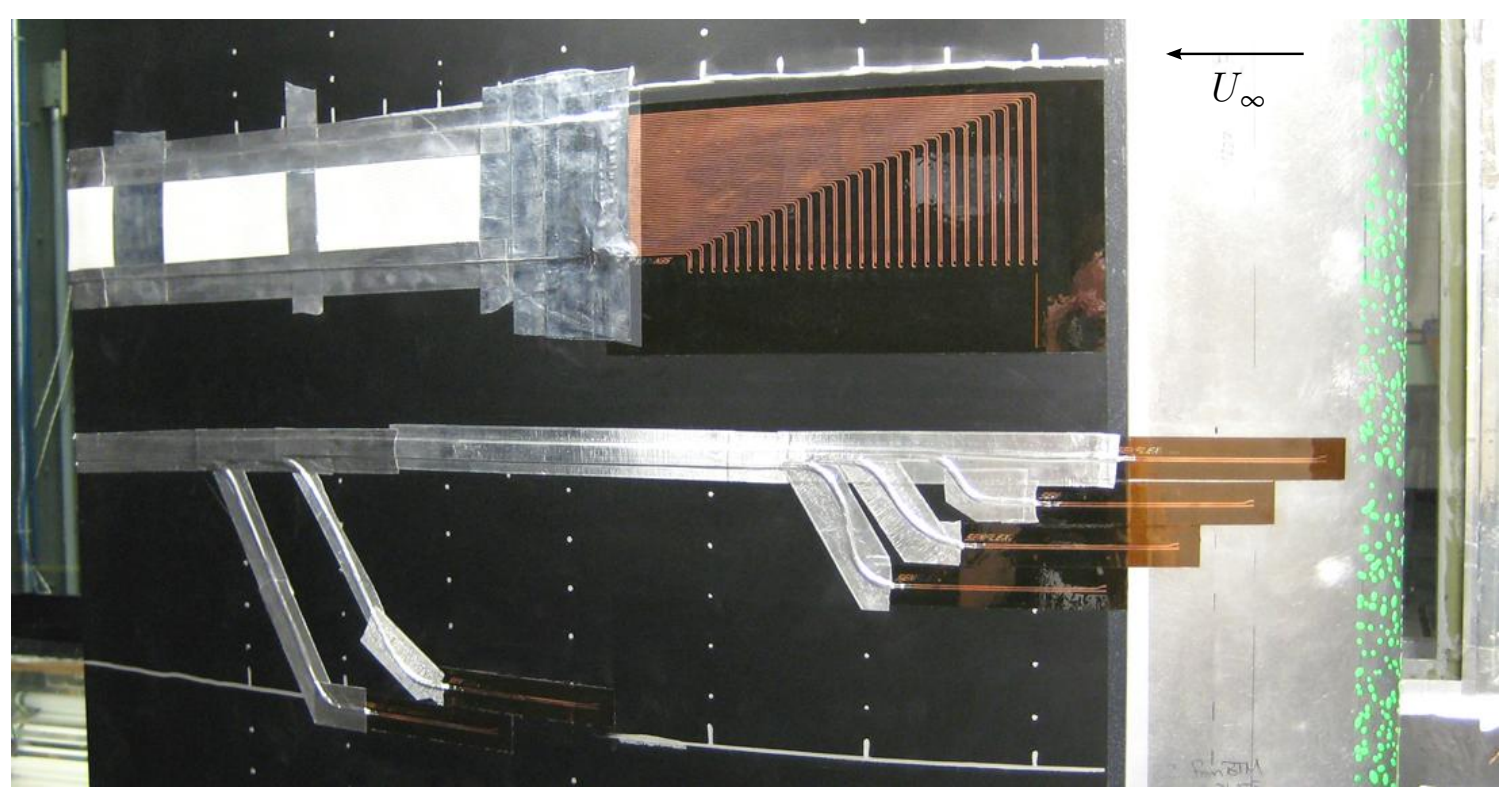

Figure II.14. Image of the installed hotfilms and 140-15 roughness.

Tollmien-Schlichting instability. Flow intermittency is a second method to indicate transition with hotfilm anemometry. Additional discussion regarding the numerical application of these techniques is in Section III.D.

\section{II.E.3. Infrared Thermography}

The primary transition measurement is made with infrared (IR) thermography. IR thermography leverages the difference in convection rates of laminar and turbulent flows and the temperature difference between the model and air to indicate transition location [45]. Generally, the model surface temperature lags the ambient temperature variations. The warmer, ambient air will heat a turbulent region faster than a laminar region. If the model and tunnel temperature are equivalent, an internal heating sheet can heat the model above ambient temperature. In this case, the cooler ambient air will cool turbulent regions faster. 
The internal heating sheet was designed based on experience from the Texas A\&M Flight Research Laboratory [46]. The sheet is inside the model and spans a 12.5 in $\times 18.75$ in segment of its upper surface. A constant thickness section was machined into the upper surface, ensuring even heating over the model surface. Nichrome wire with a 0.008 in diameter was used as the heating element. It was laid back-and-forth with 1 in spacing over a layer of fiberglass insulation. A second layer of fiberglass was placed over the Nichrome to further insulate and protect the wire. A variable transformer was used to control voltage application to the heating element. Note that Fig. II.4 only illustrates the stepped internal surface. The final setup is shown in Fig. II.15, where a portion of the internal structure is removed. The application of approximately $100 \mathrm{~V}$ will heat the model surface by $2^{\circ} \mathrm{C}$, allowing a sufficient temperature differential for viewing transition.

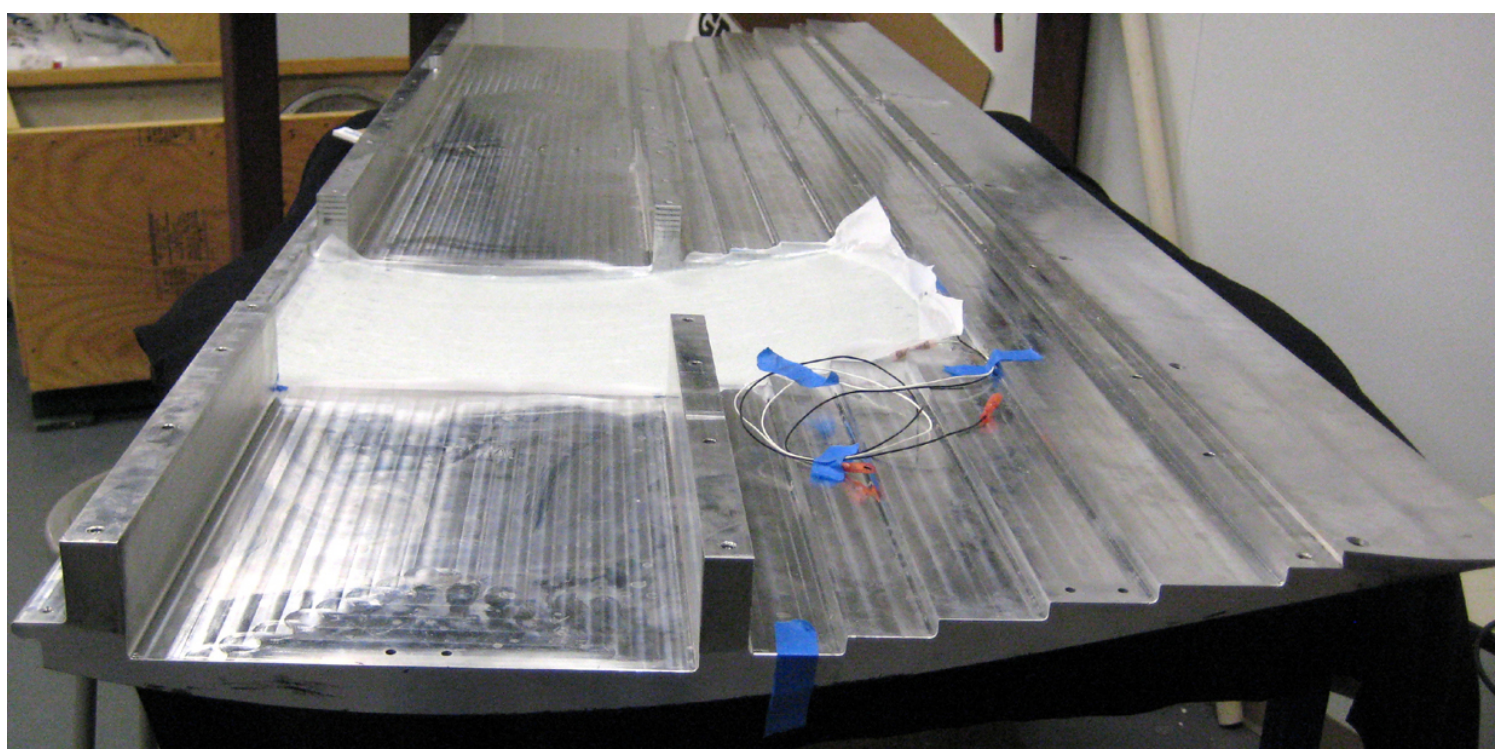

Figure II.15. Image of the model upper main body with the heating sheet installed. 
A FLIR ${ }^{\circledR}$ Indigo Merlin MID thermal camera with a $25 \mathrm{~mm}$ lens is used to observe the model surface temperature variations. Transition is difficult to view with an IR camera on smooth aluminum due to spectral surface reflections and high thermal conductivity which smears the transition location. To resolve both issues, the model was painted with a $250 \mu \mathrm{m}$ layer of Sherwin-Williams ${ }^{\circledR}$ lusterless high solids polyurethane topcoat. The paint was not sanded and has an $R_{a}=3.4 \mu \mathrm{m}$ and $R_{t}=23 \mu \mathrm{m}$. The flat surface finish is easily viewed with the IR camera. The thick coat acts as a layer of insulative material which reduces smearing. Normal glass is opaque in the IR range, so a hole was cut in the tunnel wall. A pressure box was built around the camera to minimize flow disturbance in the test section due to leakage. The test section is vented to atmospheric pressure, so there is minimal pressure differential.

\section{II.F. Test Operations}

The tests were split into multiple entries, allowing time to process the data and determine the next best course of action. The first entry focused upon the clean configuration, trip strip, and wavy, forward-facing step. Aerodynamic, IR thermography, hotfilm, and boundary layer rake measurements were made between $R e_{c}=0.8$ to $3.6 \times 10^{6}$. The transition model being validated is designed for distributed roughness, so data from entry one was only useful in validating natural transition.

Entry two therefore focused on insect roughness. Tested chord Reynolds number was increased to $4.4 \times 10^{6}$ by reducing the maximum angle of attack to $6^{\circ}$. Aerodynamic, IR thermography, hotfilm, and boundary layer rake measurements were 
made. The clean configuration was retested for repeatability. For comparison to the wavy, forward-facing step, the straight, forward-facing step was tested. Insect configurations included 100-03, 140-03, 140-03E, 140-15, 200-03, and 140-03 combined with the SFF. A sparse 3\% roughness and dense 15\% roughness configuration were compared to investigate sensitivity to accumulation density. Density was found to be an important factor. However, the installation approach for the $15 \%$ configuration resulted in roughness stacked on itself, yielding earlier transition than anticipated.

Entry three sought to answer these questions. Only aerodynamic and IR thermography measurements were made, as these proved most productive and highest quality. Roughness configurations 100-03, 100-09, 100-15, 140-03, 140-06, 140-09, 140-12, 140-15, and 140-03E were tested. Repeatability and density variation were determined. Chord Reynolds number was increased to $4.8 \times 10^{6}$ by reducing angle of attack to $4^{\circ}$ and operating during the winter with a cold test section.

In summary, each configuration was tested at chord Reynolds numbers of 0.8, $1.6,2.4,3.2 \times 10^{6}$ with angle of attack varying from $-4^{\circ}$ to $16^{\circ}$, capturing the operationally relevant data. Higher Reynolds numbers of 4.0, 4.4, and $4.8 \times 10^{6}$ were included for the distributed roughness configurations. Angle of attack was limited to $6^{\circ}$ at $4.0 \times 10^{6}$ and $4^{\circ}$ at 4.4 and $4.8 \times 10^{6}$ due to floor balance limits.

The LSWT data system was utilized to acquire freestream conditions, model static pressure, wake rake pressure, and boundary layer rake pressure. Angle of attack and the wake rake position were controlled with the data system as well. The model static, wake rake, and boundary layer rake pressures were measured with three 32 port pressure scanners. The scanners are read with a System 8400. Output from 
the System 8400 was acquired by the LSWT data system.

Hotfilm and IR measurements were made separately from the LSWT. Hotfilm anemometer output was acquired with two, 16 analog input NI USB-6211. Differential measurements were made. Entry one had seven hotfilm channels, requiring a single data acquisition board. Entry two had 14 channels, requiring both boards. IR images were acquired on a computer with a dedicated data acquisition board compatible with the IR camera. Remote desktop was used to access the computer from the control room. For both hotfilm and IR measurements, data were acquired manually while the LSWT data system pitched through a set of angles of attack. 


\section{CHAPTER III METHODOLOGY}

This chapter describes approaches used to calculate results. First, the methods to calculate lift, moment, and drag are detailed. Next, the angle of attack corrections are described. Third, the application of wall corrections is discussed. Fifth, the four transition measurement approaches are elucidated. Lastly, the annual energy production calculation for a NREL 5 MW wind turbine is described.

\section{III.A. Lift, Moment, and Drag}

Lift and moment are calculated by integrating the pressure coefficient over the airfoil surface. The pressure coefficient is defined as

$$
C_{P}=\frac{p-p_{\infty}}{q_{\infty}}
$$

where $p$ is local static pressure, $p_{\infty}$ is freestream static pressure, and $q_{\infty}$ is the freestream dynamic pressure. Because static pressure is not measured at the trailing edge, a weighted average is calculated from the nearest two ports. The pressure coefficient is one at the stagnation point. However, as defined, the experimental stagnation point was not exactly equal to one. This was likely due to a small discrepancy between the measured freestream static pressure and the actual static pressure. This was resolved by eliminating $p_{\infty}$ from Eq. 3.1, recasting the pressure coefficient as

$$
C_{P}=\frac{p-p_{0}}{q_{\infty}}+1,
$$

where $p_{0}$ is the total pressure. The tunnel total pressure, measured from a wall Pitot-static probe, minimally varies throughout the test section, yielding a stagnation 
pressure coefficient much closer to unity.

The normal force coefficient is the nondimensional force acting normal to the model chordline. It is defined as

$$
c_{n}=-\frac{1}{c} \oint C_{P} d x
$$

where $d x$ is a differential length in the chordwise direction and $c$ is the airfoil chord. The closed integral is taken clockwise from the trailing edge lower surface. Similarly, the axial force coefficient acts in the chord-parallel direction and is defined as

$$
c_{a}=\frac{1}{c} \oint C_{P} d y
$$

where $d y$ is a chord-normal differential length. Lift is defined parallel to the freestream velocity, and is transformed from the normal and axial force coefficients by

$$
c_{l}=c_{n} \cos \alpha-c_{a} \sin \alpha,
$$

where $\alpha$ is the angle of attack. The axial component is generally ignored as a second order term since both $c_{a}$ and $\sin \alpha$ are much smaller than $c_{n}$ and $\cos \alpha$. Once stalled however, neither term is small, so the $c_{a} \sin \alpha$ term is included.

Moment coefficient about quarter chord is calculated by multiplying the pressure coefficient by a moment arm around quarter chord, or

$$
c_{m, c / 4}=\frac{1}{c^{2}} \oint C_{P}(x-c / 4) d x+\frac{1}{c^{2}} \oint C_{P} y d y
$$

where a positive moment corresponds to positive pitch (nose up).

Drag is calculated with a control volume approach. This approach has more sensitivity than a force balance at low angles of attack, where accurate measurements 
are of primary concern. The momentum deficit behind the airfoil corresponds to the drag as

$$
D=\iint \rho V\left(V_{0}-V\right) d a
$$

where $V_{0}$ is the upstream velocity, $V$ is the wake velocity, $\rho$ is the air density, and $d a$ is a differential area. Assuming the flow is two-dimensional and nondimensionalizing the drag by dynamic pressure and chord yields

$$
c_{d}=\frac{2}{c} \int\left(\sqrt{\frac{q}{q_{0}}}-\frac{q}{q_{0}}\right) d y .
$$

where $y$ is the chord normal direction, $q 0$ is the upstream dynamic pressure, and $q$ is the wake dynamic pressure deficit.

The dynamic pressure deficit was measured with a rake wake, described in Section II.E.1. The wake rake had somewhat large spacing. This was improved by making two measurements at different chord-normal locations. The additional data improved wake resolution. Though the wake rake was placed sufficiently aft of the model, static pressure varied in the test section. Therefore, static pressure variation was estimated by fitting a linear, least-squares curve to three static pressure measurements along the wake rake. The fit was subtracted from the measured wake deficit, yielding the wake dynamic pressure, $q$.

The upstream dynamic pressure, $q_{0}$, is assumed to equal the dynamic pressure outside of the wake. Due to circulation, dynamic pressure outside of the wake is not constant. A linear, least-squares curve was fit to the local dynamic pressure outside of the wake, resulting in a complete estimate of the upstream dynamic pressure. The corrected wake deficit, $q / q_{0}$, is then known, allowing drag to easily be calculated. The above steps are illustrated in Fig. III.1. The blue points indicate the measured 
dynamic pressure with the green line indicating the local freestream fit. The corrected deficit, $q / q_{0}$, is shown with the red line.

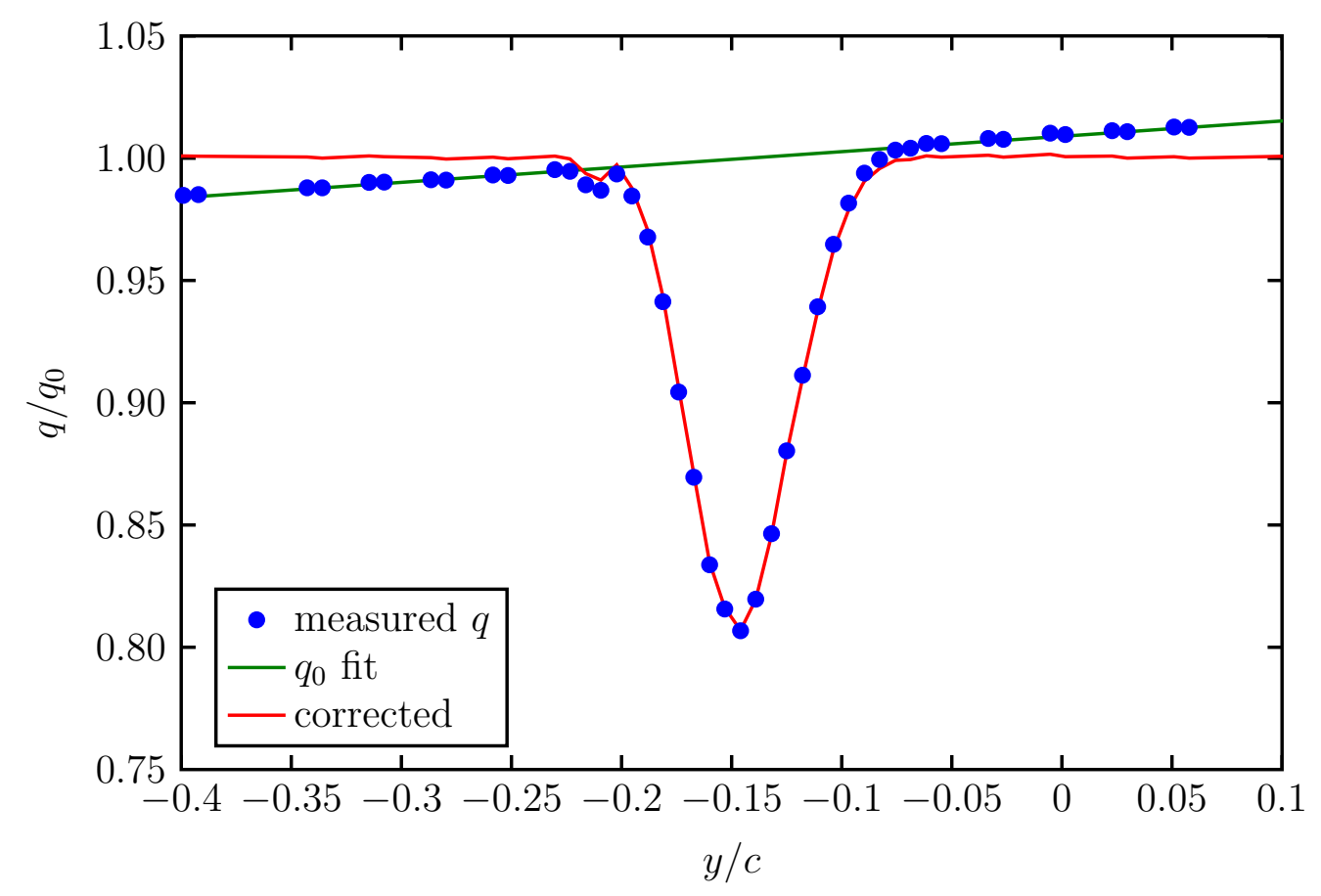

Figure III.1. Pressure deficit at $\alpha=6^{\circ}$.

The momentum deficit method assumes the wake is in equilibrium and is two dimensional. Because two wake measurements are acquired, equilibrium is easy to visualize. Figure III.2 illustrates the wake at $\alpha=11^{\circ}$. An unsteady separation region persists on the airfoil upper surface, resulting in two distinct wake structures. An example of a wake in equilibrium is shown in Fig. III.1, evidenced by the smoothly varying wake. Therefore, drag at high angles of attack is suspect. For the current study, this region is of no interest.

The two dimensionality of the flow is brought into question due to Fig. II.12. 


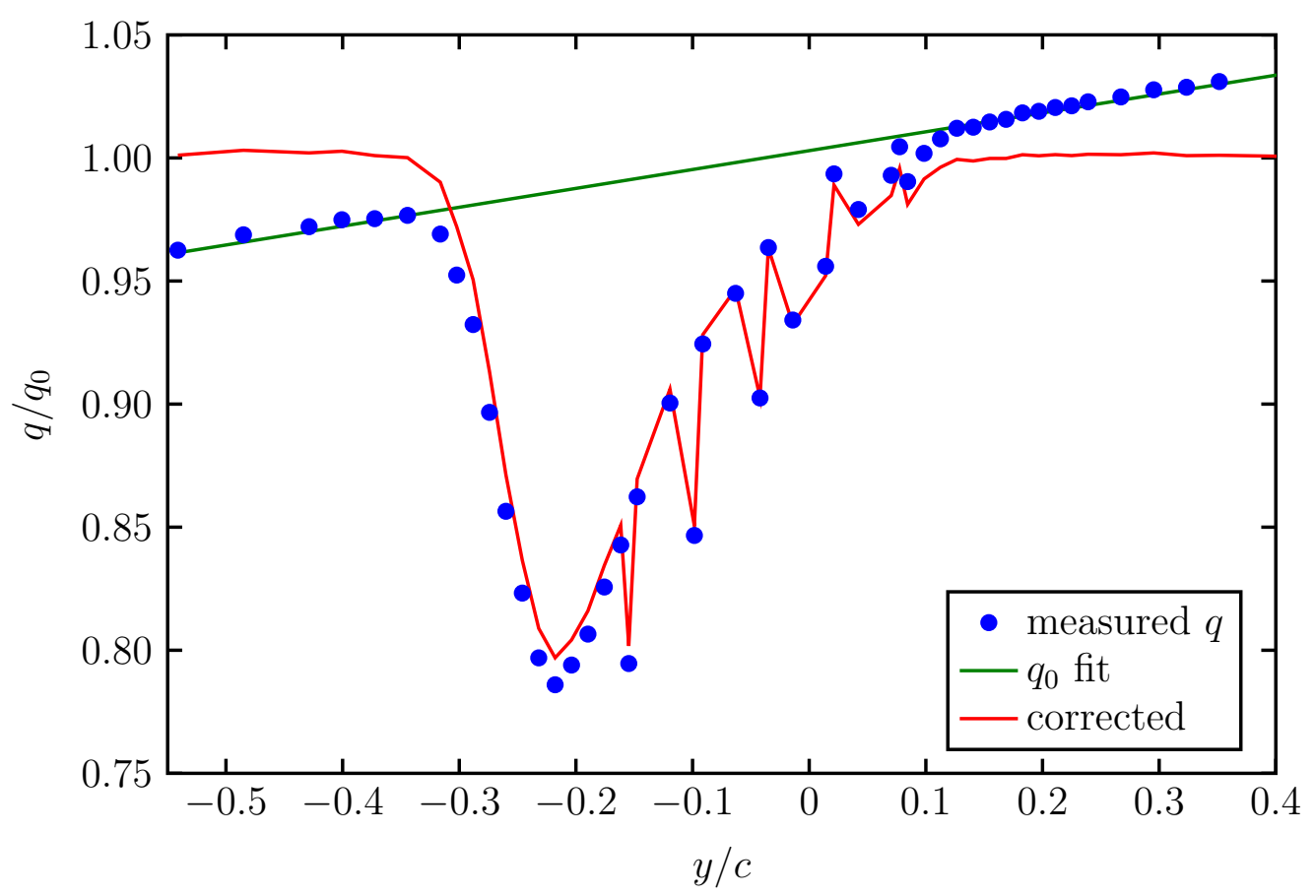

Figure III.2. Airfoil wake at $\alpha=11^{\circ}$ illustrating separation.

Drag is shown to vary spanwise in a repeatable manner between two Reynolds numbers. The spanwise variation in drag is larger than the individual measurement uncertainty. One explanation is that pressure ports are causing premature transition and increasing the drag. This is supported by comparing the pressure port location to the drag rise location. To remedy this, drag was measured 18 in above the model center span. Barlow et al. have an extended discussion regarding the wake two dimensionality [44].

No compressibility corrections were made. The primary goal within this work was to compare percent differences in performance between configurations. Correcting the performance to an effective zero Mach number was unnecessary. The model matches some scale conditions on wind turbines, so the measured performance is 
more representative of actual turbine performance. For reference, a common correction is the Prandtl-Glauert transformation, given by

$$
C_{P}=\frac{C_{P, \text { inc }}}{\sqrt{1-M_{\infty}^{2}}},
$$

where $C_{P}$ is the compressible pressure coefficient, $C_{P \text {,inc }}$ is the incompressible pressure coefficient, and $M_{\infty}$ is the freestream Mach number [47]. At maximum dynamic pressure, the Mach number is 0.25 , resulting in a $3.2 \%$ difference between $C_{P}$ and $C_{P, \text { inc }}$. The identical correction may be extended to lift and moment coefficients. Higher order corrections are derived by Karman-Tsien and Laitone [47].

\section{III.A.1. Uncertainty}

Uncertainty for the normal and moment coefficients was calculated with a firstorder Taylor series expansion. Drag uncertainty may be calculated in a similar manner. However, uncertainty is generally overestimated with this method. Instead, drag uncertainty was determined with a bootstrapping technique [48]. These calculations are described below.

The normal and moment coefficient uncertainty is a function of the pressure coefficient uncertainty. Expanding the pressure coefficient with a first order Taylor series and simplifying results in

$$
\sigma_{C_{P}} \approx \frac{1}{q_{\infty}} \sqrt{\sigma_{p}^{2}+\sigma_{p_{0}}^{2}+\left(1-C_{P}\right)^{2} \sigma_{q_{\infty}}^{2}}
$$

assuming zero covariance. The variable $\sigma$ represents component uncertainties, summarized in Section II.E.1. Equations 3.3 and 3.6 may be discretized as

$$
c_{n}=\frac{-1}{2 c} \sum_{i=1}^{N-1}\left(c_{p_{i+1}}+c_{p_{i}}\right)\left(x_{i+1}-x_{i}\right)
$$




$$
c_{m}=\frac{1}{4 c} \sum_{i=1}^{N-1}\left(c_{p_{i+1}}+c_{p_{i}}\right)\left(x_{i+1}+x_{i}-c / 4\right)\left(x_{i+1}-x_{i}\right),
$$

where $N$ is the number of pressure ports on the airfoil, counting the trailing edge twice. Equation 3.12 is a simplified version of Eq. 3.6, removing chord-normal components. Assuming the pressure port positions and chord length are exactly known, and there is no covariance, the normal and moment variance may be represented as

$$
\begin{aligned}
\sigma_{c_{n}}^{2} \approx & \frac{1}{4 c^{2}}\left\{\sigma_{c_{p_{1}}}^{2}\left[\left(x_{2}-x_{1}\right)^{2}+\left(x_{N}-x_{N-1}\right)^{2}\right]+\sum_{i=2}^{N-1} \sigma_{c_{p_{i}}}^{2}\left(x_{i+1}-x_{i-1}\right)^{2}\right\} \\
\sigma_{c_{m}}^{2} \approx & \frac{1}{16 c^{4}}\left\{\sigma_{c_{p_{1}}}^{2}\left[\left(x_{2}^{2}-x_{1}^{2}+c \frac{x_{1}-x_{2}}{4}\right)^{2}+\left(x_{N}^{2}-x_{N-1}^{2}+c \frac{x_{N-1}-x_{N}}{4}\right)^{2}\right]+\right. \\
& \left.\sum_{i=2}^{N-1} \sigma_{c_{p_{i}}}^{2}\left(x_{i+1}^{2}-x_{i-1}^{2}+c \frac{x_{i-1}-x_{i+1}}{4}\right)^{2}\right\},
\end{aligned}
$$

where $\sigma_{c_{p_{i}}}$ was determined from the pressure transducer uncertainty. Span and zero offset drift due to temperature variation during a run were included. Uncertainty in the axial coefficient was assumed to be small and ignored, so $\sigma_{c_{n}} \approx \sigma_{c_{l}}$. At $R e_{c}=0.8 \times 10^{6}$, the median percent uncertainty, $\sigma_{c_{l}} / c_{l}$ and $\sigma_{c_{m}} / c_{m}$, are $3.7 \%$ and $31 \%$, respectively. At $R e_{c}=1.6 \times 10^{6}$, they decreased to $0.8 \%$ and $5.2 \%$, respectively. Errorbars are not indicated on the lift results because the uncertainty is small. A significant amount of the uncertainty is related to temperature variation in the tunnel. The transducer temperature variation is assumed to equal the tunnel temperature variation. Because the transducers are inside the model, the actual temperature variation is smaller.

The calculation of drag had distinct processes, making the function nondifferentiable. For instance, a linear, least-square fit was applied to the local dynamic pressure variation in the tunnel. Drag had high sensitivity to this fit, as any offset would result in non-zero drag outside the wake. To capture the total sensitivity, a 
bootstrap method was employed. Each measured data point was assumed to have a normally distributed position and pressure. The measurement location was assumed to have a one standard deviation value of 0.1 in. The pressure standard deviation was determined from the manufacturer specifications, summarized in Section II.E.1. Span and zero offset drift due to temperature variation during a run was included. From these values, a normal distribution of $M$ points was created. Drag was calculated $M$ times utilizing the method described in Section III.A. The process converged near $M=2500$. The $20 \mathrm{inH}_{2} \mathrm{O}$ pressure scanner had insufficient sensitivity to measure the wake at $R e_{c}=0.8 \times 10^{6}$. At $R e_{c}=1.6 \times 10^{6}$ and $R e_{c}=2.4 \times 10^{6}$, the mean $\sigma_{c_{d}} / c_{d}$ is $12 \%$ and $5.1 \%$, respectively. Drag uncertainty was not shown to decrease at higher dynamic pressure, and was generally near $5 \%$.

\section{III.B. Wall Corrections}

Barlow et al. summarize the boundary corrections for two-dimensional flow from various sources [44]. In brief, corrections are made to velocity terms accounting for solid and wake blockage. Additional correction is added for streamline curvature, correcting angle of attack, lift, drag, and moment. Buoyancy effects are ignored because the test section wall expansion compensates for wall boundary layer growth. Also, pressure variations due to buoyancy must occur over long distances to cause a measurable difference.

Blockage corrections are made for the model solid blockage and wake blockage. In the first case, the local flow around the model has additional velocity due to the constrained streamlines. For the second case, continuity demands accelerated flow 
outside of the wake region. Each results in decreased static pressure around the model. Many approaches for blockage corrections exist. As they are all small corrections, little concern was taken between the method variations. The solid blockage correction term may be defined as

$$
\epsilon_{\mathrm{sb}}=\Lambda \sigma
$$

where $\Lambda \approx 0.316$ for a baseline NACA $63-018$ and $\sigma=\pi^{2} / 48(c / h)^{2} \approx 0.0146$, where $c$ is the model chord and $h$ is the tunnel height (width for vertical model). The solid blockage correction is then $\epsilon_{\mathrm{sb}} \approx 0.0046$. Wake blockage is directly proportional to the amount of drag the model body generates and equals

$$
\epsilon_{\mathrm{wb}}=\frac{c}{2 h} c_{d u}
$$

where $c_{d u}$ is the uncorrected drag coefficient. The total blockage term is

$$
\epsilon=\epsilon_{\mathrm{sb}}+\epsilon_{\mathrm{wb}}
$$

The last correction is applied for streamline curvature. Due to the wind tunnel walls, the airfoil appears to have increased camber, resulting in increased angle of attack, lift, and moment. The coefficient corrections are as follows:

$$
\begin{gathered}
q=q_{u}(1+2 \epsilon) \\
c_{d}=c_{d u}\left(1-3 \epsilon_{\mathrm{sb}}-2 \epsilon_{\mathrm{wb}}\right) \\
\alpha=\alpha_{u}+\frac{\sigma}{2 \pi}\left(c_{l u}+4 c_{m u, c / 4}\right) \\
c_{l}=c_{l u}(1-\sigma-2 \epsilon) \\
c_{m, c / 4}=c_{m u, c / 4}(1-2 \epsilon)+\sigma c_{l} / 4,
\end{gathered}
$$


where the $u$ subscript indicates uncorrected values and $\sigma$ is defined above. Note that drag is required to make blockage corrections and that Eq. 3.20 has units of radians. Drag measurements were not made beyond stall, so drag was estimated from Sheldahl and Klimas [49].

\section{III.C. Shaft Deflection Corrections}

Aligning the model's chordline with the freestream is a difficult task. For the first entry, the model was physically aligned with the tunnel centerline. The lower model surface has an access panel to reach the pressure scanners. An alignment panel was designed to fit in the same location. The panel was parallel to the model chordline and was offset below the lowest surface. A transit level was aligned with a line which was offset the distance between the tunnel centerline and the alignment panel. The model was pitched until aligned with the transit level.

The above method yielded a $0.4^{\circ}$ offset between the measured and Abbott and von Doenhoff's lift curve. A linear, least-squares fit applied between $-4^{\circ}<\alpha<6^{\circ}$ on both curves was used to determine the offset. For ease of installation, entries two and three had no freestream alignment applied. Entry two was nearly aligned and remained uncorrected. A large offset was discovered and corrected during the shakedown of entry three. The lift curve slope at $R e_{c}=1.6 \times 10^{6}$ is utilized as a baseline comparison to Abbott and von Doenhoff because shaft deflections are minimal at this Reynolds number.

The mounting shaft has additional deflections which need to be considered. Shaft translation has no performance effect while shaft rotation will change the angle 
of attack. A rectangular, 1.5 in long section was machined into the cylindrical beam balance to increase the measurable strain. The shaft was centered on the airfoil quarter chord. Therefore, $c_{m, c / 4}$ describes the moment on the shaft and was used to calculate the shaft torsion. The shaft boundary conditions were fixed at the floor and pinned (rotation, but no translation) at the ceiling. All of the torsion was constrained by the floor mount. The torsion was assumed to equal the linear combination of deflection in the circular shaft and the rectangular bar. Deflection in a circular shaft is

$$
\phi=\frac{M l_{1}}{G J}
$$

where $M$ is the applied moment, $l_{1}$ is the length between the floor and model mounts, $G$ is the shear modulus of steel, and $J=\pi r^{4} / 2$. Deflection in a rectangular beam is

$$
\phi=\frac{M l_{2}}{c_{2} a b^{3} G},
$$

where $l_{2}$ is the strain gage cutout length, $c_{2}$ is a coefficient based on the beam aspect ratio, $a / b$, where $a$ is the longer dimension. For the particular geometry, $c_{2}=0.246$ [50]. The moment was determined from Abbott and von Doenhoff [40]. At $R e_{c}=1.6 \times 10^{6}$, the maximum deflection is $-0.01^{\circ}$ (nose down). At $R e_{c}=5.0 \times 10^{6}$, the maximum deflection reached $-0.11^{\circ}$. Moment is relatively constant through the linear lift region, so the major consequence of the balance deflection correction is proper alignment of the zero-lift angle of attack.

\section{III.D. Laminar-to-Turbulent Transition}

Laminar-to-turbulent transition was measured using multiple techniques. The predominant technique was infrared (IR) thermography. The second transition mea- 
surement was made with hotfilms. Hotfilms can indicate transition through spectral content, intermittency, and mean-voltage variations. The following methodologies are discussed below.

\section{III.D.1. Infrared Thermography}

An IR image was acquired at each angle of attack or velocity during a test run. Variations in surface temperature indicate the transition location, as seen in Fig. III.3. The light colored, warm region on the left is laminar while the dark colored, cool region on the right is turbulent. Here, the model is warmer than the tunnel freestream. Fiducials at $5 \%$ chord intervals on the model surface were used as fiducials. Images with a two dimensional transition front were analyzed by sight. This was sufficiently accurate $( \pm 1 \%$ chord $)$ because the two-dimensional transition front is somewhat indistinct.

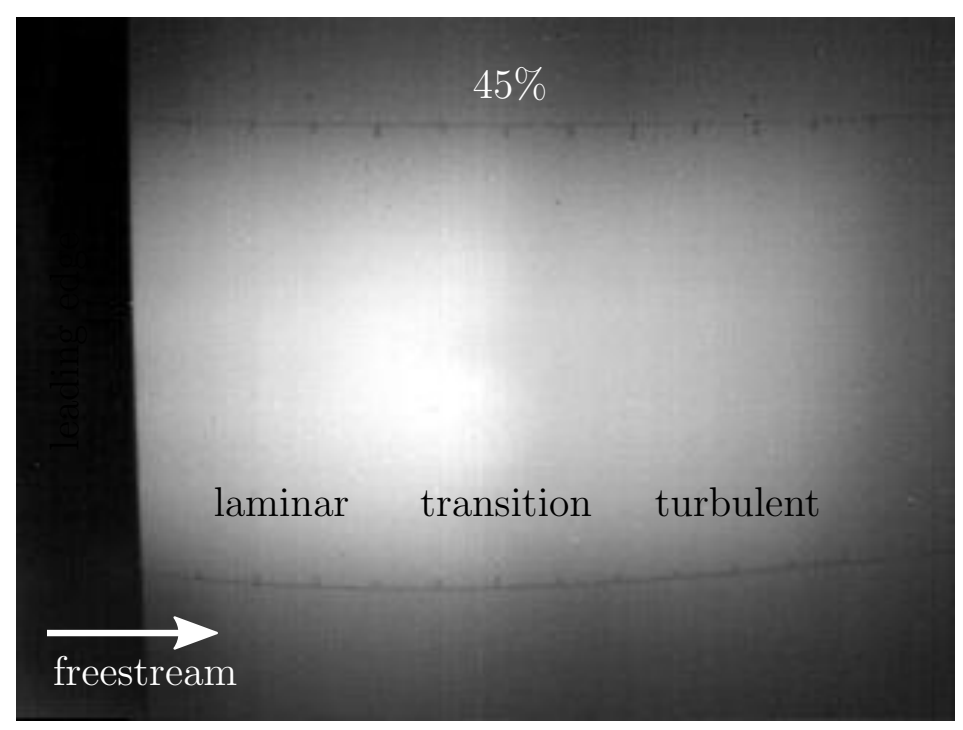

Figure III.3. IR image of two-dimensional transition front at $45 \%$ chord. 
However, once roughness becomes critical and bypass transition occurs, transition cannot be estimated visually. Figure III.4 illustrates an example of bypass transition with flow left to right. The white region is the aluminum leading edge. The airfoil main body is to the right of the leading edge. The transition front is located by hand with a plot digitizer and indicates bypass transition emanating from locations on the white leading edge region. It is assumed that the transition front extends linearly onto the leading edge. Using the known tick mark locations on the model surface, the transition front can be translated from pixel to chord coordinates. Because spanwise stretching is small, no spanwise correction was applied.
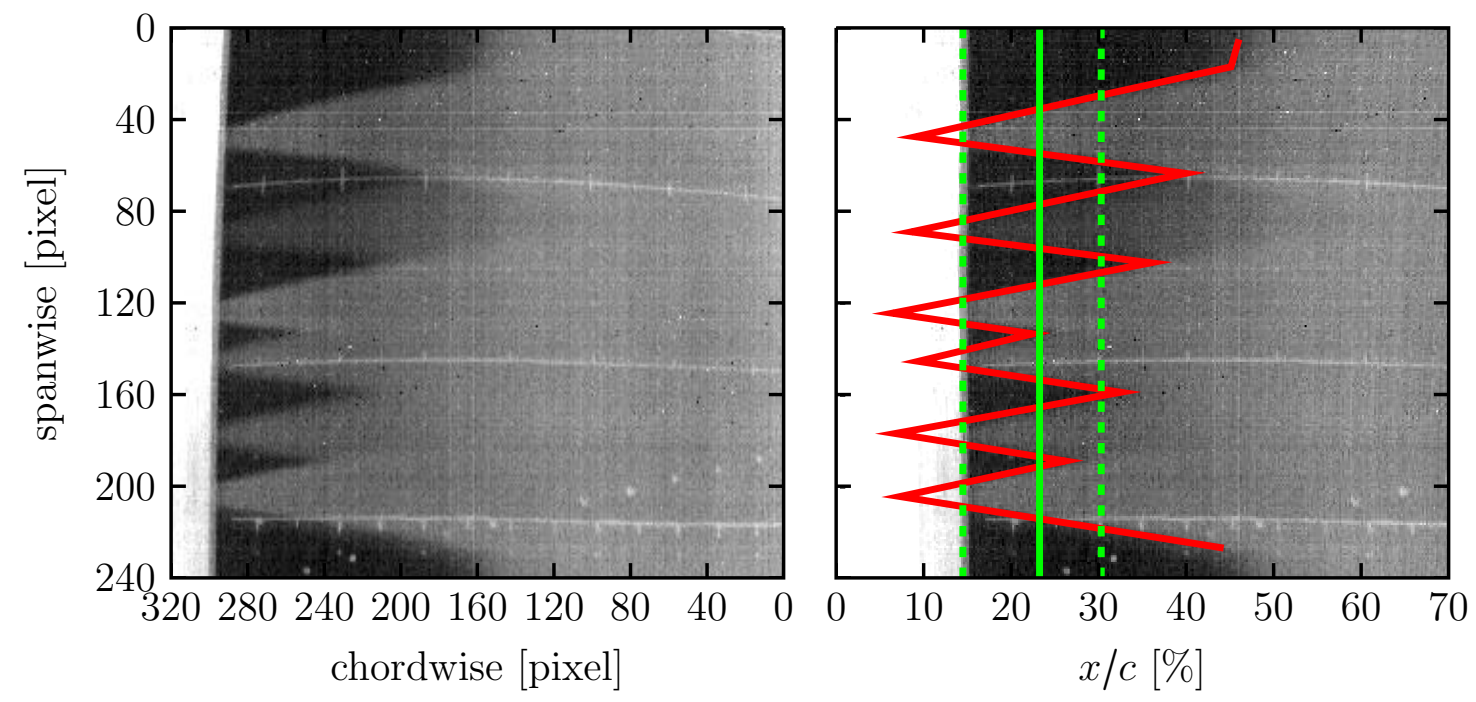

Figure III.4. Example of (left) original and (right) corrected IR images. The transition front is indicated in red, with the transition mean and bound locations indicated with a solid and dashed green line, respectively.

The corrected image is shown at right in Fig. III.4. The red line indicates the corrected transition front. The solid green line is the mean transition location at 
$23.2 \%$ chord. The lower and upper bounds are indicated by dashed green lines at $14.5 \%$ and $30.3 \%$ chord, respectively. They represent the $25^{\text {th }}$ and $75^{\text {th }}$ percentiles.

\section{III.D.2. Spectral Content}

Hotfilms are useful to investigate local flow phenomena. Time series were transformed into the frequency domain with a Fourier transform. This allows the dominant flow frequencies to be indicated more clearly. The Fourier analysis follows the recommendations of Press et al. [48]. The power spectral density (PSD), generically $P$, of a time series $d$ with $N$ discrete points is defined as follows

$$
\begin{gathered}
D_{k} \equiv \sum_{j=0}^{N-1} d_{j} w_{j} e^{2 \pi i j k / N} \quad k=0, \ldots, N-1, \\
P(0)=P\left(f_{0}\right)=\frac{1}{W_{s s}}\left|D_{0}\right|^{2} \\
P\left(f_{k}\right)=\frac{1}{W_{s s}}\left[\left|D_{k}\right|^{2}+\left|D_{N-k}\right|^{2}\right] \quad k=1,2, \ldots,\left(\frac{N}{2}-1\right) \\
P\left(f_{c}\right)=\frac{1}{W_{s s}}\left|D_{N / 2}\right|^{2}
\end{gathered}
$$

where $f_{c}$ is the Nyquist frequency. Each bin represents a discrete frequency in a continuous spectrum. Because of this, there is leakage between neighboring bins. A window function, $w_{j}$ which varies from zero at the endpoints to one at the center smoothes this variation. A Welch window, where $w_{j}=1-\left(\frac{j-N / 2}{N / 2}\right)^{2}$, was applied. As written above, $W_{s s} \equiv N \sum_{j=0}^{N-1} w_{j}$. The standard deviation of the PSD is $100 \%$ of its value. This can be improved by splitting the original time series into $K, 50 \%$ overlapping segments, reducing the uncertainty by a factor of $1 / \sqrt{9 K / 11}$. For this study $K=31$, resulting in a PSD standard deviation of $20 \%$ its value.

Figure III.5 is an example of the hotfilm spectra of six sensors varying from 

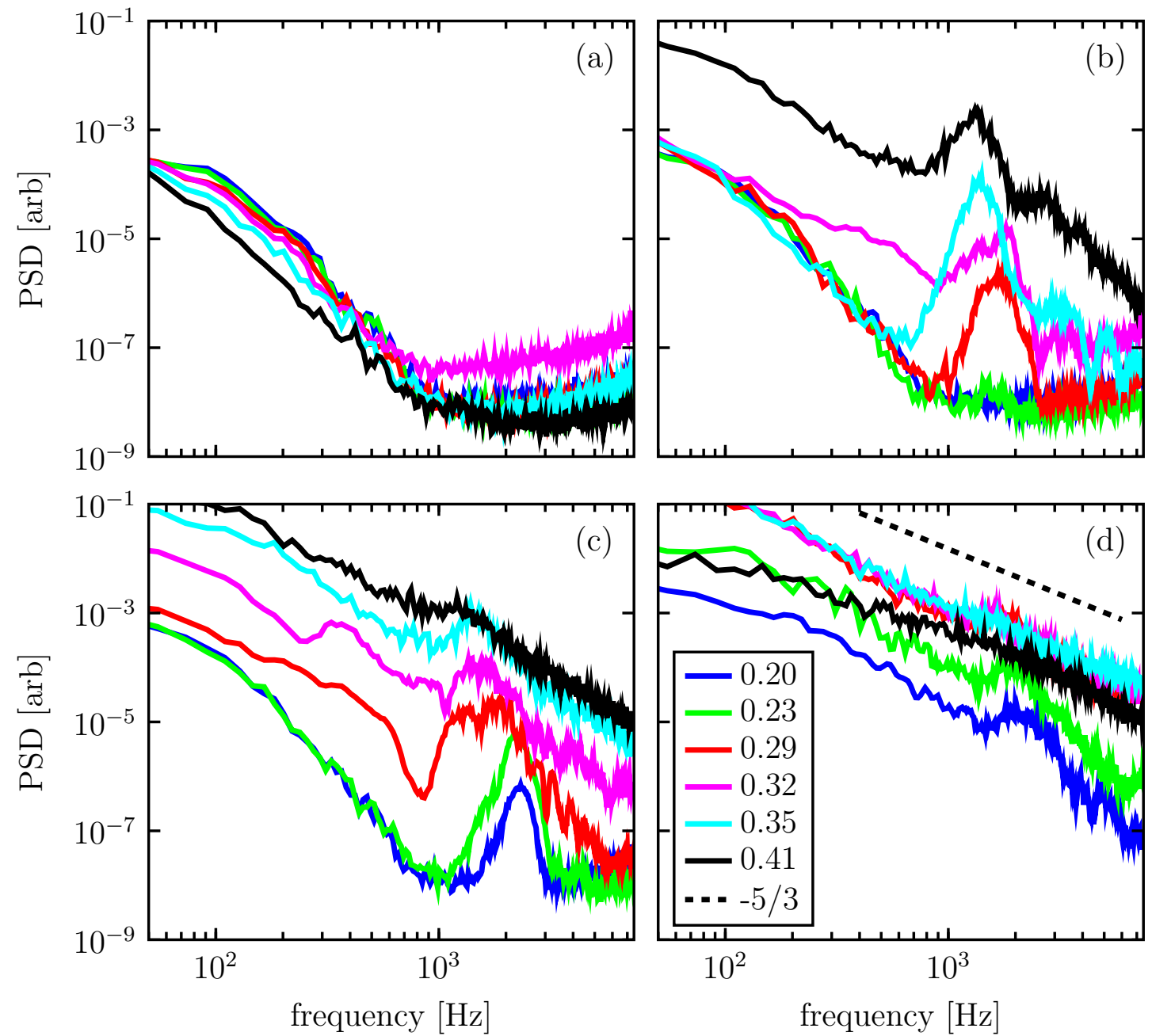

Figure III.5. Hotfilm spectra at $R e_{c}=1.6 \times 10^{6}$. Each line represents an individual hotfilm sensor $x / c$ location, and each plot represents an angle of attack of (a) $0^{\circ}$, (b) $5^{\circ}$, (c) $6^{\circ}$, and (d) $7^{\circ}$.

$20 \%$ to $41 \%$ chord, with each subplot represent an angle of attack of $0^{\circ}, 5^{\circ}, 6^{\circ}$, or $7^{\circ}$. Figure III.5a illustrates completely laminar flow. There is little power in the spectra, indicating low disturbances. When the angle of attack increases to $5^{\circ}$ in Fig. III.5b, the four aft sensors show a peak around $1.5 \mathrm{kHz}$. The peak amplitude increases moving further aft. This represents Tollmien-Schlichting (TS) wave growth. The typical nondimensional frequency of a TS wave on a flat plate is $60 \times 10^{-6}<$ 
$F<200 \times 10^{-6}$, where $F=2 \pi f \nu / U_{\infty}^{2}$. At the given conditions with $f=1.5 \mathrm{kHz}$, $F=130 \times 10^{6}$, typical for a TS wave on a flat plate. As angle of attack continues to increase, Fig. III.5c shows fully turbulent flow at $41 \%$ chord. The most forward

sensor indicates TS wave growth now. As the TS wave strengthens and begins to breakdown, the peak broadens with a rise in energy, shown at $29 \%$ chord. Chord locations of $32 \%$ and $35 \%$ are characterized as transitional. The TS wave is indistinct, and energy levels have greatly risen. Lastly, Fig. III.5d clearly illustrates turbulent spectra with a characteristic $-5 / 3$ slope.

Data from similar plots was individually analyzed, as above, to indicate laminar, TS-dominated, transitional, or turbulent flow. The data visualizes how transition develops as configurations are varied. Specifically, it is desirable to know if transition behind roughness elements is still TS-dominated or if breakdown occurs before TS waves destabilize.

\section{III.D.3. Intermittency}

A second method of determining transition location with hotfilm time series is with intermittency. Intermittency is an indication of whether the flow is laminar or turbulent. Transitional flow will have turbulent fluctuations pass over the sensor, causing large voltage spikes, illustrated in Fig. III.6. Along with large voltage variations, the signal appears noisy due to TS waves which are obscured at this time scale. As the flow becomes more turbulent, more voltage spikes will occur until the entire noise level in the signal rises into a broadband, turbulent signal. A numerical treatment may be applied to indicate where flow is intermittent. In the current 
research, the intermittency is calculated following the recommendations of Fransson et al. [51]. Intermittency is calculated by measuring the fraction of time turbulent fluctuations occur in laminar flow.

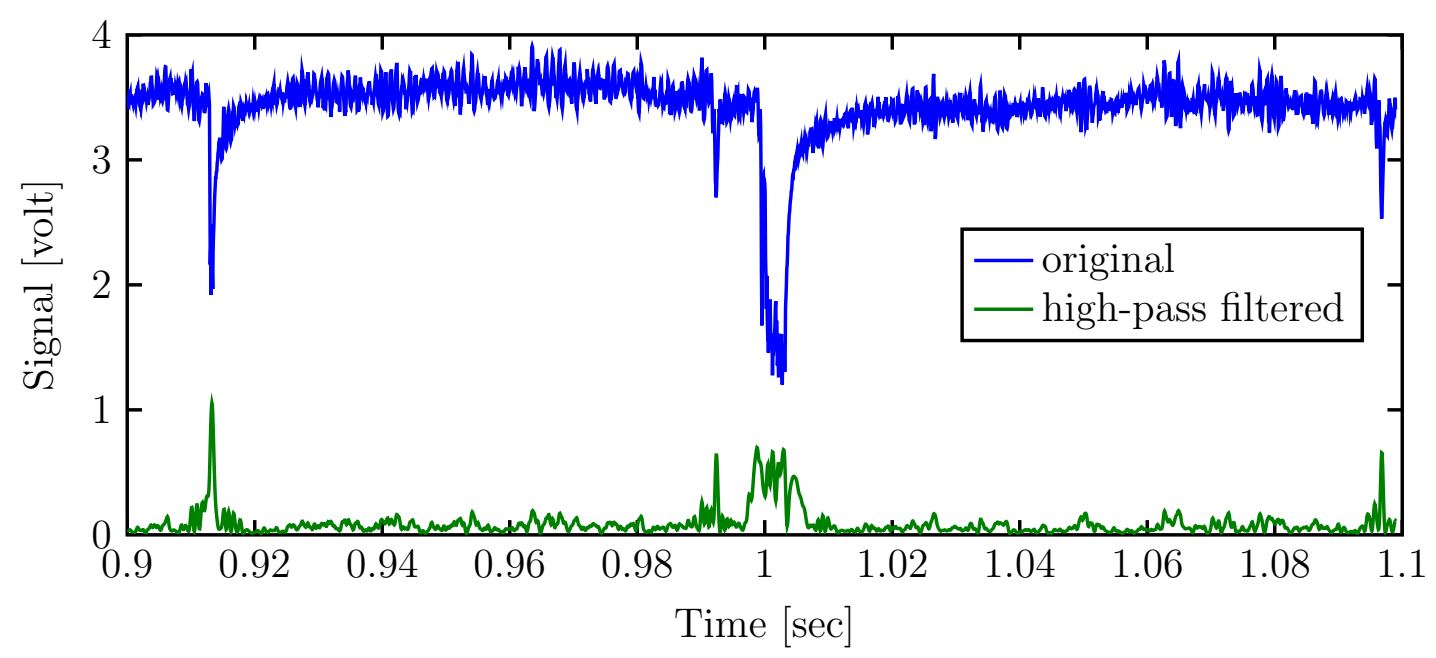

Figure III.6. Hotfilm time series illustrating voltage spikes due to turbulent spots.

The first step is to high-pass filter the hotfilm signal at $f_{\text {cut }}=U_{\infty} / 5 \delta$, where boundary-layer thickness is taken to be $\delta \approx 4.91 x / \sqrt{R e_{x}}$ for the Blasius solution. The Blasius solution was deemed a sufficient approximation for the boundary-layer thickness over the airfoil. It is updated for each chord location, as the boundary layer is vastly different from $4 \%$ to $56 \%$ chord. The cutoff frequency was empirically determined, but based on the convective velocity and streamwise scale. The absolute value of the high-passed signal is taken. A low-pass filter is applied to this section to smooth discontinuities created by taking the absolute value, resulting in a signal function, $\mathcal{F}(t)$. Threshold values, $v_{t}$, ranging from 0.001 to the maximum of $\mathcal{F}(t)$ 
are chosen such that

$$
\mathcal{I}^{j}= \begin{cases}1 & \text { if } \mathcal{F}(t) \geq v_{t}^{j} \\ 0 & \text { if } \mathcal{F}(t)<v_{t}^{j}\end{cases}
$$

where $\mathcal{I}$ is an indicator function for $j$ threshold values. Intermittency, $\gamma$, can then be defined as the ratio where $\mathcal{I}=1$ to the length of $j$.

Each threshold value has a unique intermittency value. Determining the actual intermittency value is difficult. Figure III.7a illustrates $\log (\gamma)$ versus the threshold voltage. Fitting a line through the linear region and solving the y-intercept represents the actual intermittency value, $\log (0.1697)=-0.7703$, for a given time series. Varying multiple angles of attack results in an indication of where transition occurs, shown in Fig. III.7b. This curve is fit with

$$
\gamma=\frac{1}{\pi} \arctan \left(c_{1} \alpha+c_{2}\right)+0.5
$$

where $c_{1}$ and $c_{2}$ are constants. Transition is assumed to occur where $\gamma=0.5$, with uncertainty bounds specified as the chordwise locations where $\gamma=0.1$ and 0.9 .

\section{III.D.4. Mean Voltage Variation}

The last methodology to analyze hotfilm data is investigating the mean voltage variation. The hotfilm sensor was attached to a constant temperature anemometer. As the local convection rate varied, voltage was varied to maintain a constant sensor temperature. These mean voltage variations can indicate when the flow is laminar or turbulent. Figure III.8 shows the variation of hotfilm mean voltage with angle of attack for a sensor at $31.6 \%$ chord. The airfoil is at $R e_{c}=0.8 \times 10^{6}$ with the $100-03$ roughness configuration on the leading edge. There is a slow rise in voltage as angle 

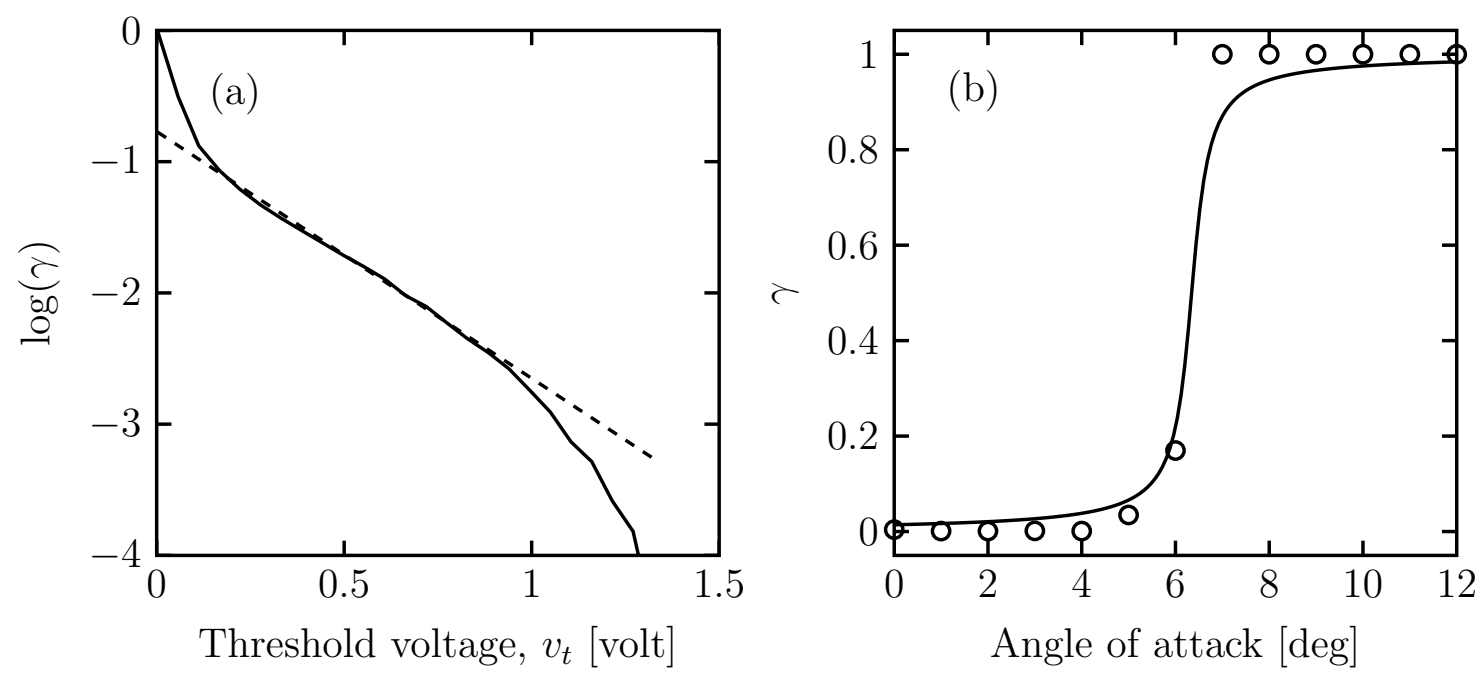

Figure III.7. Example of processed hotfilm intermittency calculations. (a) Hotfilm intermittency variation with threshold voltage shown as a solid line. The dashed line is a linear fit to the center third of the data. (b) Variation of intermittency with angle of attack with the curve fit (solid line) applied.

of attack increases. When transition occurs, the voltage drops. As angle of attack continues to increase, the voltage once again increases.

A fit is applied through the mean voltage data. The voltage rise appears quadratic while the drop in voltage may be represented by the arctan function. The resulting fit is

$$
E=\frac{1}{c_{3}} \arctan \left(c_{1} \alpha-c_{2}\right)+c_{4}+c_{5} \alpha+c_{6} \alpha^{2}
$$

where $E$ is the voltage and $c$ are the fit coefficients. Removing the polynomial fit results in the dashed blue line in Fig. III.8. Transition is assumed to occur when $\arctan \left(c_{1} \alpha-c_{2}\right)=0$, or $\alpha=c_{2} / c_{1}$. The bounds on transition are determined by when the absolute value of the slope of the arctan function is 0.4 . While the 0.4 value was empirically chosen, the slope is a good indicator of the width of the transition regime. The transition bounds are indicated by vertical black lines in Fig. III.8. 


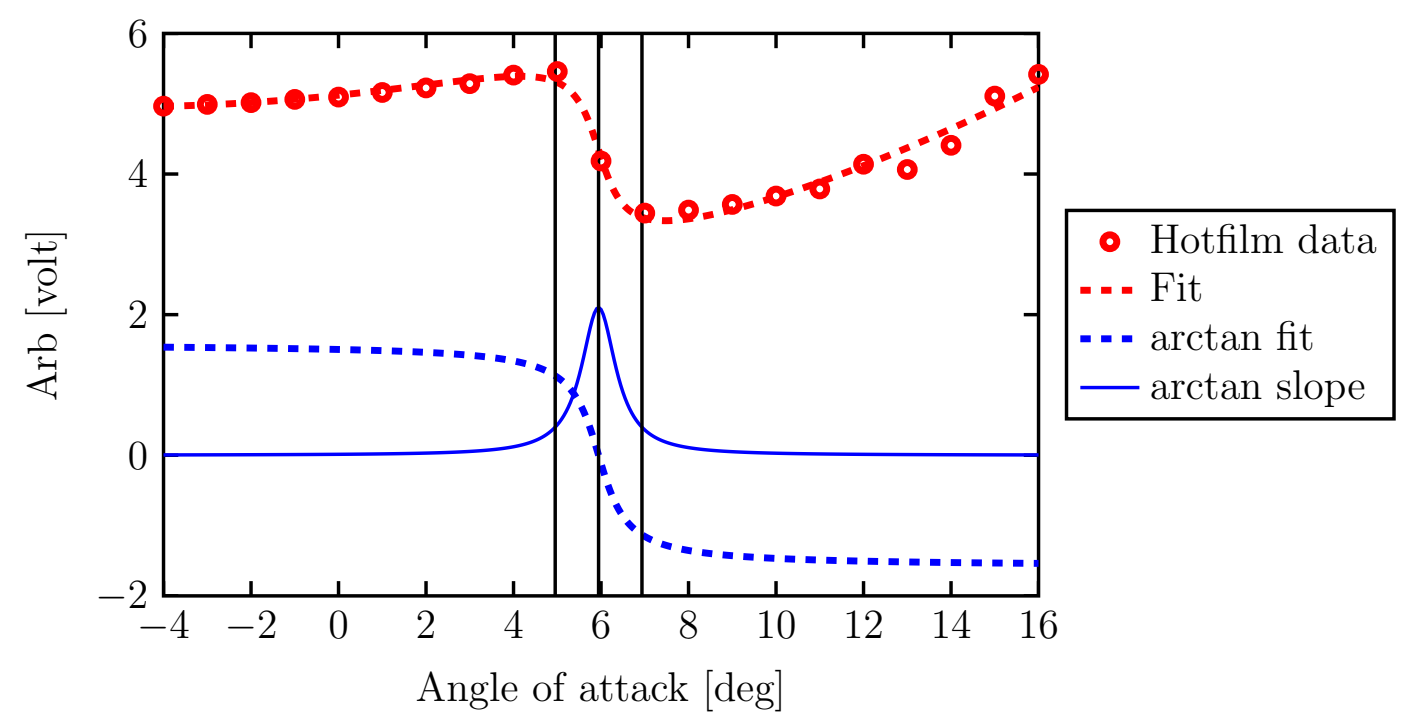

Figure III.8. Hotfilm voltage variation with angle of attack. Transition location is shown by the center black line.

\section{III.E. Annual Energy Production}

Airfoil performance is generally evaluated with a lift-to-drag ratio. For aircraft, this parameter directly relates to range. However, wind turbine torque is more dependent on lift than drag. Here, lift-to-drag variation tells an incomplete story. Instead of only comparing lift-to-drag ratios, annual energy production (AEP) for soiled wind turbine blades is calculated, giving significance to the airfoil performance data.

The NREL 5 MW offshore reference turbine was utilized for the baseline comparison [52]. It is rated at $5 \mathrm{MW}$ at $11.4 \mathrm{~m} / \mathrm{s}$. The turbine has a $90 \mathrm{~m}$ hub height and $126 \mathrm{~m}$ rotor diameter. The cut-in and cut-out velocities are $3 \mathrm{~m} / \mathrm{s}$ and $25 \mathrm{~m} / \mathrm{s}$. It has a variable-speed generator. In region 2 (between cut-in and rated power), the turbine was designed as "torque-controlled" to optimize power capture. The ideal 
tip speed ratio and generator speed was determined at a single wind speed, $8 \mathrm{~m} / \mathrm{s}$. The ideal pitch was determined and held constant throughout region 2. During operation, the generator speed is varied to optimize power capture for the idealized configuration. In region 3 (rated power), generator speed is held constant and the controller pitches to maintain torque.

For reference, a map of U.S. wind speed at $100 \mathrm{~m}$ above the ground is shown in Fig. III.9 [53]. The wind resource map was developed by NREL with data from AWS Truepower. The offshore wind resource is excellent, with many regions averaging above $8 \mathrm{~m} / \mathrm{s}$. IEC 61400-1 specifies wind turbine design requirements, defining three wind turbines classes: I, II, and III with mean wind speeds of $10,8.5$, and $7.5 \mathrm{~m} / \mathrm{s}$, respectively. The wind may additionally be specified with turbulence intensities of $12 \%, 14 \%$, or $16 \%$. Atmospheric turbulence is ignored in the following research. A Rayleigh wind distribution is assumed, with probability density function, $f$, and cumulative distribution function, $F$, defined with turbulence intensities of $12 \%, 14 \%$, or $16 \%$. Atmospheric turbulence is ignored in the following research. A Rayleigh wind distribution is assumed, with probability density function, $f$, and cumulative distribution function, $F$, defined as

$$
\begin{gathered}
f(u)=\frac{u}{\sigma^{2}} e^{-u^{2} /\left(2 \sigma^{2}\right)} \\
F(u)=1-e^{-u^{2} /\left(2 \sigma^{2}\right)}
\end{gathered}
$$

where $u$ is the wind speed and $\sigma$ is the shape factor. The shape factor is defined by the mean wind speed, $\bar{u}$, for a particular turbine class as $\sigma=\bar{u} \sqrt{2 / \pi}$.

Power is estimated with Wind-Turbine Performance (WT_PERF) from NREL [54]. WT_PERF is a blade-element momentum code, which determines individual 


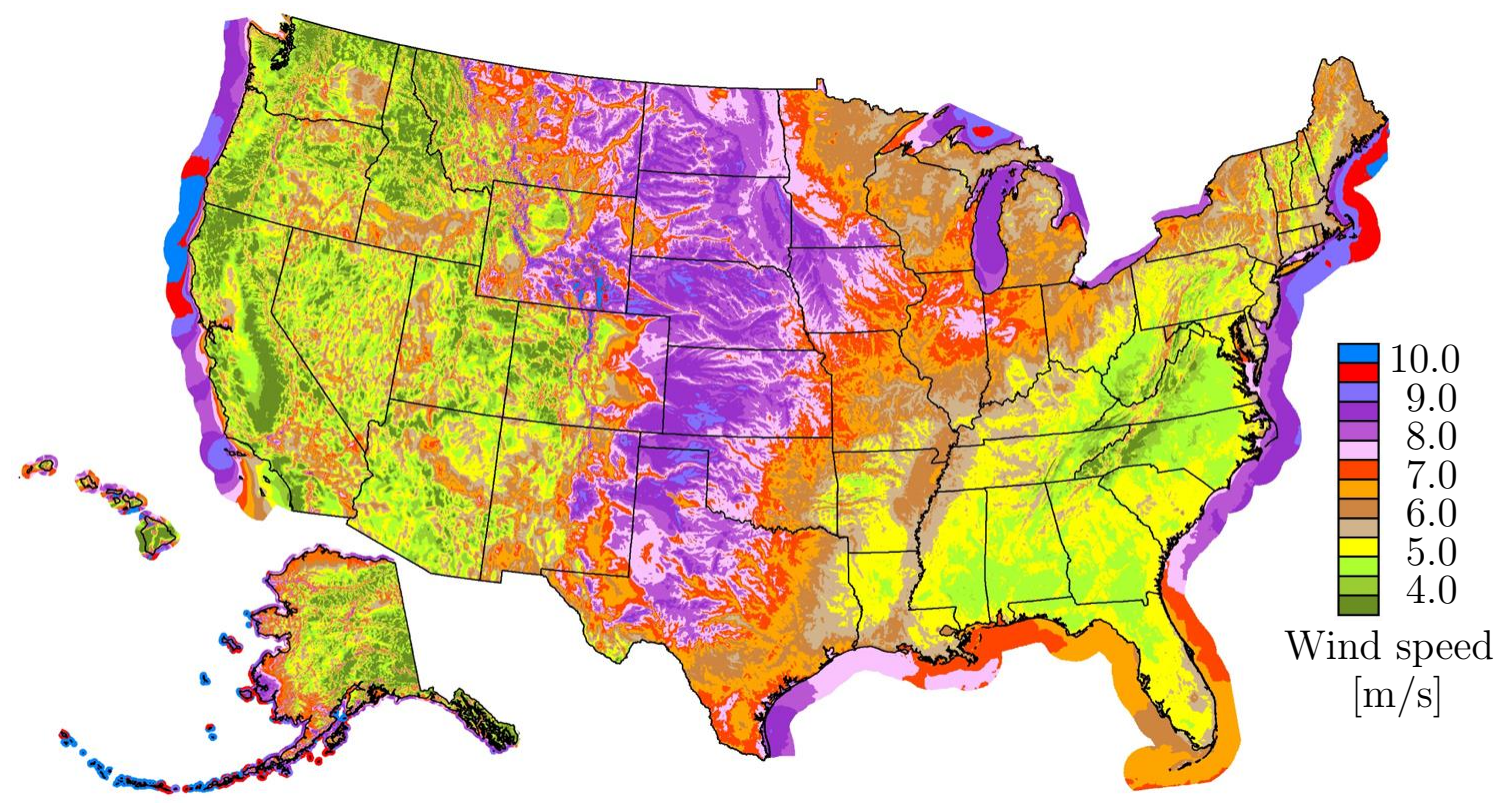

Figure III.9. Map of U.S. wind speed at $100 \mathrm{~m}$ above the ground. Wind resource map developed by NREL with data from AWS Truepower [53].

airfoil element performance to calculate the overall power. Corrections are made for tip and hub loses, wind shear, and induction. The performance of each section is estimated from two-dimensional airfoil performance data. This data is updated for rotational stall delay on the inboard sections. The airfoil performance data is summarized in Jonkman et al. [52]. A single airfoil data set is used for all Reynolds numbers.

Relative performance loss for the tested model is determined from the baseline clean configuration. The result is a $\Delta c_{l}$ and $\Delta c_{d}$ as functions of angle of attack. However, the NACA $63_{3}-418$ has a different zero-lift angle of attack and stall angle of attack (where lift is maximum) than the NREL 5 MW airfoils. To remedy this, the baseline $\Delta c_{l}(\alpha)$ and $\Delta c_{d}(\alpha)$ are skewed to match the zero-lift and stall angle of attacks of the individual NREL 5 MW airfoil sections. This ensures performance 
variation is applied at the relative locations for the lift and drag. The outboard section on the NREL $5 \mathrm{MW}$ is a NACA 64-618. Moving inboard, the sections become thicker. The outboard airfoil is sufficiently similar to the tested NACA $63_{3}-418$ to have appropriately simulated performance loss. However, as the inboard sections thicken, the insects form a different pattern and the airfoil sensitivity to roughness changes. From previous research, thicker airfoils have an increased sensitivity to roughness $[24,55,56]$. This is not simulated in the following study.

Performance variations based upon each roughness configuration are added to the baseline airfoil data for the NREL 5 MW. A power curve is generated with WT_PERF. The power is only affected in region II because the control scheme was designed for ideal airfoil performance. In region III, the blades are pitched to maintain rated torque, so any performance loss is compensated for. With the power curve calculated, AEP can be estimated by integrating the power curve multiplied by the cumulative distribution function

$$
\mathrm{AEP}=N_{h} \sum_{i=1}^{N-1}\left[F\left(u_{i+1}\right)-F\left(u_{i}\right)\right]\left(\frac{P_{i+1}+P_{i}}{2}\right)
$$

where $N_{h}$ is the number of hours in a year, $P$ is the power produced by the turbine, and $N$ is the number of discretized elements in the power curve. 


\section{CHAPTER IV RESULTS AND DISCUSSION}

The following chapter describes pertinent aerodynamic and boundary-layer transition results. Repeatability, Reynolds number variation, and roughness configuration aerodynamic performance are discussed. Boundary layer development behind roughness is described. Detailed boundary-layer transition data aft of the surface roughness is compared. Infrared thermography illustrates transition location for all configurations. The use of critical roughness Reynolds number to estimate bypass transition is discussed. Lastly, the aerodynamic data is used to estimate annual energy production.

\section{IV.A. Lift, Moment, and Drag}

Lift, drag, and moment are the primary performance metrics for wind turbine airfoils. Sectional values are used to estimate performance in blade element momentum codes. This section focuses on how these values vary due to the addition of simulated roughness. Results for all configurations are summarized in Appendix G.

\section{IV.A.1. Repeatability}

Due to three test entries, data repeatability is important to verify. A comparison of the clean configurations is shown in Fig. IV.1. The lift curve slope and linear offset is negligible between configurations. Stall in the first entry is more gradual, with a

maximum lift coefficient, $c_{l, \max }, 3.7 \%$ higher than the second and third entry. In the 
linear region, drag is within one standard deviation. The gentle stall corresponds to a broader drag polar, due to the delay of separation. Similar repeatability occurred at $R e_{c}=2.4$ and $3.2 \times 10^{6}$. One potential explanation for the difference in $c_{l, \max }$ is wind-tunnel ceiling damage following entry one, which led to the use of an older ceiling in entries two and three. The second ceiling has leaks which may encourage premature stall. As $c_{l, \max }$ was not the primary concern with this research, little effort was made to improve this.
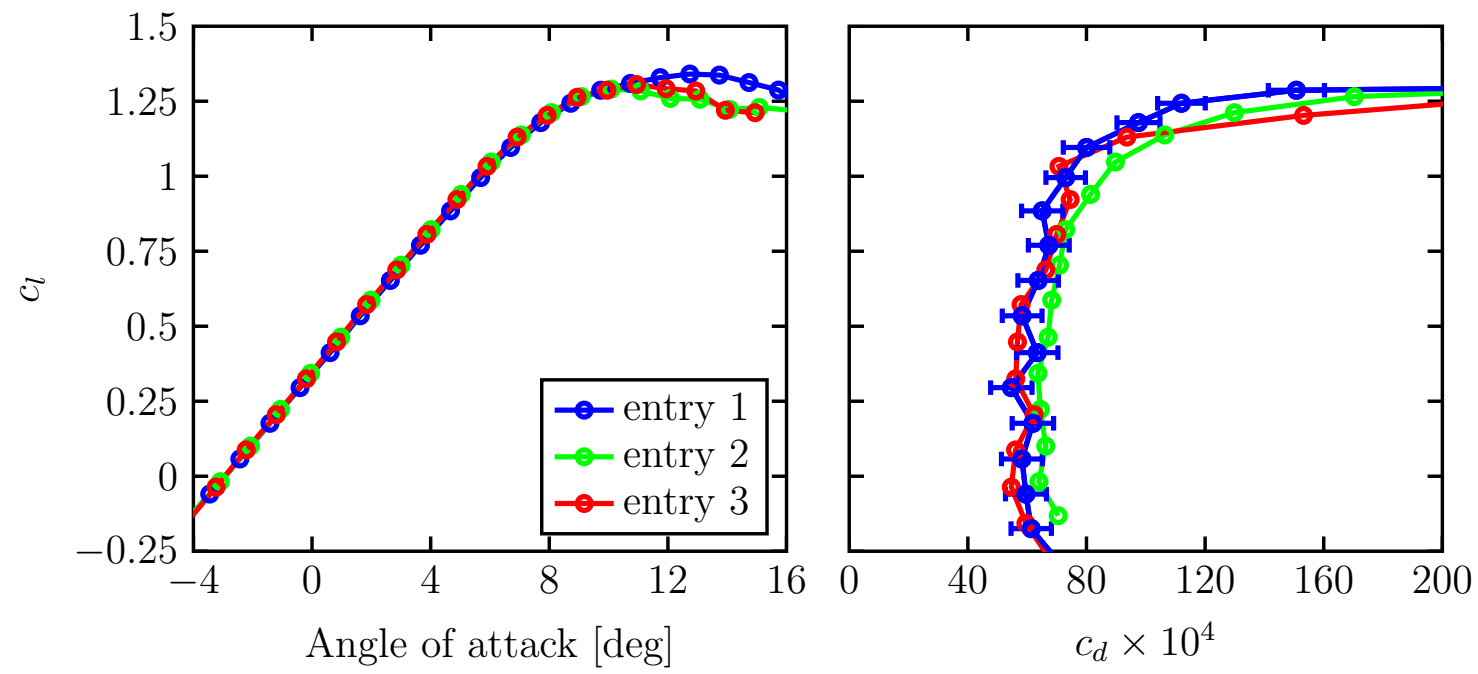

Figure IV.1. Repeatability of the clean configuration at $R e_{c}=1.6 \times 10^{6}$.

Figure IV.2 shows repeatability for the $140 \mu \mathrm{m}, 3 \%$ coverage roughness at $R e_{c}=$ $2.4 \times 10^{6}$. Lift is extremely consistent, with only slight variations in the post-stall region. Drag is more variable. At low lift before transition, drag is comparable. As lift increase, flow becomes transitional and repeatability decreases. The maximum variation between configurations is 14 counts, where one drag count is 0.0001 of drag 
coefficient. Once the wing is fully turbulent at higher lift, the drag is equivalent. Since transition is a chaotic phenomenon, the variation in drag between roughness entries was deemed acceptable.
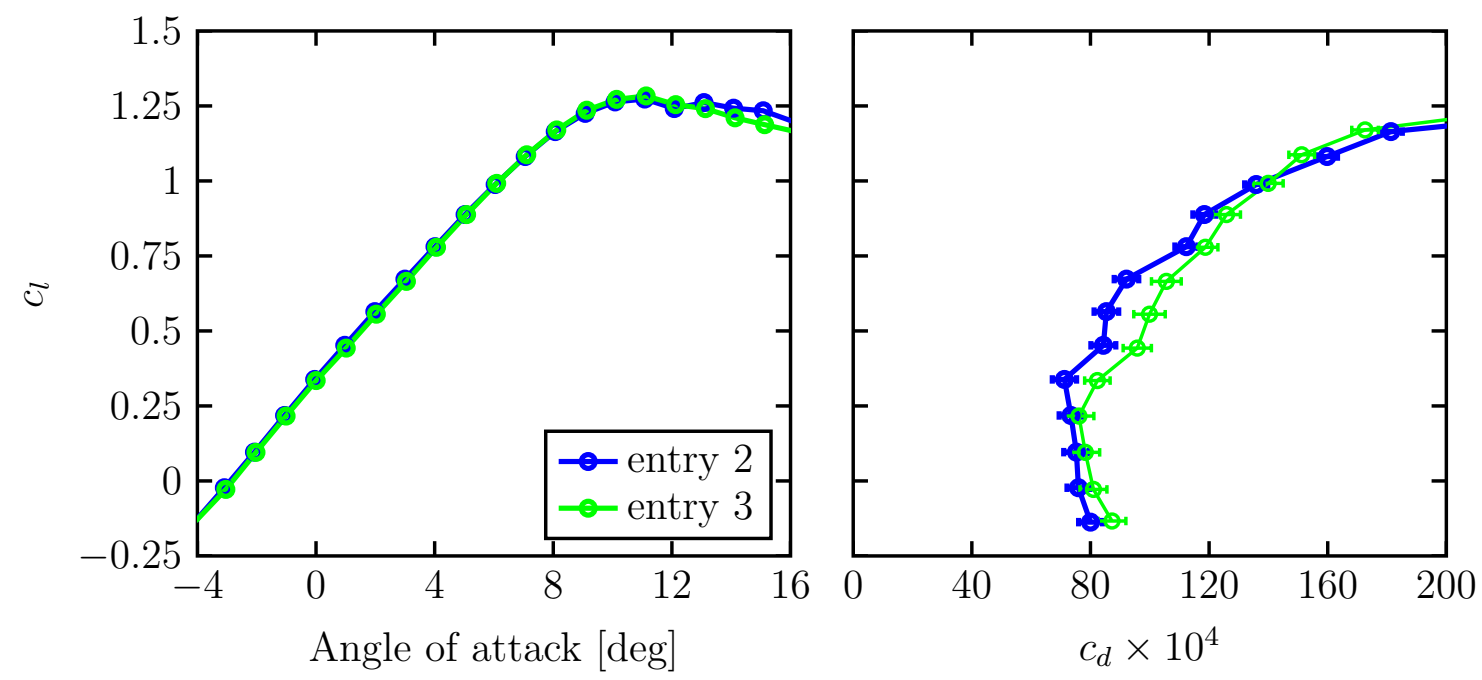

Figure IV.2. Repeatability of the 140-03 configuration at $R e_{c}=2.4 \times 10^{6}$.

\section{IV.A.2. Reynolds Number Dependency}

Abbott and von Doenhoff's data for a NACA $63_{3}-418$ at $R e_{c}=3.0 \times 10^{6}$ is used throughout this work as a baseline clean configuration [40]. Figure IV.3 shows variation with Reynolds number for the clean configuration for entry three data. Data above $R e_{c}=4.0 \times 10^{6}$ have curtailed angles of attack. The floor balance has a load limit which reduces the maximum angle of attack during testing. Drag could not be accurately measured at $R e_{c}=0.8 \times 10^{6}$ and is omitted. $R e_{c}=3.2 \times 10^{6}$ is nearest to Abbott and von Doenhoff's data acquired at $R e_{c}=3.0 \times 10^{6}$, and matches up to 
$\alpha=11^{\circ}$. Entry one matches to $\alpha=13^{\circ}$ (not shown). In both cases, the post-stall region is more severe than Abbott and von Doenhoff. Otherwise, lift data performs well, matching in the linear region. Stall angle of attack and maximum lift coefficient are extended as Reynolds number increases.
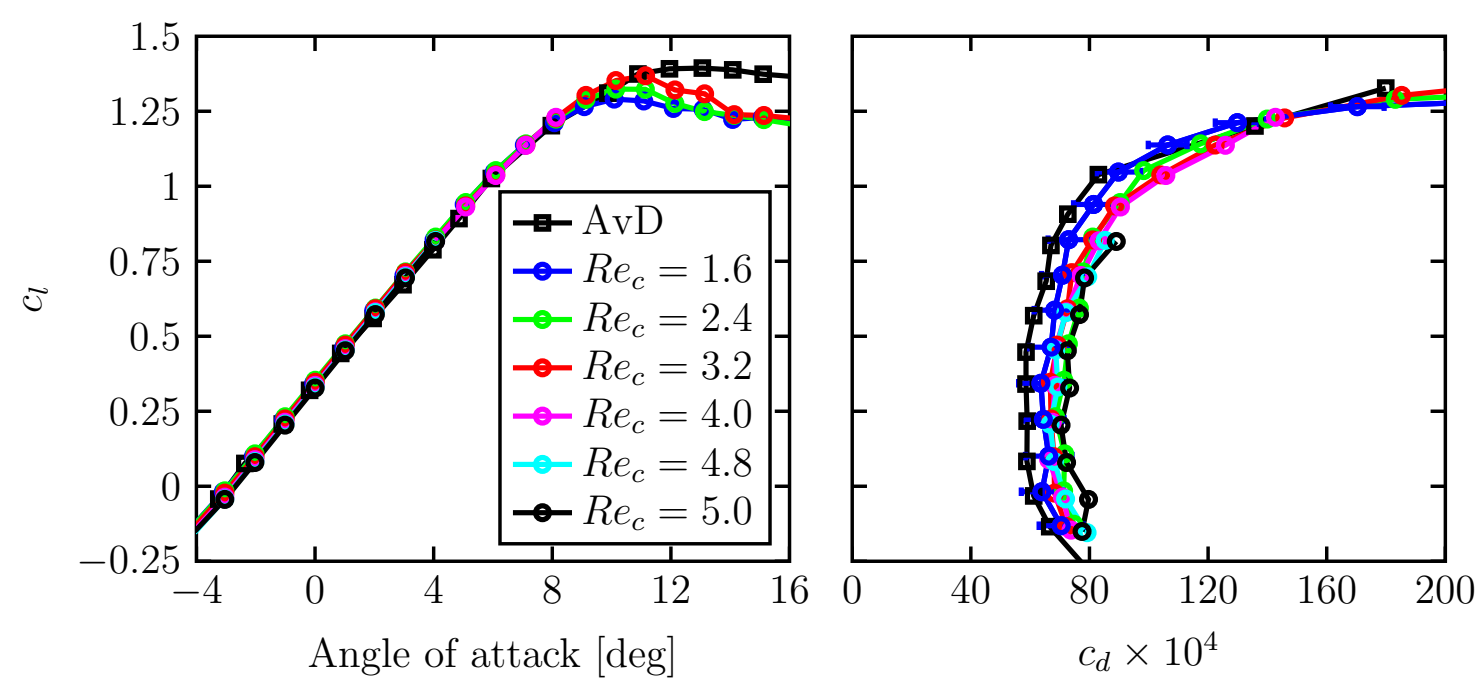

Figure IV.3. Reynolds number variation of the clean configuration. AvD indicates Abbott and von Doenhoff's data and $R e_{c}$ is $\times 10^{-6}$.

Baseline drag is higher than Abbott and von Doenhoff for every case. Drag increases slightly as Reynolds number increases. Somers indicated that drag coefficient should decrease as Reynolds number increases [23]. One likely explanation is the relatively high freestream turbulence in the LSWT of $0.25 \%$. Abbott and von Doenhoff tested in the Langley Low-Turbulence Pressure Tunnel with a streamwise turbulence of $0.03 \%$ at $R e_{c}=3 \times 10^{6}$, much lower than the LSWT [57]. The clean drag measurement at corresponding Reynolds numbers is used as a reference point when calculating performance loss of rough configurations. If the clean, baseline drag is 
not appropriately decreasing as Reynolds number increases, roughness configuration performance loss may be underestimated.

\section{IV.A.3. Two-Dimensional Steps}

The first entry focused on performance of 2D steps. A wavy, forward-facing (WFF) step was tested to simulate paint that had chipped off the leading edge. A trip strip was also tested. Figure IV.4 shows performance variation relative to the clean configuration. There is minimal lift variation due to the WFF step. The step was placed at $10 \%$ chord, so it had little effect on stall. No increase in drag occurred for $R e_{c}=1.6$ and $2.4 \times 10^{6}$. At $R e_{c}=3.2 \times 10^{6}$, a drag rise coincides with the WFF causing transition. Lastly, the trip strip performance is shown to have a significant decrease on lift-curve slope, stall angle of attack, and maximum lift. Drag increases by $100 \%$. The trip strip is $460 \pm 2 \mu \mathrm{m}$ tall, over twice the height of the tallest roughness tested. It is placed at $2 \%$ chord, a sensitive location for roughness. Trip strip performance varies little with Reynolds number. The remaining data are summarized in Appendix G.

\section{IV.A.4. Distributed Roughness}

The majority of testing focused upon distributed roughness. Configurations include three densities of $100 \mu \mathrm{m}$, five densities of $140 \mu \mathrm{m}$, and one density of $200 \mu \mathrm{m}$ roughness, all varying from $2 \%$ on the upper surface to $13 \%$ chord on the lower surface. One additional pattern extended to $6 \%$ chord on the upper surface. The general performance characteristics at $R e_{c}=2.4 \times 10^{6}$ for each pattern is summarized 

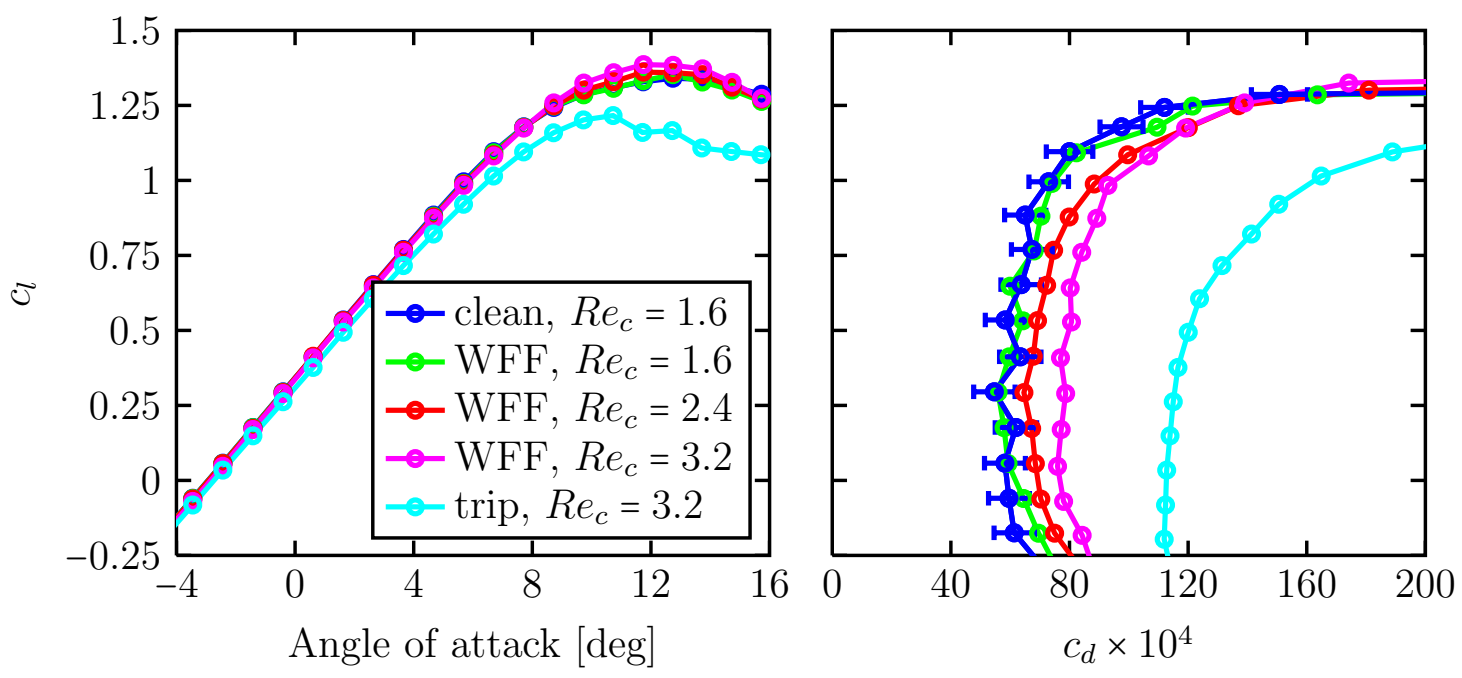

Figure IV.4. Lift and drag data for the wavy, forward-facing step where $R e_{c}$ is $\times 10^{-6}$.

in Figs. IV.5-IV.7, with the legend for all three shown in Fig. IV.5. All data are from entry three, except 200-03.

Generally, lift-curve slope and maximum lift are shown to decrease as roughness height and density increase. At worst, lift-curve slope and maximum lift decrease $6.1 \%$ for $140-12$ and $7.2 \%$ for $140-15$, respectively, relative to the clean configuration. While the lift-curve slope decreases for 200-03 comparably to $140 \mu \mathrm{m}$ roughness, maximum lift extends with a more gentle stall.

The drag polar at $R e_{c}=2.4 \times 10^{6}$ is shown in Fig. IV.6. Drag for the $100 \mu \mathrm{m}$ roughness is similar to the clean configuration. The $140 \mu \mathrm{m}$ roughness drag increases with angle of attack. This suggests bypass transition is occurring at higher lift. Both Boermans and Selen and Moroz and Eggleston simulated insect roughness on airfoils, indicating a pattern similar to the $140 \mu \mathrm{m}$ roughness [8,14]. This suggests the vinyl decal pattern and application location appropriately simulate insect roughness. The 


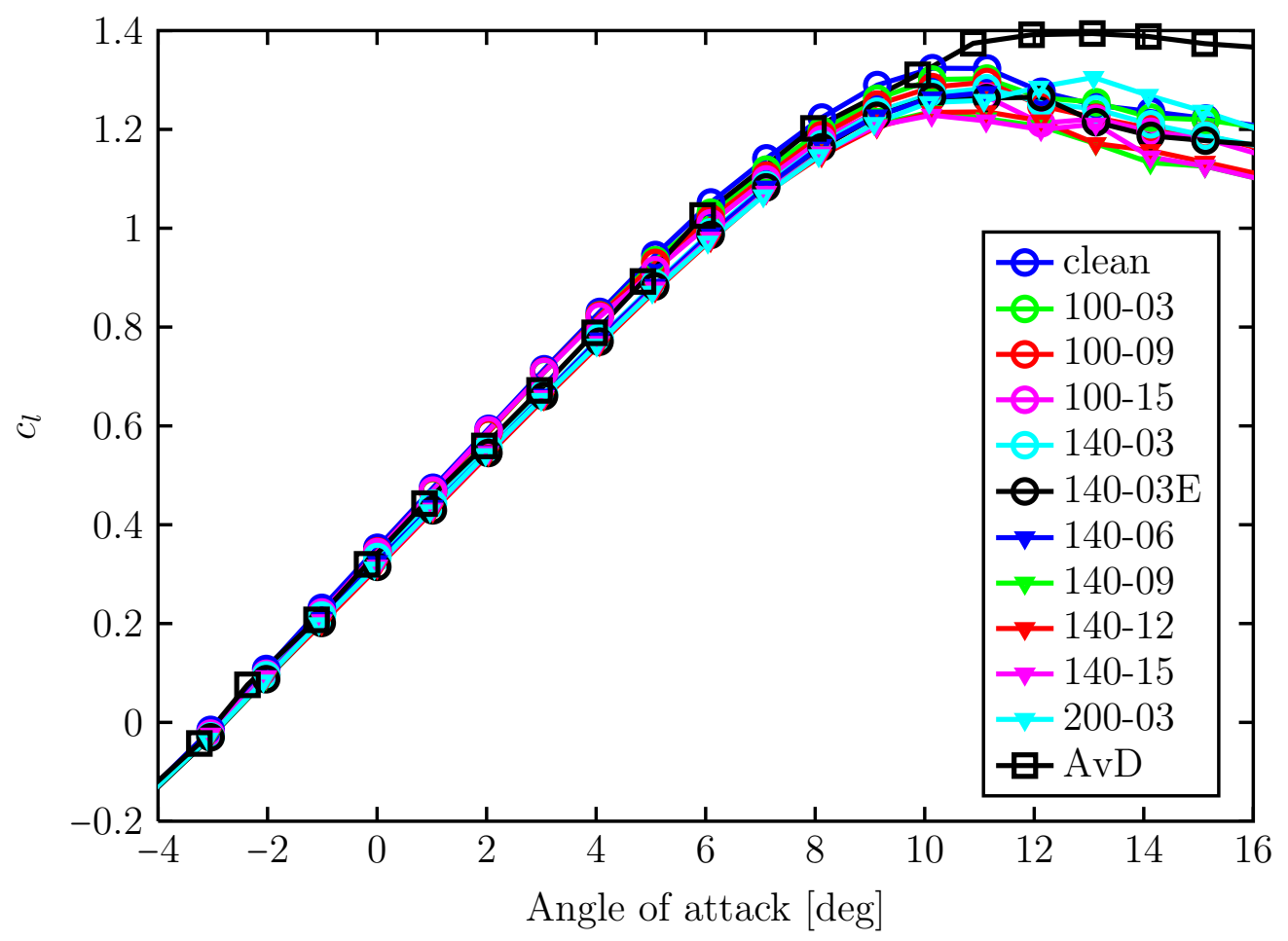

Figure IV.5. Lift coefficient variation with angle of attack for distributed roughness at $R e_{c}=2.4 \times 10^{6}$. Lift generally decays as roughness increases in density and height.

maximum lift-to-drag ratio, $L / D_{\max }$, decreases mostly due to drag rise. At most, $L / D_{\max }$ decreases $40 \pm 3 \%$ for $140-15$. The variation observed between the $140 \mu \mathrm{m}$ roughness configurations is consistent with the uncertainty of the drag measurement. Once transitioned, the $140 \mu \mathrm{m}$ roughness is comparable to the 200-03.

Moment data are summarized in Fig. IV.7. The moment about quarter chord increases as roughness height and density increases. At $\alpha=6^{\circ}$, the moment begins to increase, diverging from Abbott and von Doenhoff's data. The clean data follows this pattern. There is no obvious explanation for this behavior. However, overall variation in the quarter chord moment measurement is small. 


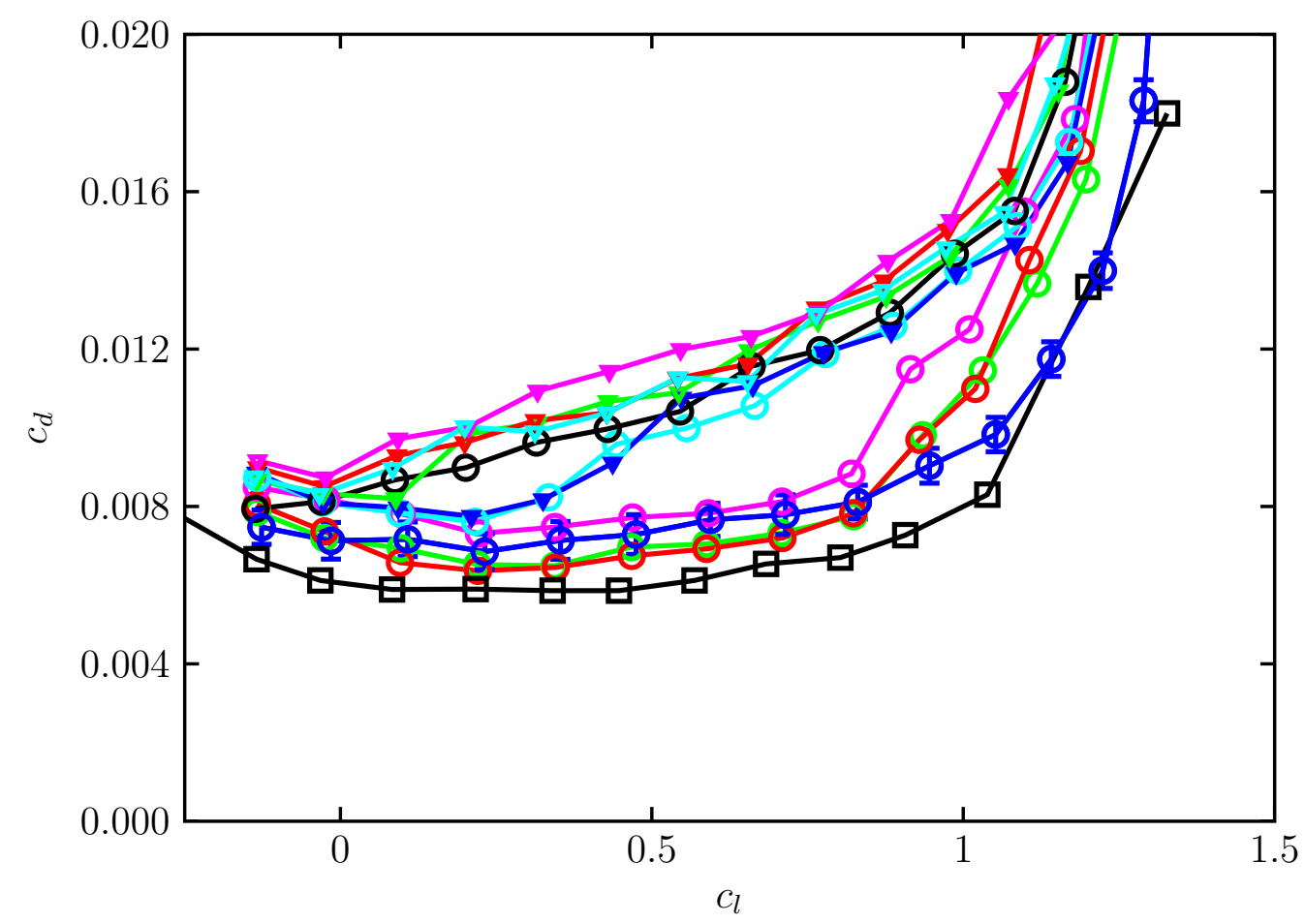

Figure IV.6. Drag polar at $R e_{c}=2.4 \times 10^{6}$ for numerous configurations. Transition is occurring for $140 \mu \mathrm{m}$ roughness.

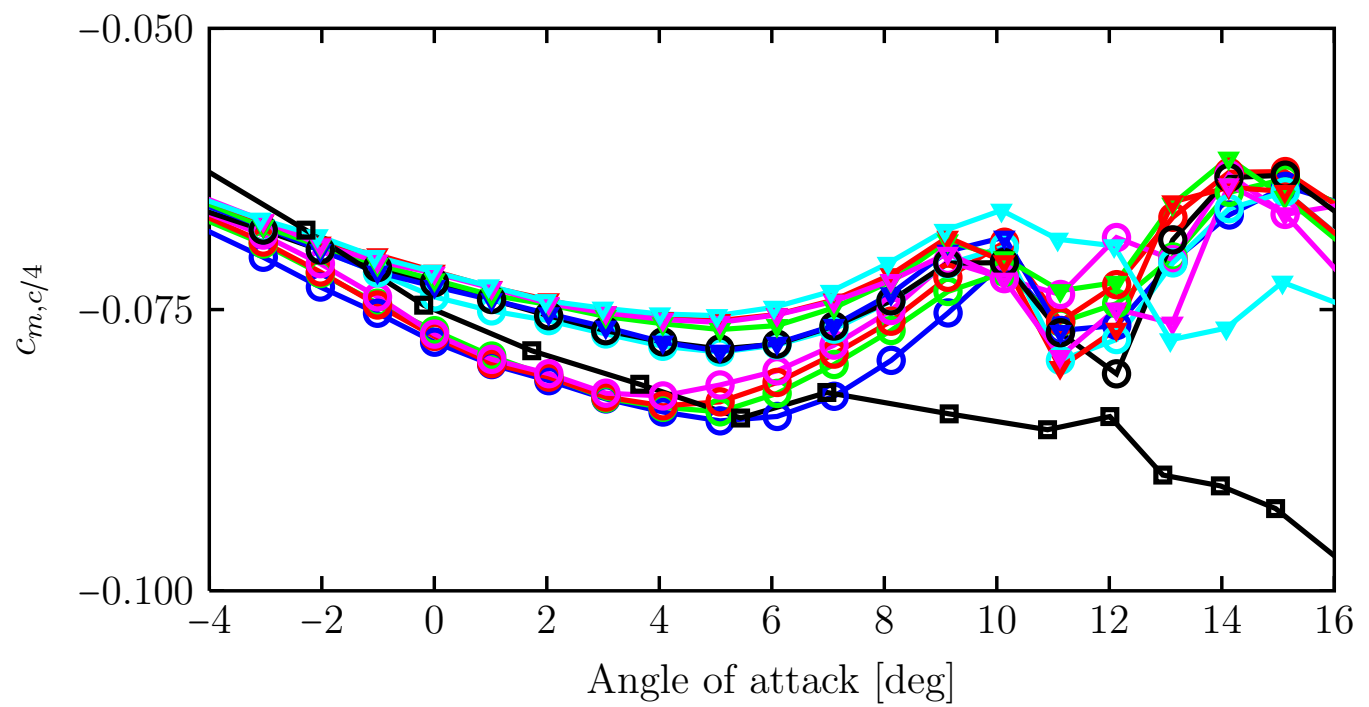

Figure IV.7. Moment coefficient variation with angle of attack at $R e_{c}=2.4 \times 10^{6}$. 
Roughness density is also a parameter of interest. Densities of $3 \%, 6 \%, 9 \%$, $12 \%$, and $15 \%$ were tested for the $140 \mu \mathrm{m}$ tall roughness. Figure IV.6 summarizes these variations. At low lift, $3 \%$ and $6 \%$ density indicate drag similar to the clean configuration. When lift coefficient increases to 0.4 , there is a drag rise corresponding to bypass transition. Densities of $9 \%, 12 \%$, and $15 \%$ transition earlier, near zero lift, indicating a characteristic difference between $6 \%$ and $9 \%$ densities. The extended roughness has drag similar to the higher density configurations. This indicates roughness location is an important factor in performance variation. At lower Reynolds numbers, the $140 \mu \mathrm{m}$ roughness has drag similar to the clean configuration. At higher Reynolds numbers, all configurations transition and have comparable drag. Transition location data, discussed in Section IV.D, validates this.

Height variation is the second roughness parameter. Heights of $100 \mu \mathrm{m}, 140 \mu \mathrm{m}$, and $200 \mu \mathrm{m}$ were tested. The trip strip was $460 \mu \mathrm{m}$ tall and is included for comparison. Only $3 \%$ density was tested for all three heights. The most variation in transition was observed at $R e_{c}=2.4 \times 10^{6}$ and is shown in Fig. IV.8. As roughness increases in height, drag increases. The $100 \mu \mathrm{m}$ roughness is nearly identical to the clean configuration. When $c_{l}=0.9$, the drag diverges and is slightly higher. The $140 \mu \mathrm{m}$ configuration has slightly higher drag for $c_{l}<0.4$. As lift increases, a drag rise occurs. The $200 \mu \mathrm{m}$ drag is significantly larger until $c_{l}>1.1$, at which point the $200 \mu \mathrm{m}$ drag coincides with $140 \mu \mathrm{m}$. At higher Reynolds numbers, the $140 \mu \mathrm{m}$ and $200 \mu \mathrm{m}$ drag coincide. The trip strip drag is consistently larger than all other configurations. At lower Reynolds numbers, the $140 \mu \mathrm{m}$ is more similar to the clean configuration while the $200 \mu \mathrm{m}$ drag is still higher. 


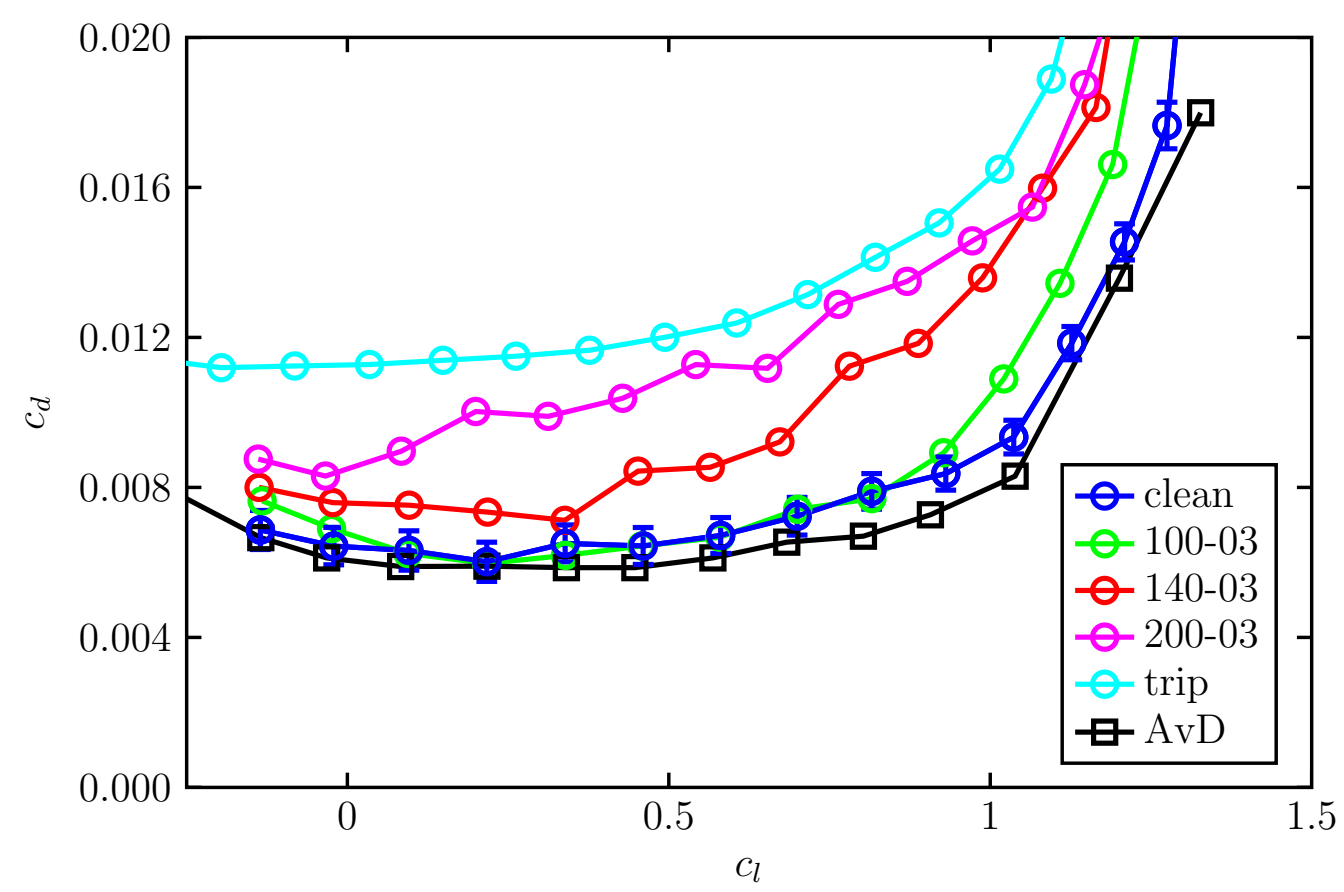

Figure IV.8. Drag polar illustrating roughness height variation at $\operatorname{Re}_{c}=2.4 \times 10^{6}$.

Reynolds number variation for distributed roughness is shown in Fig. IV.9 for 140-03. A clean configuration at $R e_{c}=1.6 \times 10^{6}$ is included for comparison. Drag diverges from the clean configuration at $c_{l}=0.8,0.25$, and -0.1 for $R e_{c}=1.6,2.4$, and $3.2 \times 10^{6}$, respectively. Divergence occurs earlier, indicating bypass transition occurring earlier as Reynolds number increases. As Reynolds number increases for a fully turbulent boundary layer, the performance mildly improves. At $R e_{c}=4.0 \times 10^{6}$, drag is consistently larger, but lift curve slope decreases less, resulting in a higher $L / D_{\max }$. This is consistent for $100-15$ and each $140 \mu \mathrm{m}$ and $200 \mu \mathrm{m}$ configuration where the boundary layer is fully turbulent. For $100-03$ and 100-09, performance continues to degrade because the boundary layer is still transitional. A trend may not be determined because $L / D_{\max }$ was not measurable at higher Reynolds numbers. 


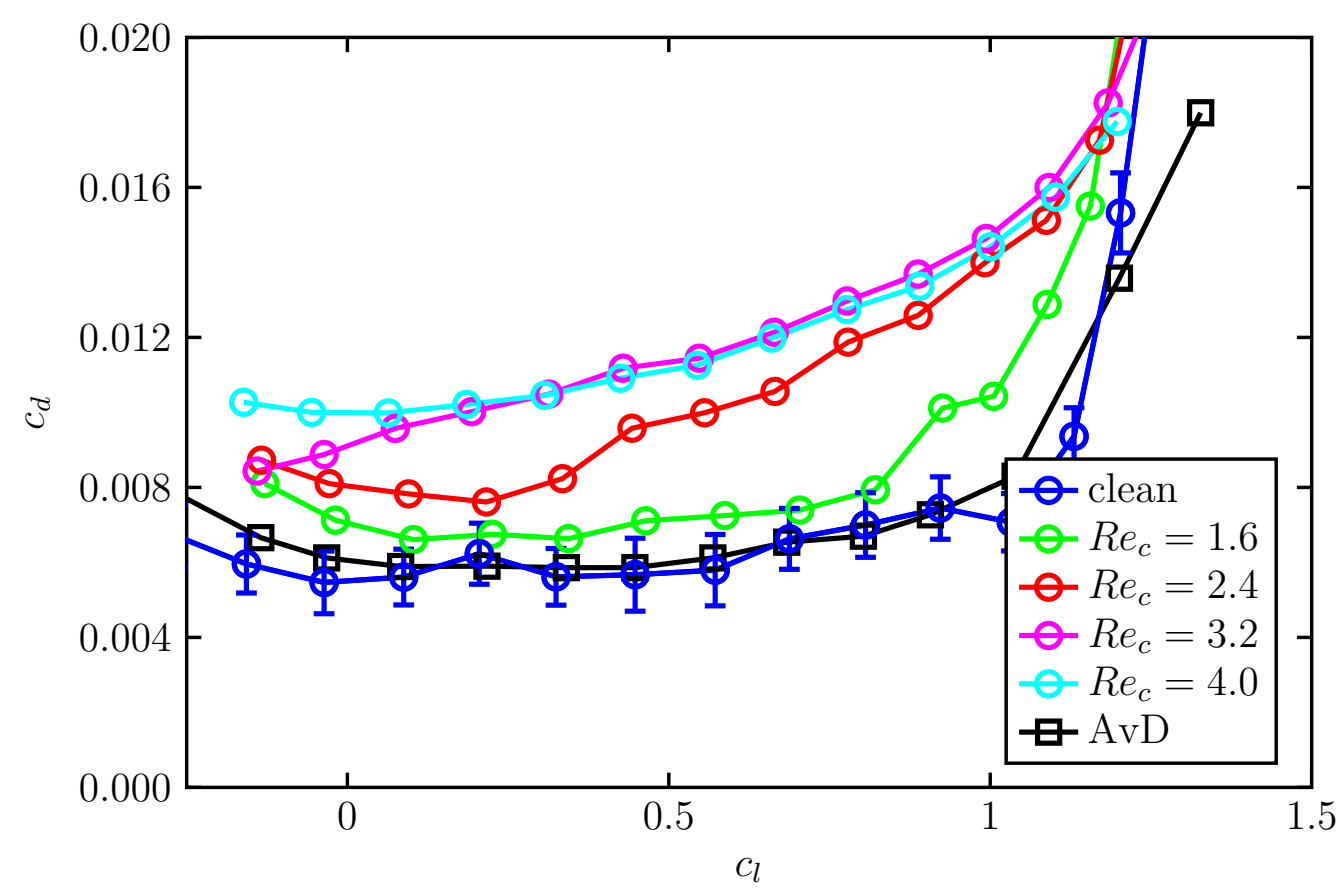

Figure IV.9. Drag polar illustrating the Reynolds number variation for 140-03. $R e_{c}$ is $\times 10^{-6}$.

Variation in lift curve slope, $d c_{l} / d \alpha, c_{l \max }$, and $L / D_{\max }$ for all configurations at $R e_{c}=1.6,2.4,3.2$, and $4.0 \times 10^{6}$ are summarized in Appendix G. The wavy, forward-facing step and trip strip data are from entry one. The 200-03 configuration was only tested in entry two. The remaining configurations are from entry three. All configurations are referenced to the clean configuration from their particular entry, removing $c_{l \max }$ variations between entries.

\section{IV.B. Boundary Layer Development}

Simulations struggle to model how the boundary layer develops from laminar to turbulent flow, particularly behind roughness. Boundary layer velocity profile measurements served to elucidate this phenomenon. Measurements were made in 
entries one and two at 30\%,40\%,50\%, and $60 \%$ chord at $\alpha=0^{\circ}$ and $6^{\circ}$. Angle of attack sweeps at constant Reynolds number were also made with the boundary layer rake at $50 \%$ chord.

Figure IV.10 shows boundary layer profiles at six different angles of attack for the clean configuration at $R e_{c}=1.6 \times 10^{6}$. The profile is taken at $50 \%$ chord. The $y$-distance is measured from the airfoil wall normal. It is nondimensionalized by chord and scaled by $R e_{c}^{1 / 2}$. Angles of attack of $-4^{\circ}$ and $0^{\circ}$ are laminar. At higher angles, $8^{\circ}, 11^{\circ}$, and $14^{\circ}$, the boundary layer becomes progressively thicker and grows a larger deficit. At $\alpha=16^{\circ}$, the flow has separated, indicated by a large, nearwall region of nearly zero or possibly reversed flow. This region is denoted by open markers.

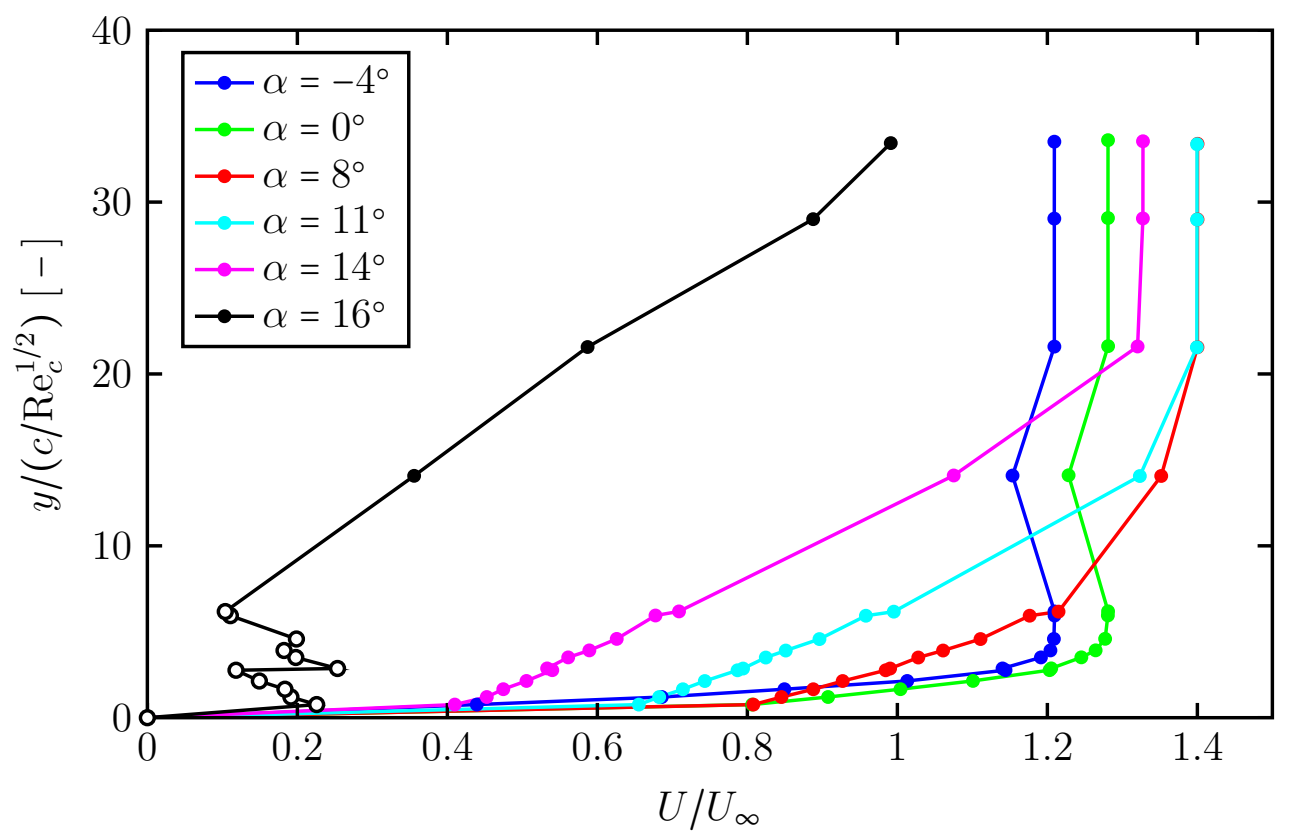

Figure IV.10. Boundary layer profiles the for clean configuration at $R e_{c}=1.6 \times 10^{6}$. Open circles indicate reversed flow. 
Boundary layer development behind multiple rough configurations is shown in Fig. IV.11 for $\alpha=-4^{\circ}, 0^{\circ}, 2^{\circ}$, and $6^{\circ}$. The data were acquired at $R e_{c}=1.6 \times 10^{6}$ and 50\% chord. Clean, 100-03, 140-03, and 200-03 configurations are plotted to illustrate how the boundary layer develops behind different roughness heights. The boundary layer rake height varied between tests due to installation inconsistencies. To remedy this, the boundary layer profiles at $\alpha=4^{\circ}$ were offset to collapse the data. A low angle of attack was chosen since it was laminar with a strongly favorable pressure gradient. The curves collapse well except at the wall, which is has large gradients and is difficult to measure with a total pressure probe. Data at $\alpha=0^{\circ}$ shows good agreement, particularly further from the wall. As angle of attack increases, the boundary layer thickens as the pressure gradient becoming more adverse and the flow transitioning to turbulent. The clean and 100-03 configurations have comparable profiles. As roughness height increases to $140 \mu \mathrm{m}$ and $200 \mu \mathrm{m}$, the boundary layer is also turbulent, but continues to thicken.

Boundary layer development with chord location is shown in Fig. IV.12 for the 140-03 roughness. The two data points nearest the wall have similar velocities. This is due to canting the boundary layer rake downward, causing the two lowest total pressure ports to be flush with the wall. The first position at $R e_{c}=1.6 \times 10^{6}$ is laminar. At 50\% chord, the flow is transitional, indicated by increasing $d u / d y$. Lastly, the $60 \%$ location is turbulent. Each profile at $R e_{c}=3.2 \times 10^{6}$ is turbulent. The roughness is more critical at higher Reynolds numbers, causing transition. The boundary layer grows as the pressure recovers moving aft. 

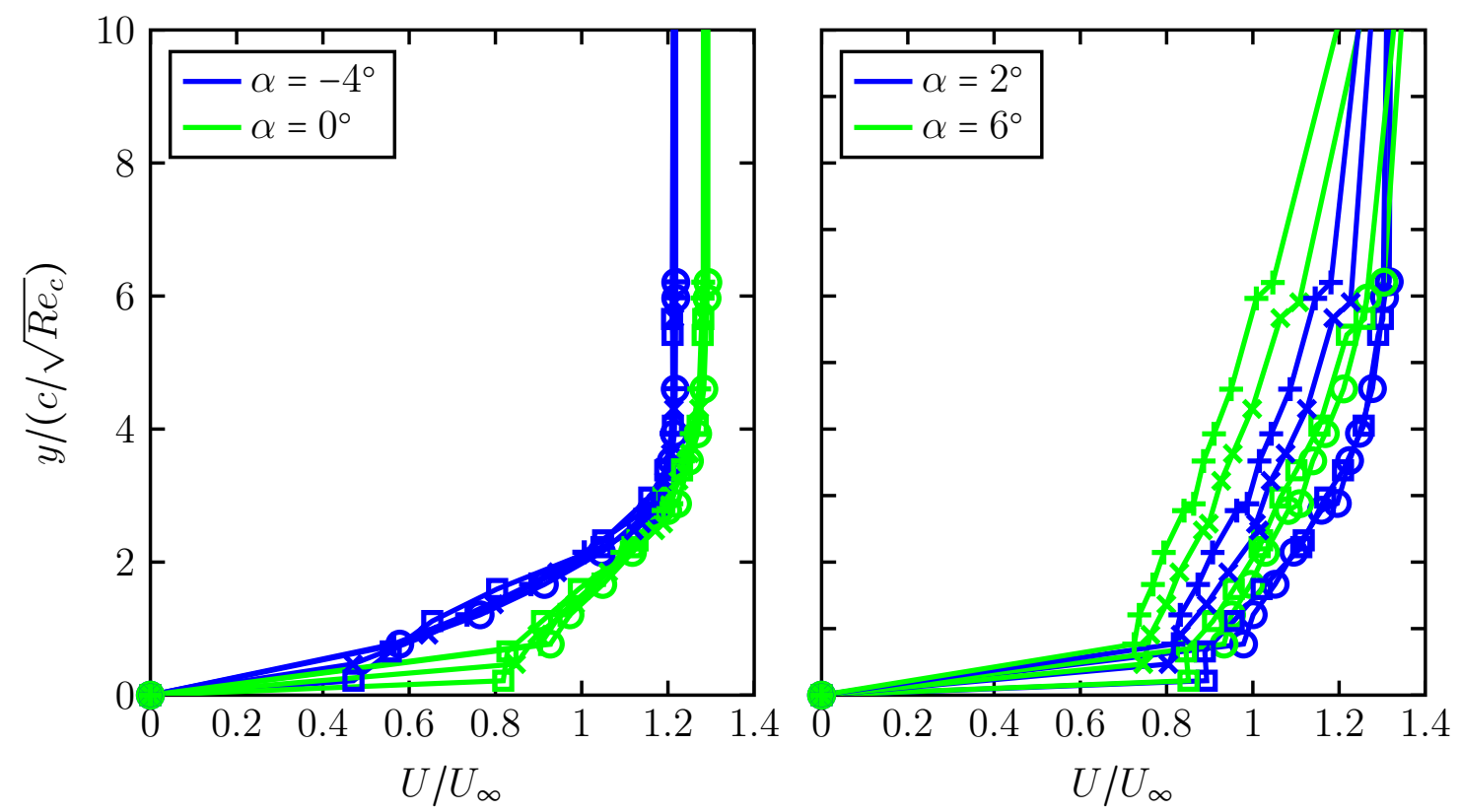

Figure IV.11. Boundary layer profiles at $R e_{c}=1.6 \times 10^{6}$ and $50 \%$ chord. Symobls indicate configuration, where $\bigcirc$ is clean, $\square$ is $100-03, \times$ is 140-03, and + is 200-03.

\section{IV.C. Boundary-Layer Transition Phenomena}

Transition is indicated with infrared (IR) thermography and hotfilm voltage, spectra, and intermittency measurements. IR thermography proved most useful at exhibiting transition, since it is a nonintrusive, global technique. The hotfilm, particularly at higher Reynolds numbers, had a tendency to cause premature transition. If transition was spanwise periodic, an upstream sensor may have been in a turbulent wedge while a downstream sensor was still laminar, further complicating analysis.

Figure IV.13 summarizes transition location variation with angle of attack for the clean configuration at $R e_{c}=0.8 \times 10^{6}$ in a Freelogram. The shaded contour shows hotfilm spectral information, indicating laminar (green), Tollmien-Schlichting (TS, 


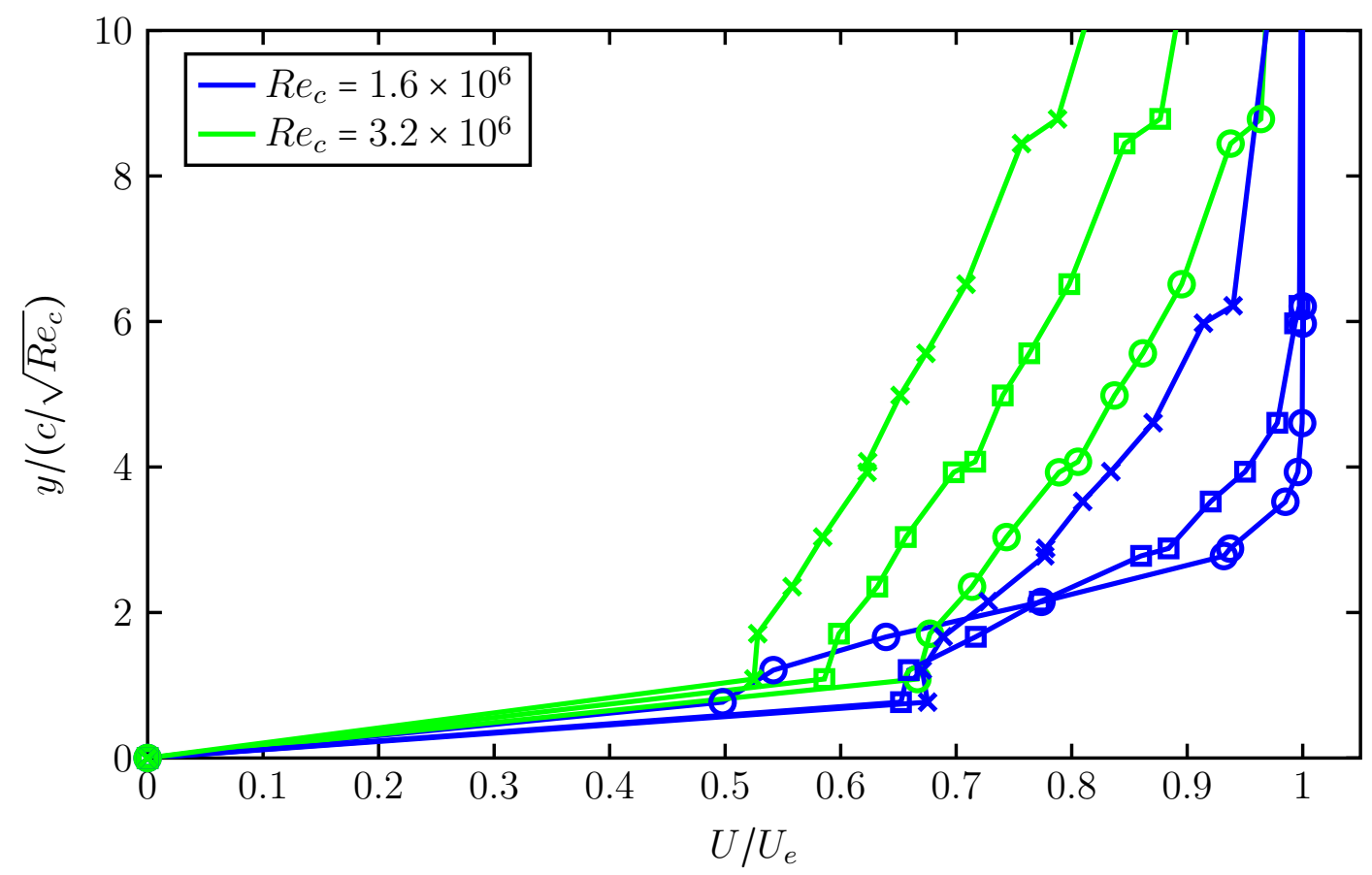

Figure IV.12. Boundary layer development for the 140-03 configuration. Chord locations are shown by $\bigcirc$ at $40 \%, \square$ at $50 \%$, and $\times$ at $60 \%$ chord.

yellow), transitional (orange), and turbulent (red) flow. IR data is indicated with a blue line. Transition based on hotfilm voltage and intermittency is shown in green and blue, respectively. Lastly, the experimental pressure minimum is depicted with open circles. For comparison, the XFOIL $N=9$ curve is indicated in black. The $e^{N}$ method was developed independently by Smith and van Ingen in 1956 [58,59]. Briefly, the $e^{N}$ method assumes transition occurs when the most unstable TS wave reaches a particular $N$-factor, where $N$ is the logarithm of the ratio of a downstream TS wave amplitude to the initial disturbance amplitude. The initial amplitude is determined by the receptivity of the boundary layer to disturbances. Since environments and disturbances vary, $N$ is between 5 and 13, where $N=9$ is a common assumption. 


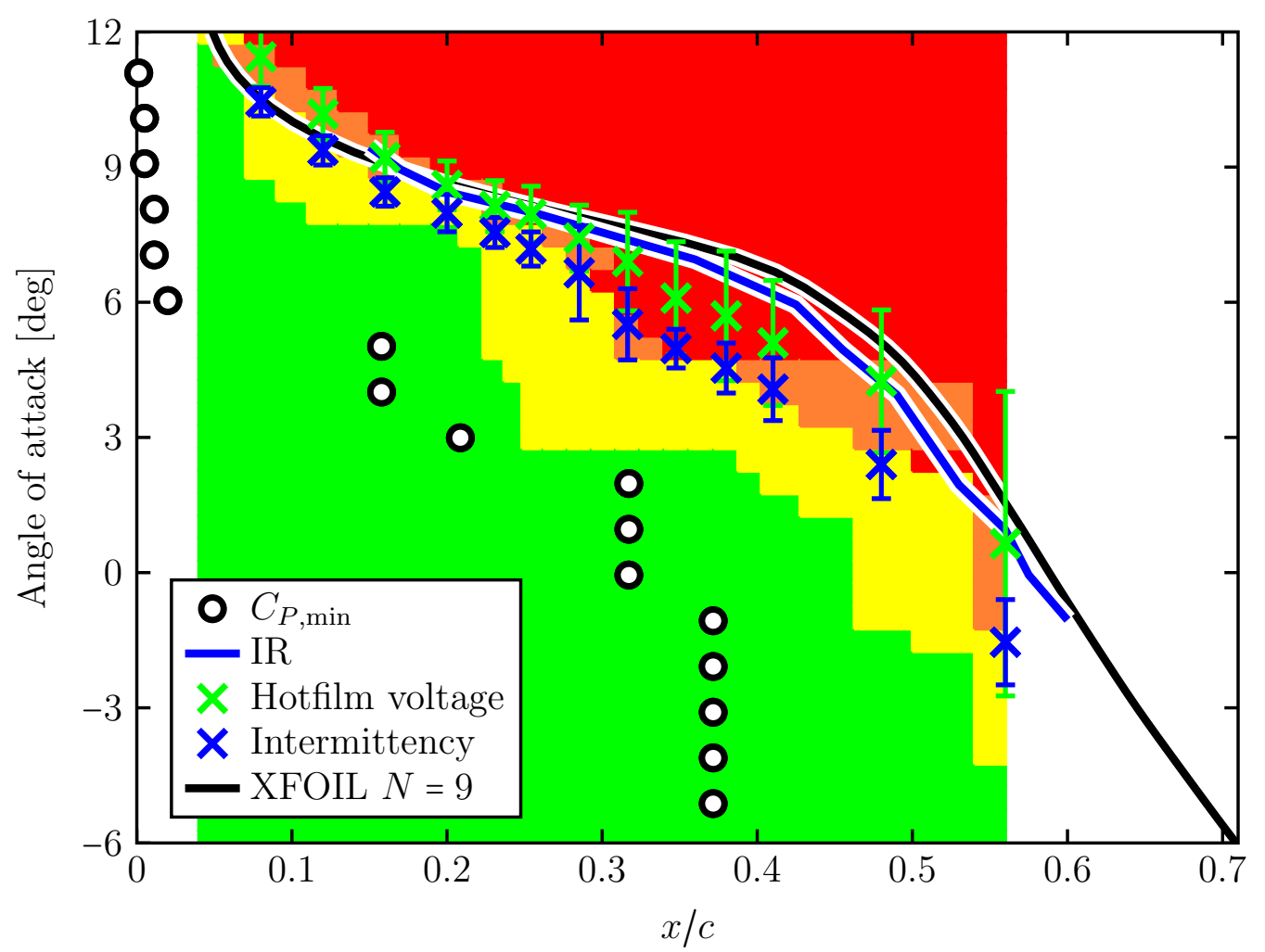

Figure IV.13. Freelogram for the clean configuration at $R e_{c}=0.8 \times 10^{6}$.

The IR data shows good correlation to the XFOIL $N=9$ curve. However, between $\alpha=1^{\circ}$ and $7^{\circ}$, there is a $3 \%$ chord offset. After the pressure minimum, the pressure gradient is adverse, which destabilizes TS waves. As TS waves grow, spanwise instabilities cause distortion. Breakdown rapidly follows as the TS waves deteriorate into turbulent flow. The spectra indicate earlier transition between $\alpha=4^{\circ}$ and $7^{\circ}$ than the IR data. Possible reasons are a noisy signal or tripped sensor. The intermittency analysis is commensurate with the spectral data. The hotfilm voltage analysis differs from the spectra, likely because mean quantities are measured.

Figure IV.14 shows a Freelogram for the 140-03 roughness at $R e_{c}=0.8 \times 10^{6}$. The hotfilm spectral content, mean voltage, and intermittency match the IR data 
well. Compared to Fig IV.13, the TS region is smaller, but matches better to the IR data. At low Reynolds numbers, the $140 \mu \mathrm{m}$ roughness has minimal effect on drag. The minimization of the TS region may be explained by the roughness decreasing the TS growth rate. Gürün showed a 3D roughness array to decrease the growth rate of TS waves due to a spanwise nonuniform basic state [60]. Despite the delayed TS growth, transition is not delayed because the secondary instability of a TS wave is spanwise varying. Therefore, TS waves will not need to grow as large before becoming unstable to secondary instabilities. An even smaller TS region is observed for the taller 200-03 roughness, shown in Fig IV.15.

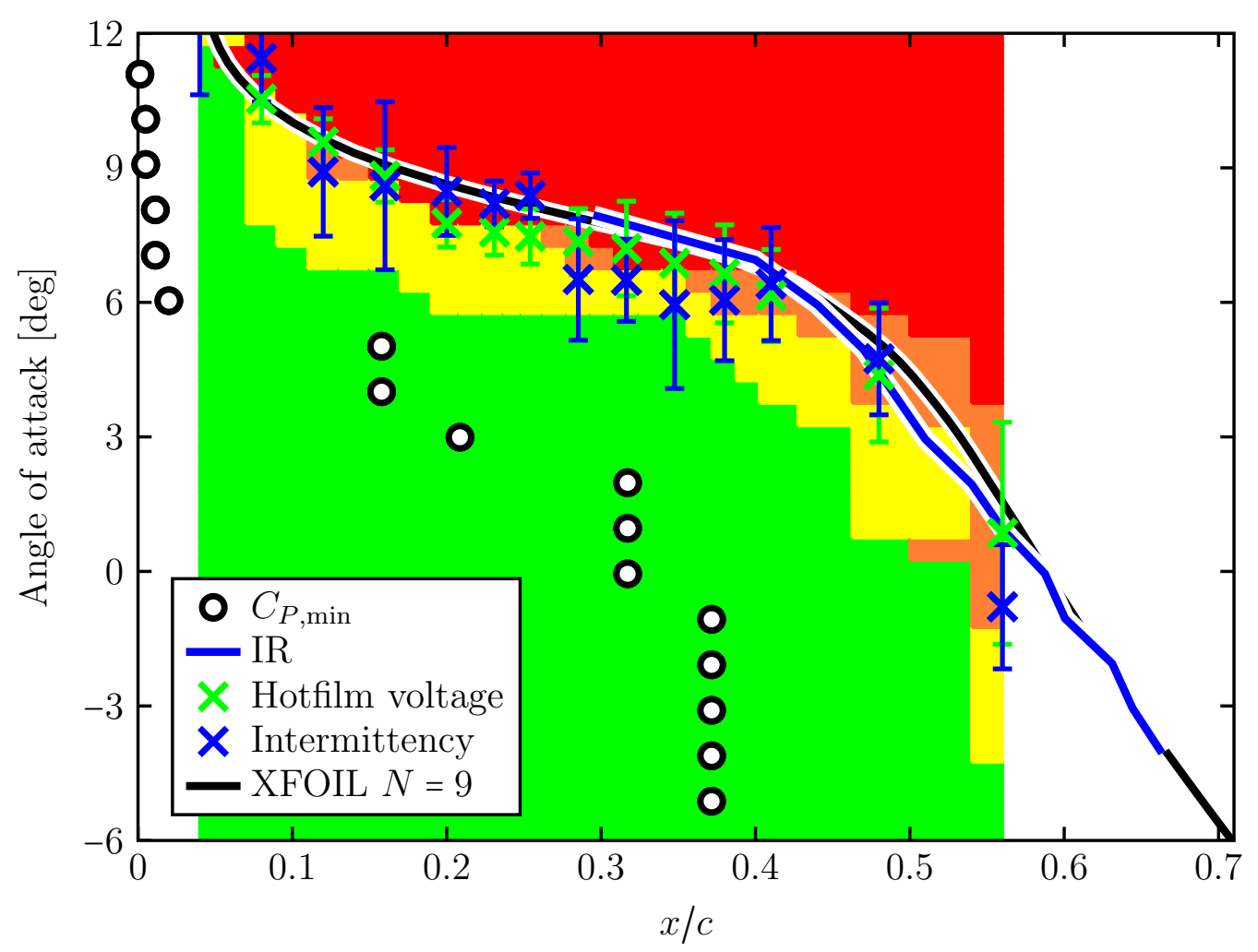

Figure IV.14. Freelogram for the 140-03 configuration at $R e_{c}=0.8 \times 10^{6}$. 


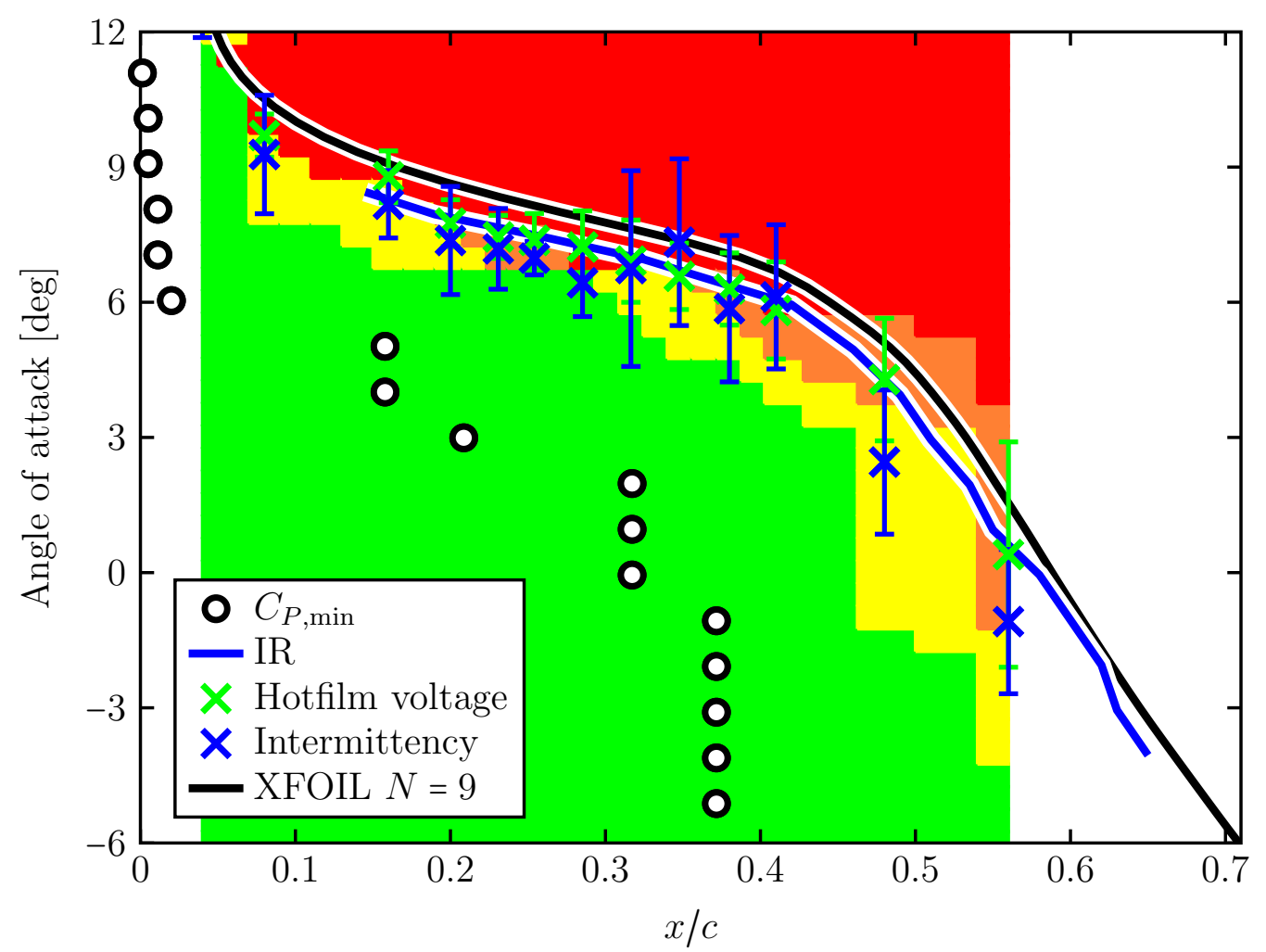

Figure IV.15. Freelogram for the 200-03 configuration at $R e_{c}=0.8 \times 10^{6}$.

At higher Reynolds numbers, roughness will cause transition to occur. If this is the case, transition appears as seen in Fig. IV.16. There is good correlation between all measurement techniques. At low angles of attack, transition follows the $N=9$ curve. At $\alpha=0^{\circ}$, transition moves forward, indicating the occurrence of bypass transition. Above this, transition progresses along the pressure minimum. TS content is only observed before bypass occurs at low angles of attack. Note that at higher Reynolds numbers, transition does not follow the pressure minimum.

Lastly, a Freelogram at $R e_{c}=0.8 \times 10^{6}$ for the straight, forward-facing (SFF) step configuration is shown in Fig. IV.17. The SFF is at $10 \%$ chord and is expected to amplify the TS wave development. This would be indicated by a larger TS region 


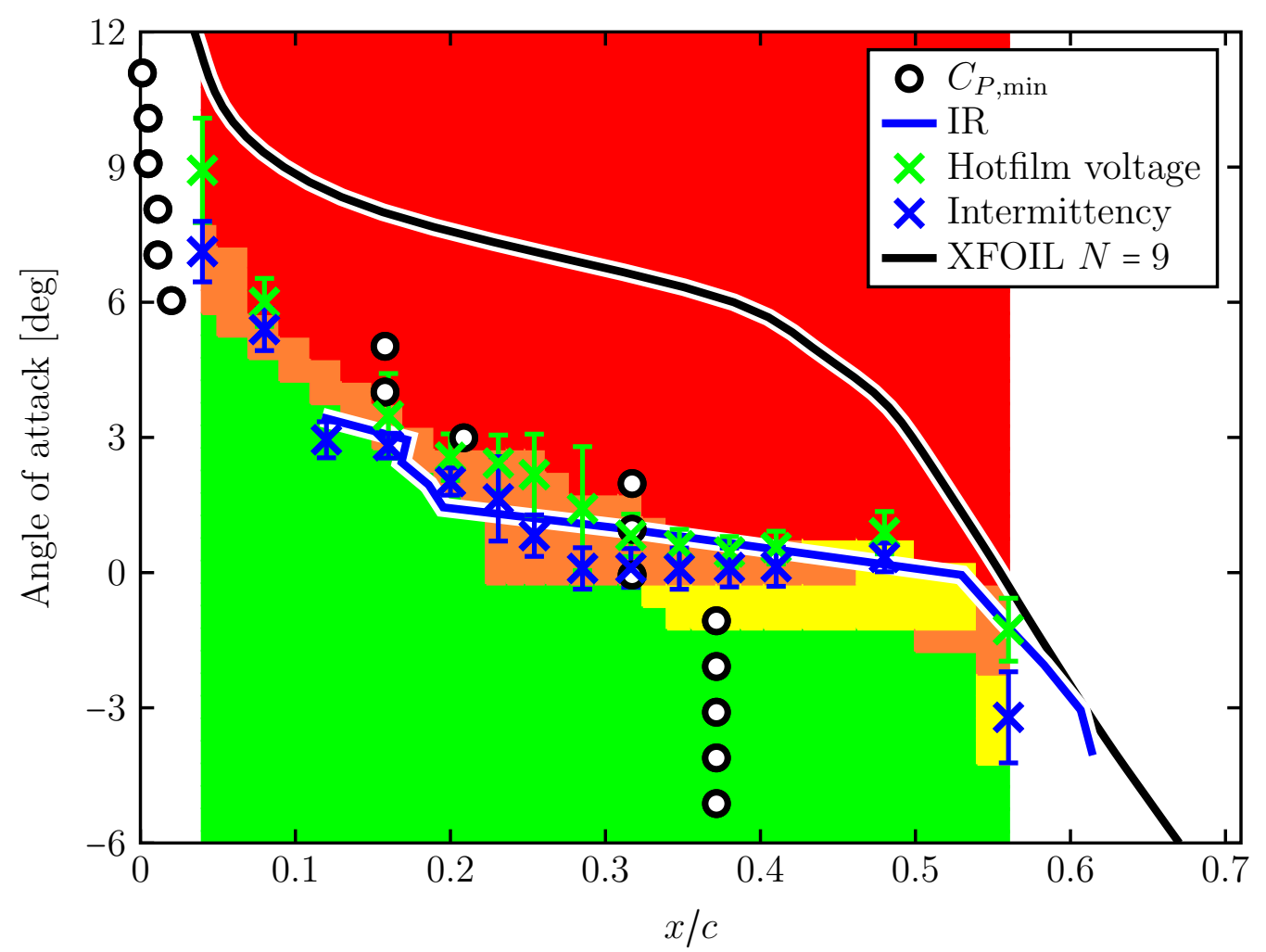

Figure IV.16. Freelogram for the 200-03 configuration at $R e_{c}=1.6 \times 10^{6}$.

or earlier transition compared to the clean configuration. Neglecting differences between $\alpha=3^{\circ}$ and $7^{\circ}$, the TS development is identical between the clean and SFF configurations. IR data is also commensurate. Similarly, no additional TS growth was observed at other Reynolds numbers. The SFF was likely to short to effect the TS wave growth. However, this data indicates repeatability for the clean configuration, serving to indicate TS growth is diminished behind roughness elements.

The hotfilm data, while comprehensive, suffered from electronic contamination and premature transition, rendering the IR measurements most useful. At low Reynolds numbers, roughness potentially decreased the amplification of TS without delaying transition onset. Bypass transition indicated no TS development, as 


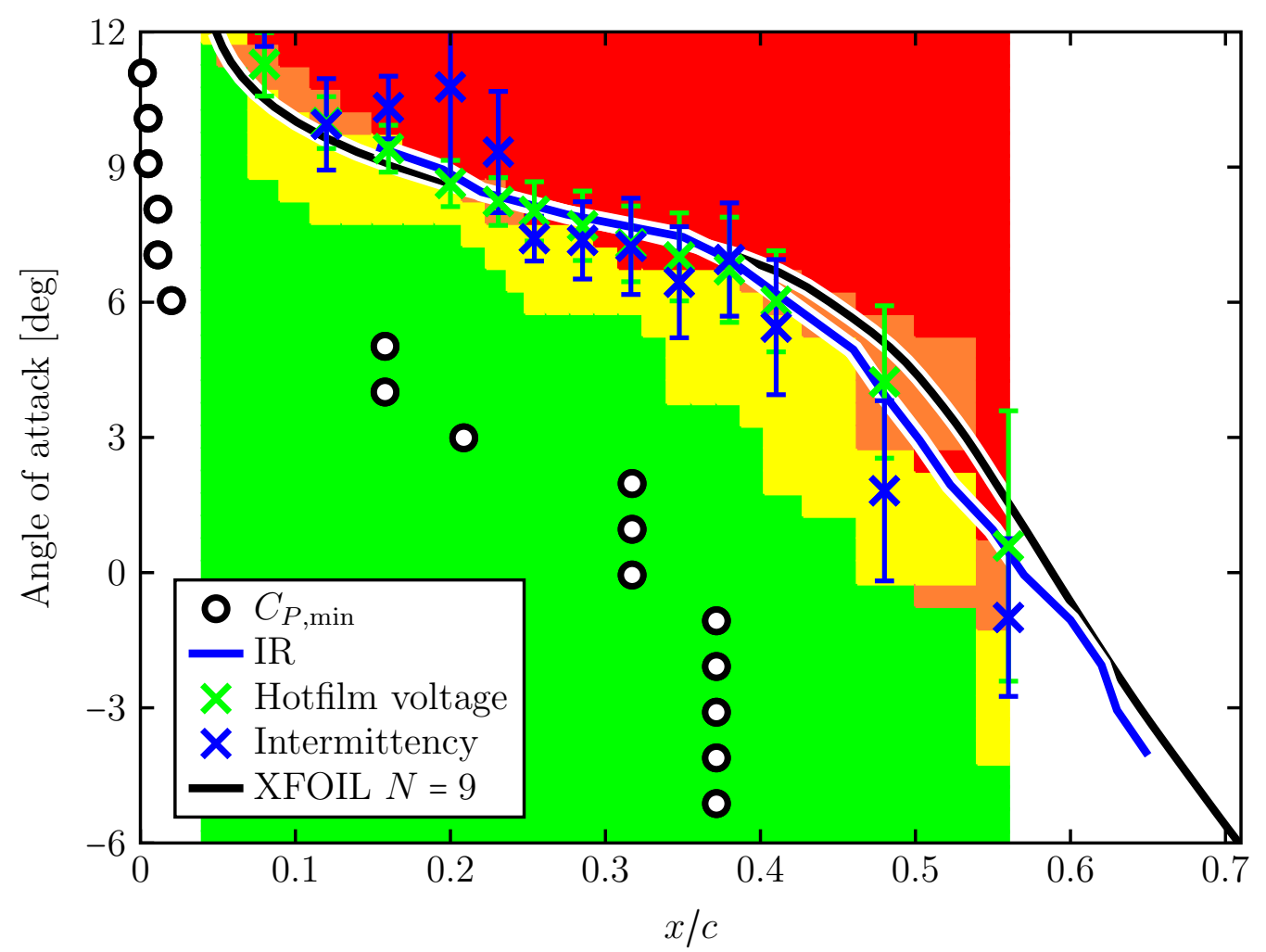

Figure IV.17. Freelogram for the straight, forward-facing step configuration at $R e_{c}=0.8 \times 10^{6}$.

the natural transition path no longer occurs. No TS amplification was observed with the addition of the straight, forward-facing step. It seems the height was insufficiently tall to effect TS development. A step near the leading edge would have a greater influence transition, since the boundary layer is thinner.

\section{IV.D. Infrared Boundary-Layer Transition}

Infrared (IR) transition data proved most consistent, being a nonintrusive, global technique. Data were acquired with constant Reynolds numbers while varying angle of attack. Appendix H summarizes the IR transition data. 
Figure IV.18 illustrates transition at $R e_{c}=2.4 \times 10^{6}$. Before bypass transition, natural transition location varies $1.5 \%$ chord between configurations. The shaded colors indicate uncertainty bounds on the transition data. There is a considerable offset from the $N=9$ curve, which varies with angle of attack. The maximum offset is $5 \%$ chord at $\alpha=4^{\circ}$. No explanation for this has been discovered. Recall Fig. IV.6, where drag for 100-03 and 140-03 rose near $\alpha=4^{\circ}$ and $1^{\circ}$, respectively. These trends are similarly indicated in the transition data, where bypass transition occurs at $\alpha=4^{\circ}$ and $1.5^{\circ}$ for $100-03$ and 140-03. Bypass transition occurs first (lowest angle of attack) for the tallest roughness, 200-03, followed by 140-15, the most dense configuration. Next, the extended roughness configuration transitions, indicating the sensitivity of roughness on the leading edge. The 140-03 and the combined 140-03 SFF transition together, indicating the SFF has no additional effect on transition. This is the last configuration where transition extends in front of the pressure minimum. When 10003 transitions, minimal variation occurs, with transition shifting $8 \%$ chord forward. Lastly, the SFF, WFF, and clean configuration indicate natural transition, further indicating the effect of the SFF is minimal.

When increasing the Reynolds number to $R e_{c}=3.2 \times 10^{6}$, the general observations from Fig. IV.18 hold true in Fig. IV.19: taller roughness transitions earlier, denser roughness transitions earlier, the SFF has no influence on transition location, and the 100-03 roughness transition is behind the pressure minimum. Bypass transition occurs at lower angles of attack due to a thinner boundary layer. The offset between $N=9$ increases to $9 \%$ chord. A key difference is that the WFF step has transitioned at every angle of attack. The nominal height of the WFF and SFF is identical. 


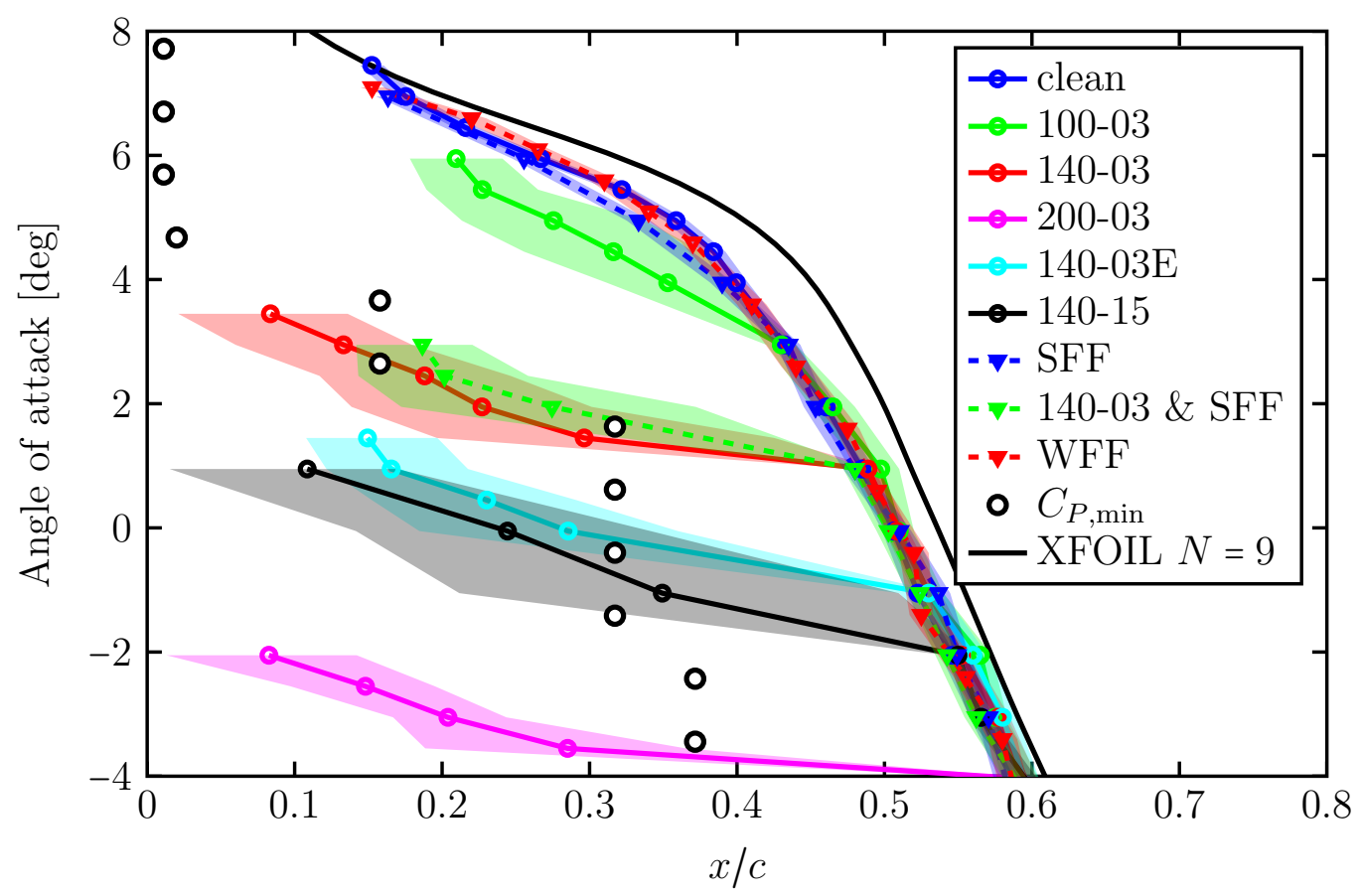

Figure IV.18. Infrared boundary-layer transition data at $R e_{c}=2.4 \times 10^{6}$.

However, the WFF leading edge is nonuniform with a coarsely cut leading edge. Transition on the WFF is significantly different from the simulated insect roughness. Once bypass occurs for distributed roughness, transition continues to move forward to the leading edge as angle of attack increases. This is true behind the pressure minimum as well, evidenced with 100-03. The WFF causes bypass in a spanwise uniform sense, similar to the distributed roughness. Yet, as angle of attack increases between $\alpha=-4^{\circ}$ to $4^{\circ}$, the mean transition location moves forward $5 \%$ chord. At low angles of attack, transition occurs before the pressure minimum. However, because transition location does not vary, it eventually occurs behind the pressure minimum.

A critical difference between the distributed and WFF, beyond shape, is location, with the WFF at $10 \%$ chord. Though the pressure gradient is favorable, the 


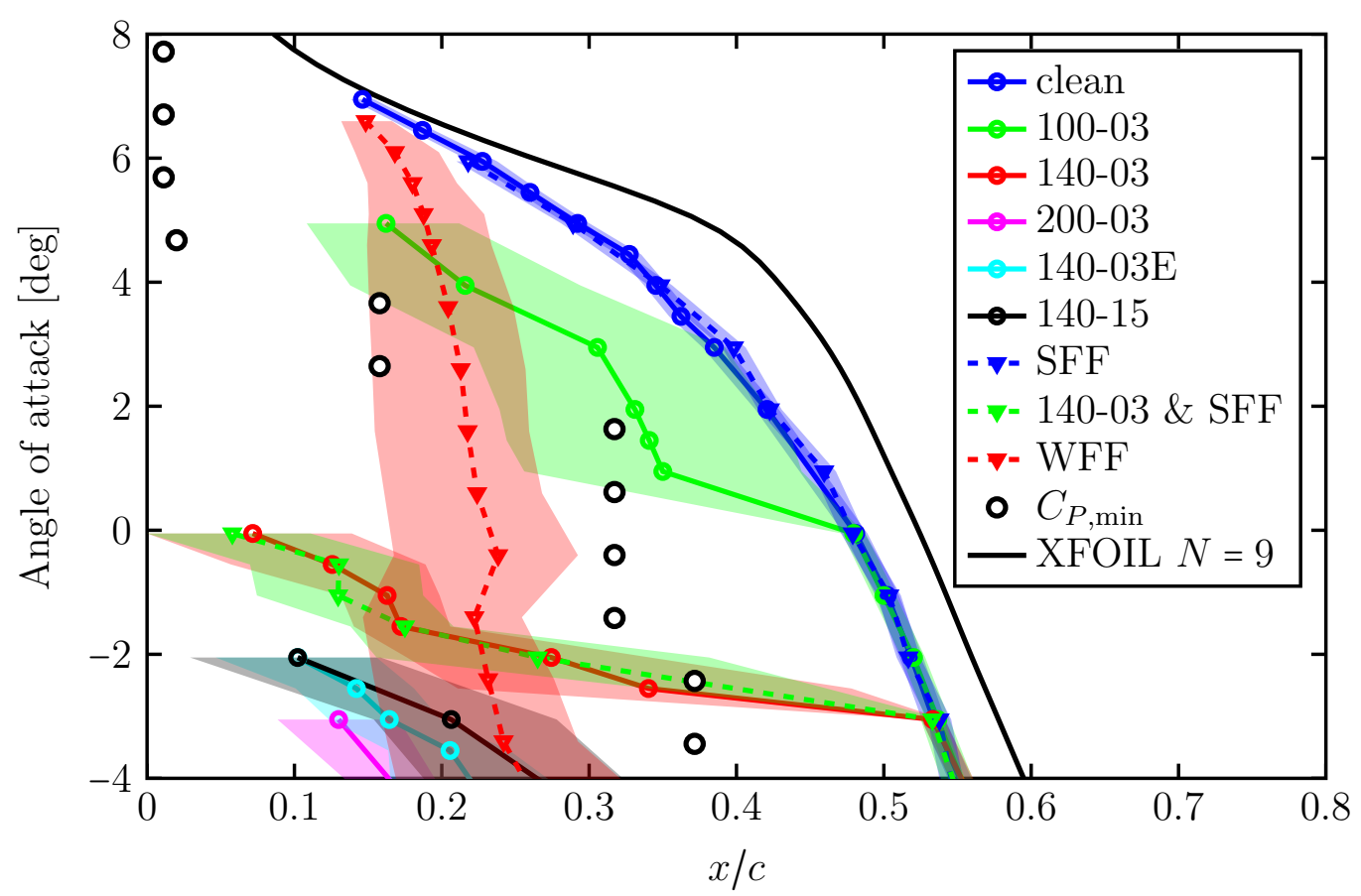

Figure IV.19. Infrared boundary-layer transition data at $R e_{c}=3.2 \times 10^{6}$.

boundary layer is thinner at $10 \%$ chord. As the angle of attack increases, the pressure gradient becomes less favorable, thickening the boundary layer, lowering the roughness Reynolds number, $R e_{k}$. From XFOIL, $R e_{k}$ varies between 460 at $\alpha=-2^{\circ}$ to 300 at $\alpha=6^{\circ}$. The roughness is effectively becoming shorter as angle of attack increases, explaining the minimal transition location movement. Eventually, transition occurs in front of the WFF.

After the second entry, density variation was determined to effect transition location. For the third entry, 3\%, 9\%, and 15\% coverage was tested for the $100 \mu \mathrm{m}$ roughness and $3 \%, 6 \%, 9 \%, 12 \%$, and $15 \%$ coverage for the $140 \mu \mathrm{m}$ roughness. Figure IV.20 shows that entries two and three lacked repeatability, with roughness transitioning $2^{\circ}$ later in entry three. However, above $\alpha=2.5^{\circ}$, the transition location 
coincides. Both 100-09 and 100-15 have bypass transition at the same location. However, the increased density in 100-15 causes transition to occur further forward. Similarly, drag is higher for the 100-15 configuration.

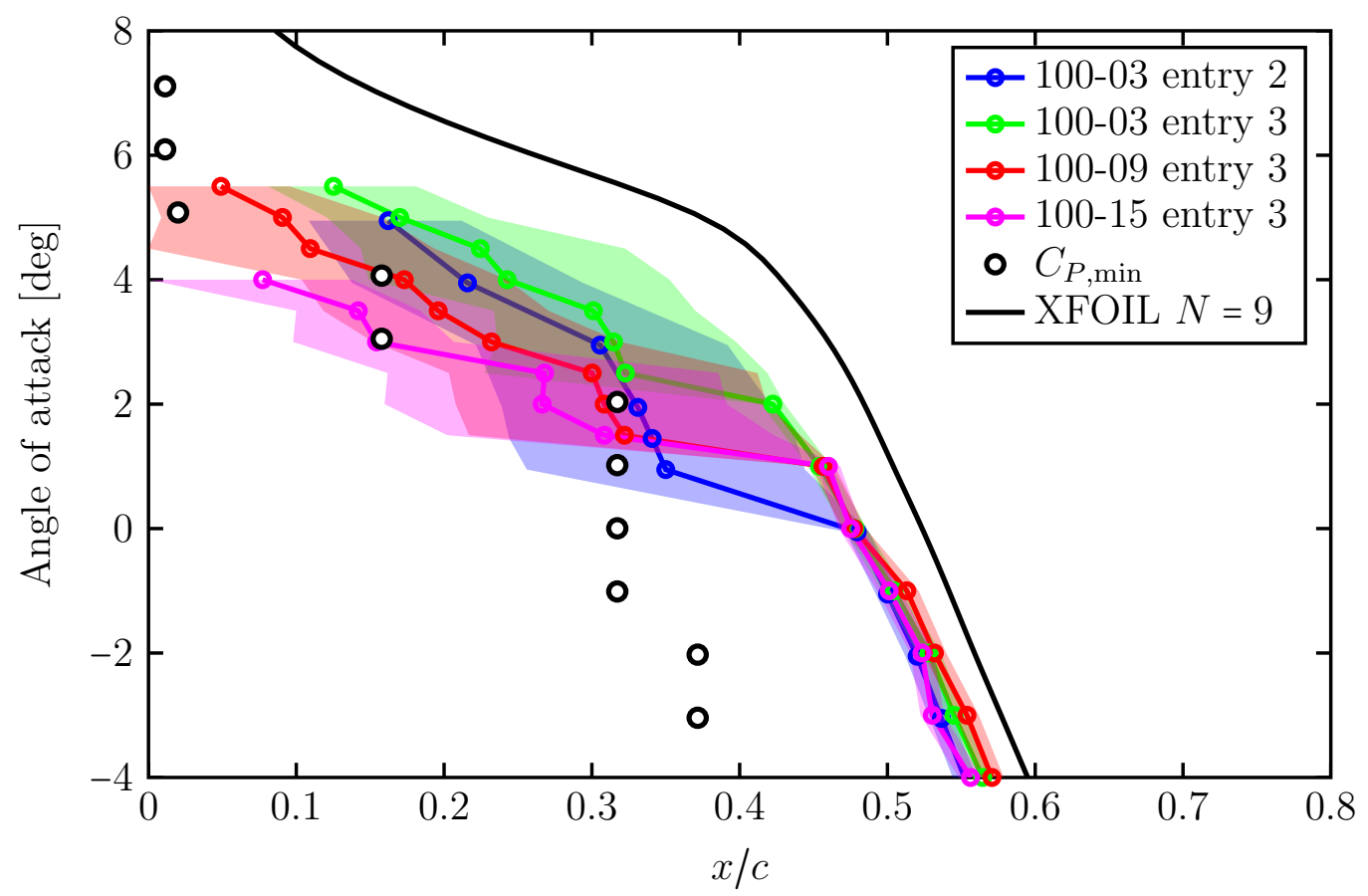

Figure IV.20. Infrared boundary-layer transition for multiple $100 \mu \mathrm{m}$ roughness densities at $R e_{c}=3.2 \times 10^{6}$.

The $140 \mu \mathrm{m}$ roughness is shown in Fig. IV.21 at $R e_{c}=1.6 \times 10^{6}$. Entries two and three showed excellent repeatability for the 140-03. The 140-15 was tested in both entries as well. During entry two, rather than applying a new roughness pattern for each configuration, the 140-15 roughness was designed to be applied in-between the 140-03 roughness, saving application time. However, some of the 140-15 roughness appears to have overlapped the 140-03 roughness, resulting in some $280 \mu \mathrm{m}$ height 
roughness and much earlier transition than expected. Entry two data for 140-15 is therefore omitted. In entry three, the roughness patterns were completely removed for each configuration change to avoid this. The $3 \%$ and $6 \%$ densities and the $9 \%$, $12 \%$, and $15 \%$ densities transition together. This indicates that there is a critical density between $6 \%$ and $9 \%$ where the roughness goes from isolated to moderately dense. This pattern was also observed at $R e_{c}=2.4 \times 10^{6}$.

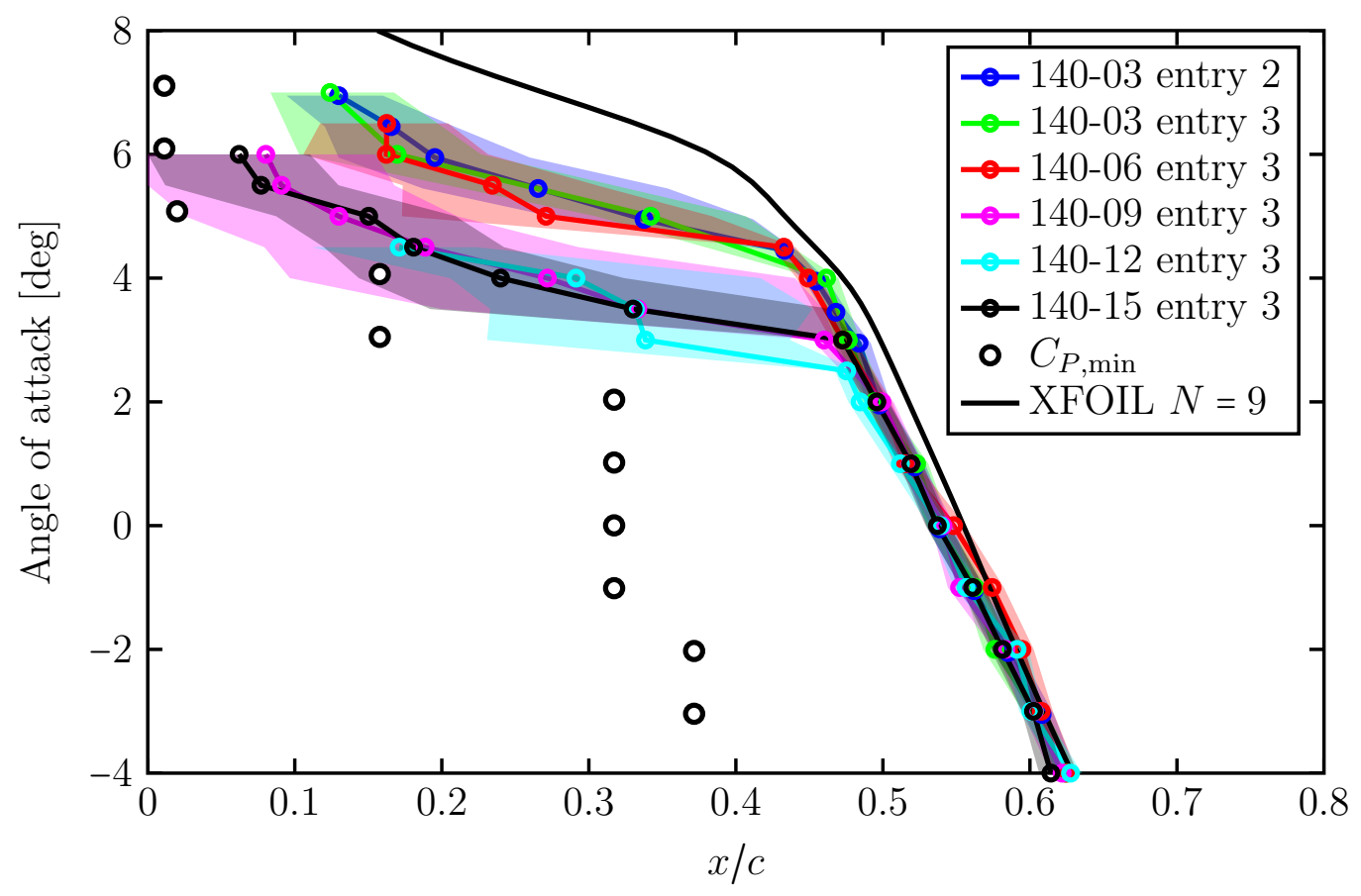

Figure IV.21. Infrared boundary-layer transition for multiple $140 \mu \mathrm{m}$ roughness densities at $R e_{c}=1.6 \times 10^{6}$.

The IR transition data indicates bypass transition to occur earlier for taller roughness. When bypass occurs, most configurations transition in front of the pressure minimum. However, low Reynolds numbers and low height configurations 
may still transition behind the pressure minimum. The SFF has no effect. At $R e_{c}=3.2 \times 10^{6}$, the WFF causes bypass transition. It is qualitatively different, with transition location essentially constant over $8^{\circ}$. This is an important distinction when simulating transition. As configurations become denser, bypass transition occurs earlier. A critical density between $6 \%$ and $9 \%$ indicates where this roughness may be defined as isolated and moderately dense. Transition tends to occur at similar locations for higher and lower densities.

\section{IV.E. Critical Roughness Reynolds Number Variation}

While investigating variation of angle of attack for constant Reynolds number proved useful, varying Reynolds number at a constant angle of attack allows the point at which bypass transition occurs to be clearly defined. The Reynolds number where this occurs is called the critical Reynolds number, $R e_{c, \text { crit }}$. With $R e_{c, \text { crit }}$ known, the critical roughness Reynolds number, $R e_{k, \text { crit }}$, may be calculated. $R e_{k, \text { crit }}$ may then be used to estimate when roughness with a particular geometry will cause bypass transition. The effect of pressure gradient was investigated by varying Reynolds number at multiple constant angles of attack for the 100-15 configuration.

Figure IV.22 illustrates the variation of transition location with Reynolds number for multiple configurations. The SFF, WFF, and combined SFF and 140-03 are omitted since no data were acquired for these configurations. The variation between the clean configuration and $N=9$ curve is significant, increasing with Reynolds number. Natural transition varies from $N=6$ to 4 as Reynolds number increases. The decrease in $N$-factor indicates the initial conditions are varying, causing transition 
to occur earlier than predicted. This is a partial explanation of the drag coefficient not decreasing with Reynolds number. Repeatability between entries two and three for configurations 140-03, 140-03E, and 100-03 indicates $R e_{c \text {,crit }}$ varied $\pm 0.07 \times 10^{6}$.

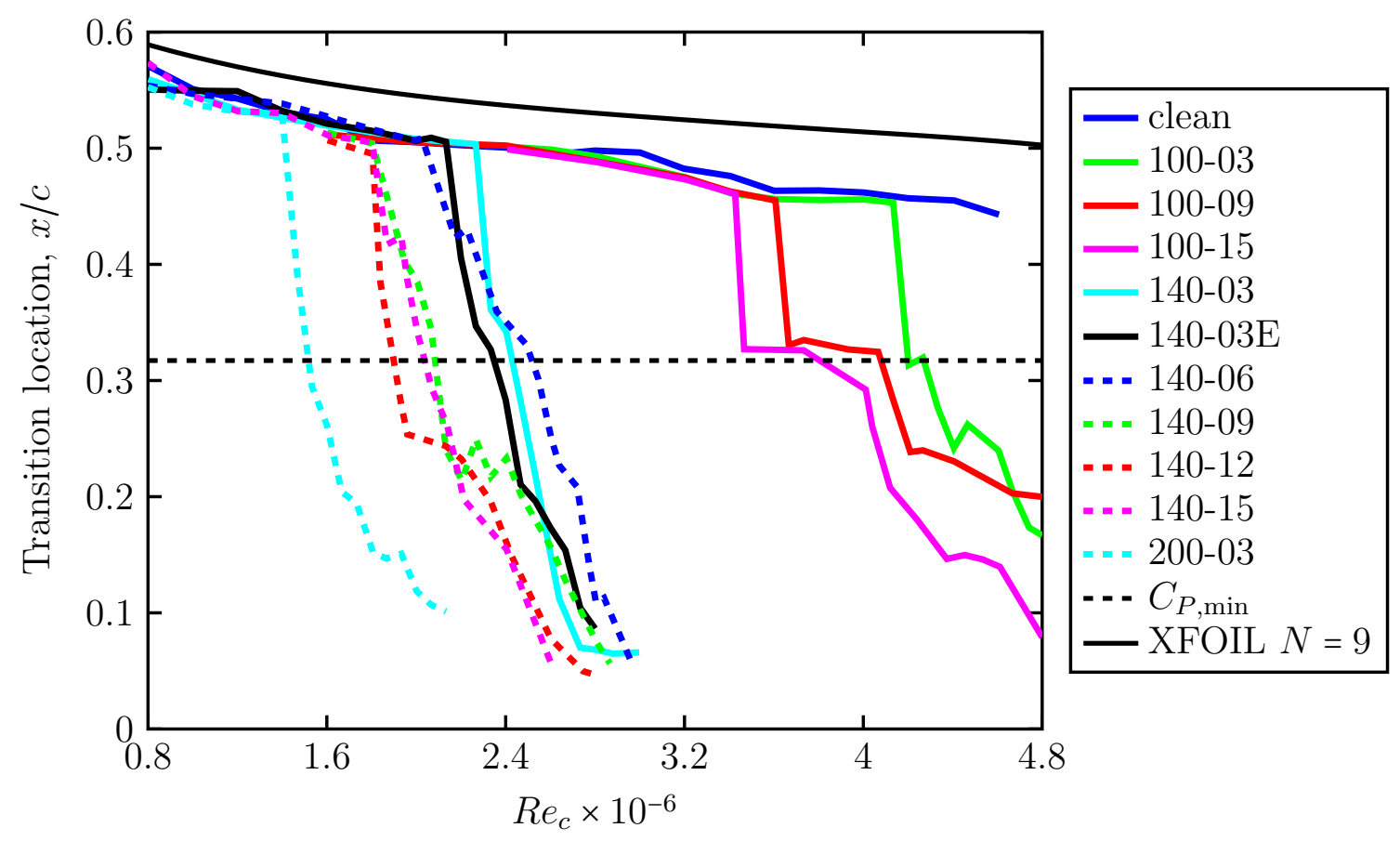

Figure IV.22. Infrared boundary-layer transition at $\alpha=0^{\circ}$ for multiple configurations.

All of the configurations have similar natural transition locations. Once bypass occurs, transition rapidly moves forward. First to transition is the tallest roughness, 200-03. The $140 \mu \mathrm{m}$ configurations transition next. First, the $9 \%, 12 \%$, and $15 \%$ densities transition followed by $6 \%$ and $3 \%$. A similar grouping is observed for moderate densities in Fig. IV.21 and in the drag polar in Fig. IV.6. However, $R e_{c, \text { crit }}$ varies by $0.24 \times 10^{6}$ between $3 \%$ and $6 \%$ densities, indicating additional sensitivity. 
This was previously unobservable because the constant Reynolds number data lacked sufficient resolution. Lastly, the $100 \mu \mathrm{m}$ roughness transitions with distinct variations between densities. While the $140 \mu \mathrm{m}$ roughness transitioned at similar locations between $9 \%$ and $15 \%$, the $100 \mu \mathrm{m}$ does not follow this pattern. However, the $9 \%$ and $15 \%$ are more closely grouped than the $3 \%$ density.

With $R e_{c, \text { crit }}$, roughness height, and roughness location, the critical roughness Reynolds numbers, $R e_{k, \text { crit }}$, can be calculated from a laminar boundary layer solution around the airfoil. Table IV.1 summarizes this data. $R e_{k \text {,crit }}$ values range between 178 and 318, generally decreasing as height and density increase. Tani found for $k / d \approx 1, R e_{k, \text { crit }} \approx 600$ to 900 [35]. Utilizing a relationship from Tani, $(k / d)^{(2 / 5)}$, an equivalent range of acceptable $R e_{k, \text { crit }}$ for the roughness in this experiment was found to be 155 to 310 . The mean $R e_{k, \text { crit }}$ from Table IV.1 is 227 , with only $100-03$ exceeding the estimated range. This indicates that within the pressure gradient at $\alpha=0^{\circ}$, historical estimates for $R e_{k, \text { crit }}$ are appropriate.

Table IV.1. Summary of $R e_{k, \text { crit }}$ data at $\alpha=0^{\circ}$.

\begin{tabular}{ccc}
\hline \hline Configuration & $R e_{c, \text { crit }} \times 10^{-6}$ & $R e_{k, \text { crit }}$ \\
\hline $100-03$ & 4.13 & $318 \pm 14$ \\
$100-09$ & 3.61 & $270 \pm 14$ \\
$100-15$ & 3.43 & $254 \pm 14$ \\
$140-03$ & 2.27 & $240 \pm 19$ \\
$140-03 E$ & 2.13 & $224 \pm 21$ \\
$140-06$ & 2.03 & $207 \pm 19$ \\
$140-09$ & 1.80 & $178 \pm 18$ \\
$140-12$ & 1.80 & $178 \pm 18$ \\
$140-15$ & 1.80 & $178 \pm 18$ \\
$200-03$ & 1.40 & $227 \pm 29$ \\
\hline \hline
\end{tabular}


Smith and Clutter described the relationship of $R e_{k, \text { crit }}$ with pressure gradient to be minimal [32]. To verify this, Reynolds number was varied for seven angles of attack for the 100-15 roughness configuration, shown in Fig. IV.23. As angle of attack increases, the natural transition location moves forward. The Reynolds number when bypass transition occurs also decreases as angle of attack increases. Because the boundary layer is developing differently due to pressure gradient and Reynolds number effects, Fig. IV.23 is only helpful in determining where $R e_{c, \text { crit }}$ occurs, not understanding how $R e_{k, \text { crit }}$ varies. The dashed lines indicate the $N=5.5$ curve and aid in illustrating where bypass transition occurs. The $R e_{c, \text { crit }}$ location is difficult to locate at $\alpha=5^{\circ}$ and $6^{\circ}$ since the bypass transition location varies with the $N$-factor curve. $R e_{c, \text { crit }}$ values are indicated with circles in Fig. IV.23.

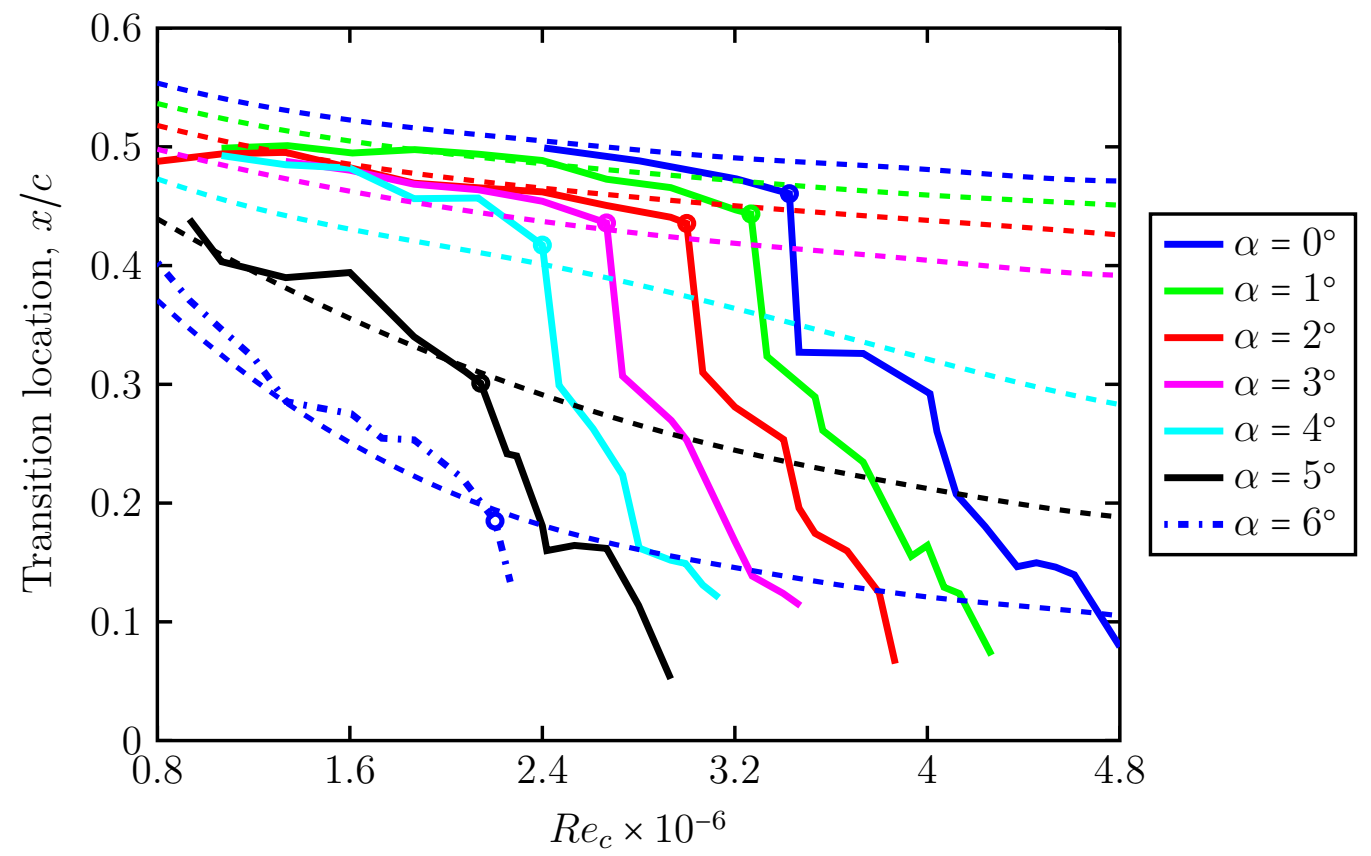

Figure IV.23. Infrared boundary-layer transition for 100-15 at various angles of attack. The dashed lines indicate XFOIL $N=5.5$ curve. 
With the $R e_{c, \text { crit }}$ locations determined from Fig. IV.23, $R e_{k, \text { crit }}$ is calculated. The development of $R e_{k}$ over the airfoil surface is shown in Fig. IV.24. Each curve represents the particular angle of attack and critical Reynolds number where bypass transition occurred in Fig. IV.23. The maximum value along the curve indicates the $R e_{k, \text { crit }}$ value. $R e_{k \text {,crit }}$ varies between 188 and 257 , well within the range of 155 to 310. The critical roughness Reynolds number appears to be weakly correlated to pressure gradient, but the range of $R e_{k, \text { crit }}$ accounts for this variation.

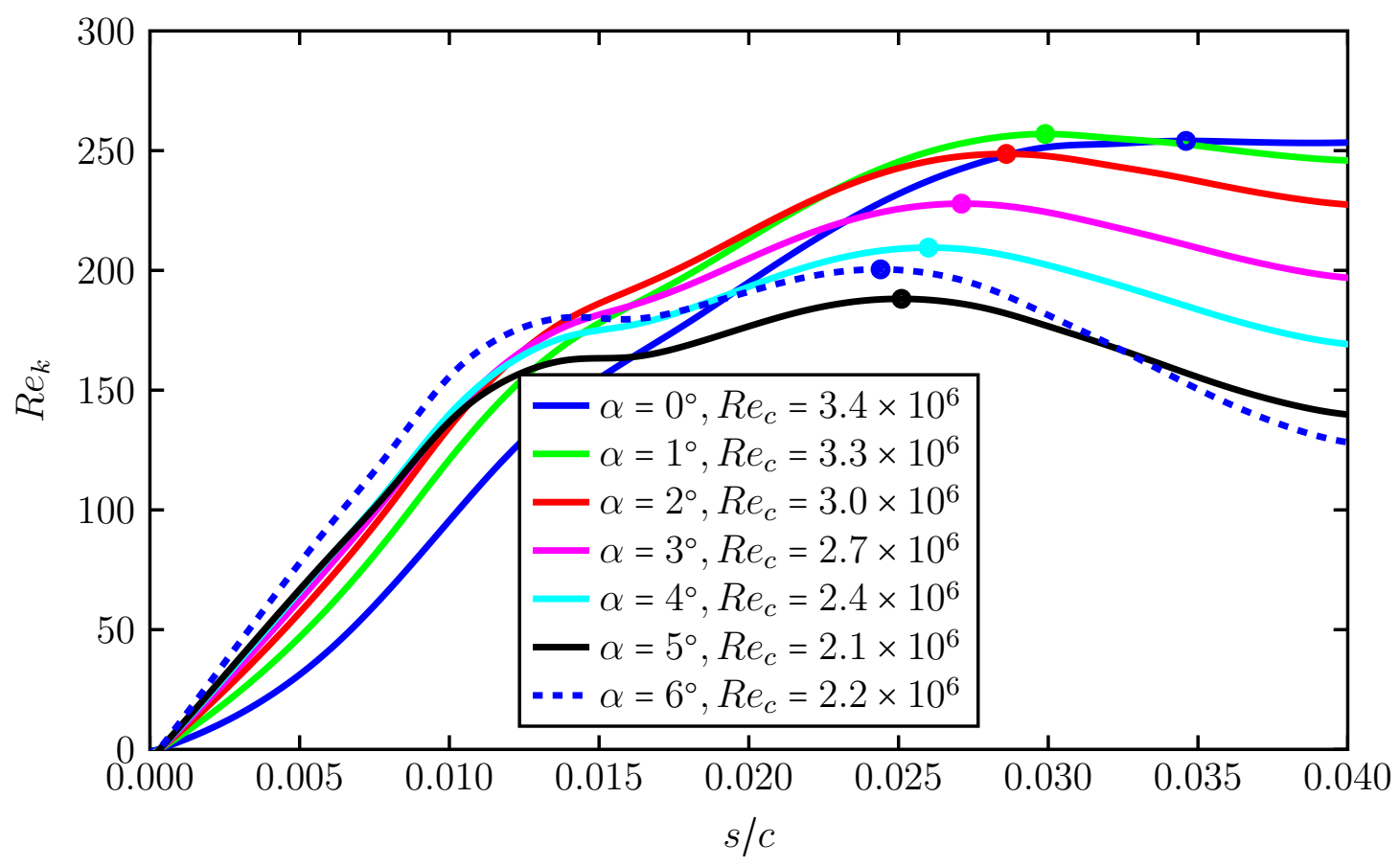

Figure IV.24. Critical roughness Reynolds number variation with airfoil arc length from the origin.

For clarity, the variation of $R e_{k \text {,crit }}$ with angle of attack is shown in Fig. IV.25. This indicates the relatively small variations between $R e_{k, \text { crit }}$ for different pressure 
gradients. Attempts were made to plot $R e_{k, \text { crit }}$ against the pressure gradient at the $s / c$ where the maximum $R e_{k}$ occurs. This proved difficult, as the pressure gradient did not vary monotonically due to varying $s / c$ locations and large pressure gradient variation with angle of attack. Improved results were obtained by nondimensionalizing with local boundary layer thickness, but changes were still not monotonic. For reference, the pressure gradient, $d C_{P} / d(x / c)$, varied between -18 and -45 for the various configurations shown in Figs. IV.24 and IV.25.

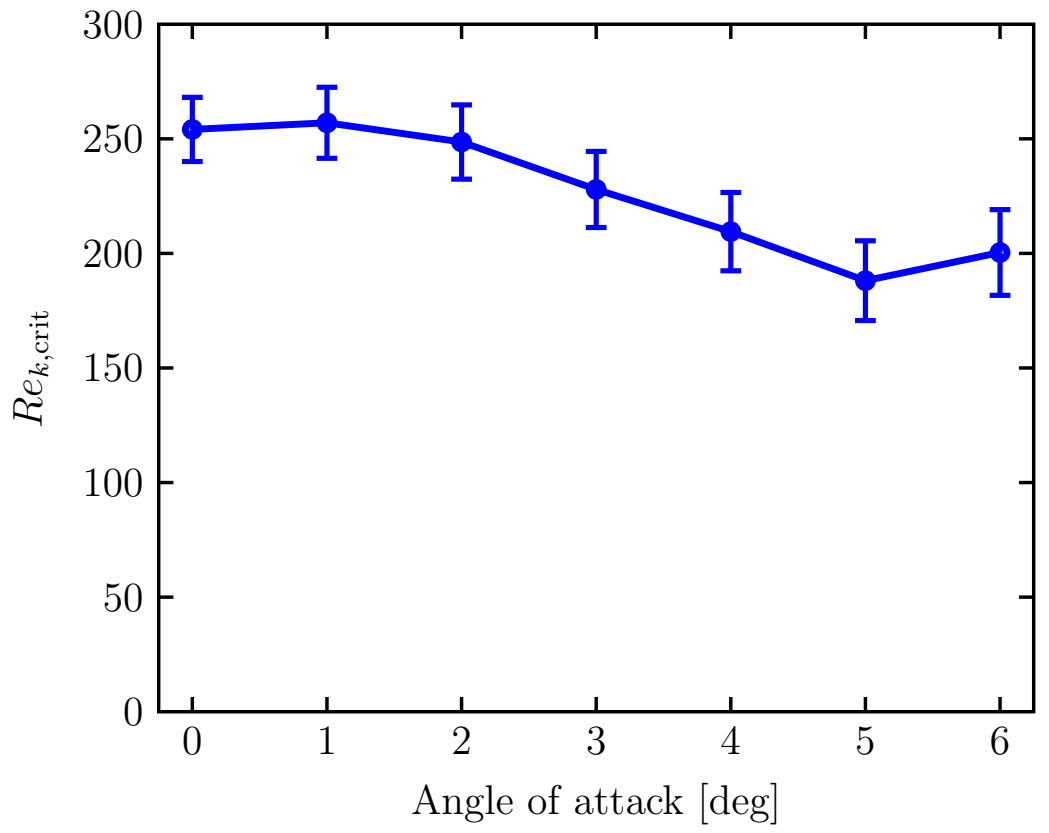

Figure IV.25. Critical roughness Reynolds number variation with angle of attack.

For all of the configurations, $R e_{k, \text { crit }}$ varied between 178 to 318 . From historical data, the expected range is 155 to 310 , placing the critical roughness Reynolds numbers within an acceptable range. Pressure gradient was varied for the 100-15 
configuration by changing angle of attack, with $R e_{k, \text { crit }}$ between 188 and 257 . This shows weak correlation to pressure gradient, but within the expected range.

\section{IV.F. Wind Turbine Performance Loss}

While $R e_{k, \text { crit }}$ values are an important parameter for transition prediction and airfoil performance, it is important to understand how transition affects annual energy production (AEP) on a wind turbine. Utilizing the NREL $5 \mathrm{MW}$ wind turbine, performance variations from lift and drag data, and a blade element momentum code, AEP loss for the various configurations was determined. Only data from $R e_{c}=3.2 \times 10^{6}$ was utilized because it contains a full angle of attack sweep, allowing both lift-curve slope and maximum lift variations to be applied. The complete methodology is detailed in Section III.E.

Table IV.2 summarizes percent decrease in AEP compared to the baseline NREL 5 MW AEP, listed in the clean row. IEC Classes I-IV indicate mean hub wind speeds of $10 \mathrm{~m} / \mathrm{s}, 8.5 \mathrm{~m} / \mathrm{s}, 7.5 \mathrm{~m} / \mathrm{s}$, and $6 \mathrm{~m} / \mathrm{s}$, respectively. Across wind classes, AEP loss is less than $1 \%$ for the WFF and $100 \mu \mathrm{m}$ roughness configurations. The $140 \mu \mathrm{m}$ configurations have consistent power loss within their respective IEC class, varying between $1.5 \%$ and $3.5 \%$. Lastly, the $200 \mu \mathrm{m}$ configuration has slightly improved performance. While the 200-03 configuration transitioned earlier and had higher drag, it had a steeper lift-curve slope and maximum lift than the 140-03 configuration. As lift is the primary performance driver, less AEP loss occurred. The trip strip resulted in $15 \%$ to $20 \%$ more energy loss than the next worst configuration, consistent with the trip strip's aerodynamic performance. 
Table IV.2. Wind turbine annual energy production percent loss.

\begin{tabular}{ccccc}
\hline \hline Configuration & IEC Class I & IEC Class II & IEC Class III & IEC Class IV \\
\hline clean & $25.1 \mathrm{GW}-\mathrm{hr}$ & $20.9 \mathrm{GW}-\mathrm{hr}$ & $17.4 \mathrm{GW}-\mathrm{hr}$ & $11.3 \mathrm{GW}-\mathrm{hr}$ \\
WFF & $-0.3 \%$ & $-0.4 \%$ & $-0.4 \%$ & $-0.7 \%$ \\
trip & $-2.1 \%$ & $-2.8 \%$ & $-3.4 \%$ & $-4.7 \%$ \\
$100-03$ & $-0.4 \%$ & $-0.6 \%$ & $-0.7 \%$ & $-0.8 \%$ \\
$100-09$ & $-0.6 \%$ & $-0.8 \%$ & $-0.9 \%$ & $-1.2 \%$ \\
$100-15$ & $-1.0 \%$ & $-1.3 \%$ & $-1.6 \%$ & $-2.1 \%$ \\
$140-03$ & $-1.4 \%$ & $-1.9 \%$ & $-2.3 \%$ & $-3.2 \%$ \\
$140-03 \mathrm{E}$ & $-1.7 \%$ & $-2.2 \%$ & $-2.7 \%$ & $-3.6 \%$ \\
$140-06$ & $-1.5 \%$ & $-2.0 \%$ & $-2.5 \%$ & $-3.4 \%$ \\
$140-09$ & $-1.7 \%$ & $-2.2 \%$ & $-2.6 \%$ & $-3.6 \%$ \\
$140-12$ & $-1.8 \%$ & $-2.3 \%$ & $-2.8 \%$ & $-3.9 \%$ \\
$140-15$ & $-1.7 \%$ & $-2.3 \%$ & $-2.8 \%$ & $-3.8 \%$ \\
$200-03$ & $-1.0 \%$ & $-1.4 \%$ & $-1.7 \%$ & $-2.4 \%$ \\
\hline \hline
\end{tabular}

Assuming $\$ 0.05 / \mathrm{kW}-\mathrm{hr}$ and ideal operating conditions, the amount of money lost due to insect roughness may be determined. The NREL 5 MW would nominally generate $\$ 1.05$ million annually for IEC Class II. Neglecting the trip strip configuration, the 140-12 would result in the most money lost at $\$ 24,000$ annually, while the WFF would lose the least, at $\$ 4,000$. Note this assumes a blade is soiled continuously throughout the year, which is unlikely due to rainfall cleaning the blades.

An example of the original and degraded power curve for the NREL 5 MW turbine is in Fig. IV.26a. Percent power loss is shown in Fig. IV.26b. Power loss is only observed in control region II, as region III is pitch controlled to maintain torque while region II is constant pitch. The smallest decrease in AEP is observed for the WFF, despite the percent power loss being large at low wind speeds. More power is generated at higher winds, so the large performance detriment for the WFF between 3 and $6 \mathrm{~m} / \mathrm{s}$ results in minimal AEP loss. Note as wind speed decreases, performance 
degrades faster for the WFF than the 100-03, since the WFF performance is worse at lower wind speeds. The WFF, 140-03, and 200-03 have similar power loss profiles, since flow has already transitioned for these configurations at $R e_{c}=3.2 \times 10^{6}$. However, for the $100 \mu \mathrm{m}$ roughness, bypass transition occurs $\alpha \approx 2^{\circ}$, near the blade local angle of attack. Because of this, performance loss is characteristically different for these configurations.
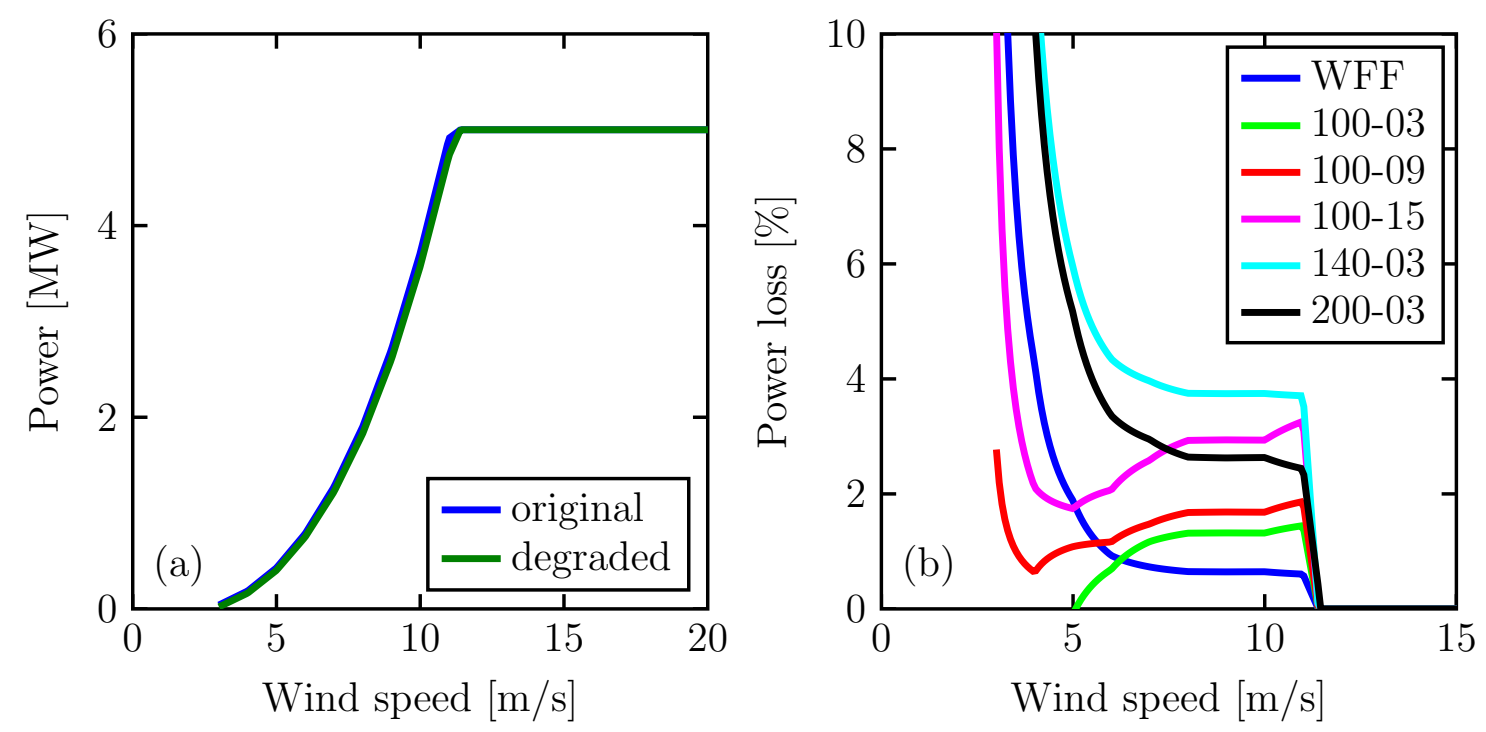

Figure IV.26. Degraded power performance illustrating (a) a representative power curve and (b) percent power loss for multiple configurations.

Figure I.2 shows power loss of an in-service, MW-scale, pitch-regulated turbine. This is compared to the simulated power loss for the NREL 5 MW wind turbine with 140-03 roughness in Fig. IV.27. The NREL 5 MW wind speed is nondimensionalized by its rated wind speed of $11.4 \mathrm{~m} / \mathrm{s}$, allowing for comparison. The calculated power loss due to simulated insect roughness properly simulates the measured power loss. 


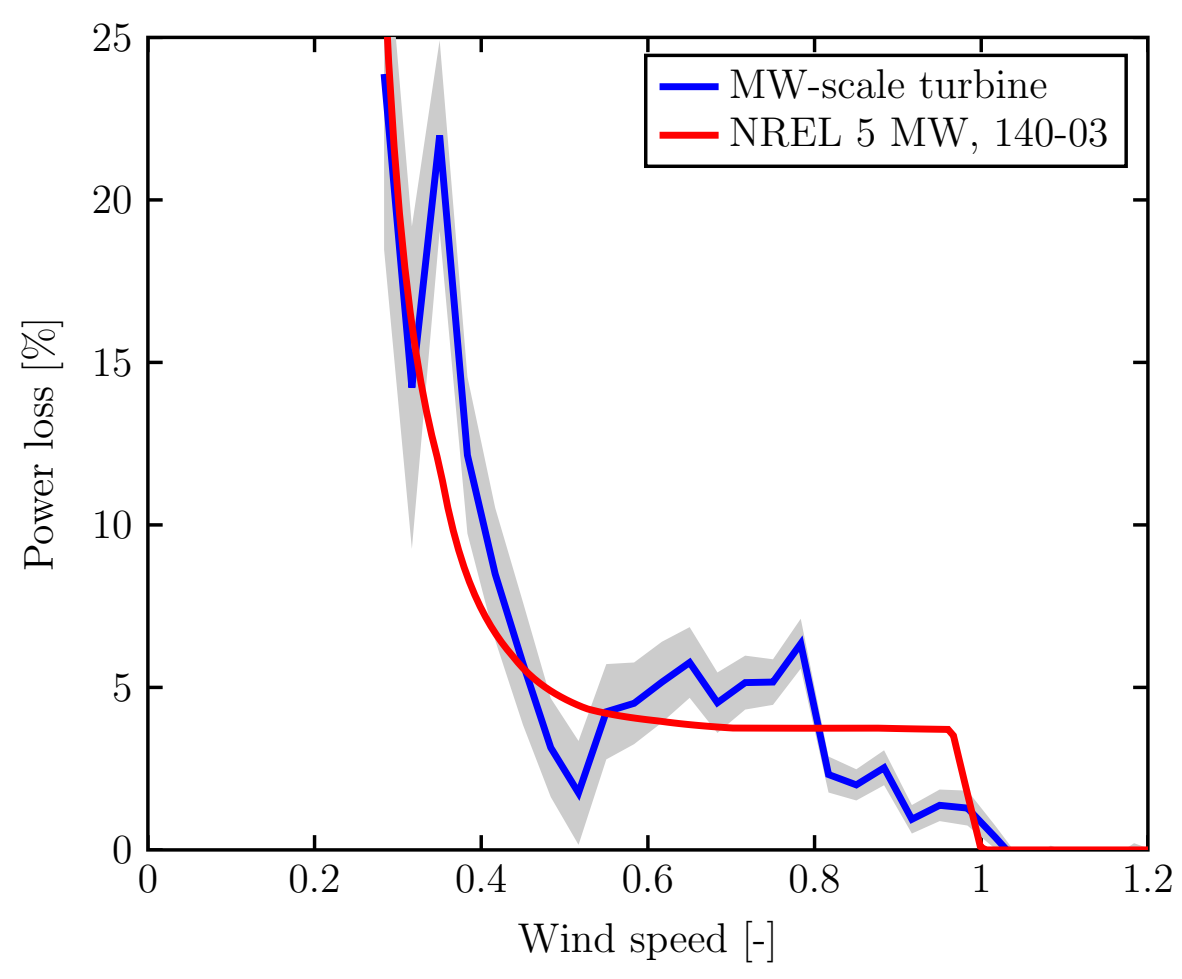

Figure IV.27. Measured power loss on a megawatt-scale wind turbine due to insect accumulation compared to predicted power loss from 140-03 simulated insect roughness.

Note the NREL 5 MW turbine is less sensitive to roughness than smaller turbines may be. Rated power is reached at $11.4 \mathrm{~m} / \mathrm{s}$, while a Vestas V80 reaches rated at $15 \mathrm{~m} / \mathrm{s}$. Therefore, compared to the NREL $5 \mathrm{MW}$, a higher percent of the energy from the V80 is generated in region II than region III. Since roughness only affects region II, wind turbines with delayed rated power will be more sensitive to blade soiling. The hub height wind speed is another important parameter to consider. A better wind resource will result in a turbine operating in region III for greater periods of time. Because less time is spent in region II, roughness has a smaller effect. Results from Table IV.2 summarize this observation, as AEP loss increases as 
wind speed decreases. Lastly, a wind turbine designed to operate near stall in region II is at greater risk for performance loss. The NREL 5 MW operates at conservative power coefficients in region II, yielding lower performance loss.

Annual energy production was found to decrease as roughness became taller and denser. Energy loss was largely a function of lift detriment. For an $8.5 \mathrm{~m} / \mathrm{s}$ mean hub height, AEP would decrease between $0.4 \%$ and $2.3 \%$, resulting in an annual loss of $\$ 4,000$ and $\$ 24,000$, respectively. The effect of bypass transition from roughness was evident on power loss. Lastly, using measured performance loss due to simulated insect roughness, power loss was simulated with a blade element momentum code, comparing excellently to field measurements from a megawatt-scale, pitch-regulated turbine. 


\section{CHAPTER V CONCLUSIONS AND FUTURE WORK}

This dissertation quantifies how roughness affects wind turbine performance. Wind turbine manufacturers and operators lack relevant data to understand how roughness changes performance. With improved performance estimates, wind farm financing may decrease. Cost effectiveness of blade maintenance can be determined with performance metrics. Aerodynamic data will also aid simulation validation efforts. Once validated, simulations will be essential during design of future low roughness sensitivity airfoils.

Performance of a two-dimensional NACA $63_{3}-418$ airfoil in a wind tunnel with and without roughness was measured. Roughness was tested as a two-dimensional step and distributed roughness. The distributed roughness had five densities (3\%, $6 \%, 9 \%, 12 \%$, and $15 \%$ by area) and three heights $(100 \mu \mathrm{m}, 140 \mu \mathrm{m}$, and $200 \mu \mathrm{m})$. Chord Reynolds numbers between 0.8 and $4.8 \times 10^{6}$ were tested. Aerodynamic and transition performance were measured.

Aerodynamic data indicated intuitive results. As roughness height and density increased, lift-curve slope, maximum lift coefficient, and drag increase. As Reynolds number increased, the roughness height effectively increased, exacerbating the performance decrease. Once fully turbulent, performance mildly improved. The most significant performance decrease was observed to be the 140-15 configuration whose $L / D_{\max }$ decreased $40.8 \%$ at $R e_{c}=3.2 \times 10^{6}$. The wavy and straight forward-facing steps had minimal affect on performance. The wavy, forward-facing step caused bypass transition at $R e_{c}=3.2 \times 10^{6}$, with a $5.8 \%$ decrease in $L / D_{\max }$. The straight, 
forward-facing step did not cause variation in transition location.

Hotfilm spectra of shear stress fluctuations indicate local flow phenomena. At low Reynolds numbers, roughness potentially decreased the amplification of TS without affecting transition onset. The straight, forward facing step height was insufficient to encourage TS amplification.

IR transition data indicated bypass transition occurring earlier for taller, denser roughness, coinciding with performance data. Bypass transition occurred in front of the pressure minimum for most configurations. At $R e_{c}=3.2 \times 10^{6}$, the WFF step caused bypass transition characteristically different from distributed roughness, with transition location essentially constant over $8^{\circ}$ of angle of attack. This was an important distinction between two-dimensional and distributed roughness. The $140 \mu \mathrm{m}$ roughness may be defined as isolated or moderately dense between $6 \%$ and $9 \%$ densities. Transition occurred at similar locations below and above these densities.

For all of the configurations, the critical roughness Reynolds number, $R e_{k, \text { crit }}$, varied between 178 to 318 when $\alpha=0^{\circ}$. From historical data, the expected range is 155 to 310, placing the critical roughness Reynolds numbers within the expected range. A weak correlation to pressure gradient and the critical roughness Reynolds number was shown for the 100-15 configuration. This variation was within the expected range.

Annual energy production (AEP) is directly correlated to aerodynamic performance. As roughness became taller and denser, production decreased. Energy loss was largely a function of lift detriment. While $L / D_{\max }$ may decrease $40 \%$, the corresponding AEP loss would be $2.3 \%$, related more to lift-curve slope variation than 
drag rise. For an $8.5 \mathrm{~m} / \mathrm{s}$ mean hub height, AEP would decrease between $0.4 \%$ and $2.3 \%$, resulting in an annual loss of $\$ 4,000$ and $\$ 24,000$, respectively, for a $5 \mathrm{MW}$ turbine. Power loss due to insect roughness compared well to field measurements from a MW-scale, pitch-regulated turbine.

Moving forward, there are several areas to focus future testing. First, the sensitivity of critical roughness Reynolds number to pressure gradient was only tested at seven angles of attack for a single roughness configuration. Testing the 140-03 and $140-03 \mathrm{E}$ between $\alpha=-4^{\circ}$ and $6^{\circ}$ would better verify the initial conclusion that pressure gradient is only weakly correlated.

While roughness measurements on the blade were useful, the blades were generally clean. Improved insect roughness characterization could be made on turbines over a continuous dry period, similar to Spruce [7]. Though the randomly distributed vinyl roughness simulated insect roughness well, actual insect roughness has a variable height and distribution. Height is a function of insect, impact speed, and impact direction. These variables were not considered in the roughness pattern, but feasibly applied with a similar vinyl decal method.

Many sources indicate roughness sensitivity increases as airfoil thickness increases $[24,55,56]$. van Rooij and Timmer approach this issue best, testing 25\%, $30 \%, 35 \%$, and $40 \%$ thick airfoils with trip-strip roughness [55]. The $25 \%$ and $30 \%$ thick airfoils were less sensitive to roughness than comparable NACA 6-series airfoils. However, the $35 \%$ and $40 \%$ airfoils were massively separated with severe performance loss. A limitation to their research is the approach to simulating insects. As airfoils grow thicker, insect accumulation and roughness sensitivity increase. The additional 
insect accumulation may prove more harmful and characteristically different from trip-strip roughness.

Lastly, a rapid airfoil design code may be created combining an insect accumulation code and viscous panel methods. Roughness height distributions over an airfoil can be calculated from an insect accumulation code. The corresponding roughness Reynolds numbers are approximated with local skin friction from a panel code. Bypass transition is predicted with historic critical roughness Reynolds number values. Both simulations are computationally inexpensive, allowing rapid transition prediction. From this, airfoils may be optimized to minimize roughness sensitivity in locations of high insect accumulation. 


\section{REFERENCES}

[1] Boccard, N., "Capacity Factor of Wind Power Realized Values vs. Estimates," Journal of Energy Policy, Vol. 37, 2009, pp. 2679-2688.

[2] White, E. B., Kutz, D., Freels, J., Hidore, J. P., Grife, R., Sun, Y., and Chao, D., "Leading-Edge Roughness Effects on $63_{3}-418$ Airfoil Performance," AIAA Paper 2011-352, 2011.

[3] Corten, G. P. and Veldkamp, H. F., "Aerodynamic: Insects Can Halve WindTurbine Power," Nature, Vol. 412, No. 6842, 2001, pp. 41-42.

[4] Berg, D. E., "A Review of the Workshop on WECS Blade-Surface Roughness," ASME Wind Energy Symposium, New Orleans, Louisiana, Jan. 1994.

[5] Rempel, L., "Rotor Blade Leading Edge Erosion - Real Life Experiences," Wind Systems Magazine, Oct. 2012, pp. 22-24.

[6] U.S. Department of Energy, "20\% Wind Energy by 2030, Increasing Wind Energy's Contribution to U.S. Electicity Supply," DOE/GO-102008-2567, Jul. 2008 .

[7] Spruce, C. J., "Power Performance of Active Stall Wind Turbines with Blade Contamination," Proceedings of European Wind Energy Conference, Athens, Greece, 2006.

[8] Moroz, E. M. and Eggleston, D. M., "A Comparison Between Actual Insect Contamination and Its Simulation," Windpower, 1992, pp. 418-425. 
[9] Malhotra-Bush, R. and Hulls, J. R., "Blade Surface Roughness Presentation," DOE Sandia National Laboratories Meeting, Golden, Colorado, 1993.

[10] Tangler, J. L., Smith, B., and Jager, D., "SERI Advanced Wind Turbine Blades," NREL/TP-257-4492, NREL, Golden, Colorado, 1992.

[11] Standish, K., Rimmington, P., Laursen, J., and Paulsen, H. N., "Computational Prediction of Airfoil Roughness Sensitivity," AIAA Paper 2010-460, 2010.

[12] Sareen, A., Sapre, C. A., and Selig, M. S., "Effects of Leading Edge Erosion on Wind Turbine Blade Performance," Wind Energy, 2013.

[13] Timmer, W. A. and Schaffarczyk, A. P., "The Effect of Roughness at High Reynolds Numbers on the Performance of Aerofoil DU 97-W-300Mod," Wind Energy, Vol. 7, 2004, pp. 295-307.

[14] Boermans, L. M. M. and Selen, H. J. W., "On the Design of Some Airfoils for Sailplane Application," Report LR-326, Delft University of Technology, Delft, Netherlands, 1981.

[15] Coleman, W. S., "The Characteristics of Roughness From Insects as Observed for Two-Dimensional, Incompressible Flow Past Airfoils," Journal of the Aerospace Sciences, Vol. 26, No. 5, 1959, pp. 264-280.

[16] Dalili, N., Edrisy, A., and Carriveau, R., "A Review of Surface Engineering Issues Critical to Wind Turbine Performance," Renewable and Sustainable Energy Reviews, Vol. 13, 2009, pp. 428-438. 
[17] Pechlivanoglou, G., Fuehr, S., Nayeri, C. N., and Paschereit, C. O., "The Effect of Distributed Roughness on the Power Performance of Wind Turbines," Proceedings of ASME Turbo Expo 2010: Power for Land, Sea, and Air, GT2010$23258,2010$.

[18] Keegan, M. H., Nash, D. H., and Stack, M. M., "On Erosion Issues Associated with the Leading Edge of Wind Turbine Blades," Journal of Physics D: Applied Physics, Vol. 46, No. 38, 383001, 2013.

[19] Tangler, J. L. and Somers, D. M., "NREL Airfoil Families for HAWTs," NREL/TP-442-7109, NREL, Golden, Colorado, 1995.

[20] Eppler, R., Airfoil Design and Data, Springer-Verlag Berlin Heidelberg, New York City, New York, 1990.

[21] Tangler, J. L. and Somers, D. M., "Status of the Special-Purpose Airfoil Families," SERI/TP-217-3264, SERI, Golden, Colorado, 1987.

[22] Ramsay, R. R., Hoffmann, M. J., and Gregorek, G. M., "Effects of Grit Roughness and Pitch Oscillations on the S801 Airfoil," NREL/TP-442-7818, The Ohio State University, Columbus, Ohio, 1996.

[23] Somers, D. M., "Design and Experimental Results for the S827 Airfoil," NREL/SR-500-36345, NREL, Golden, Colorado, 2005.

[24] Abbott, I. H., von Doenhoff, A. E., and Stivers, Jr., L. S., "Summary of Airfoil Data," NACA-TR-824, NACA, Langley Field, Virginia, 1945. 
[25] Björck, A., "Coordinates and Calculations for the FFA-W1-xxx, FFA-W2-xxx and FFA-W3-xxx Series of Airfoils for Horizontal Axis Wind Turbines," FFA TN 1990-15, The Aeronautical Research Institute of Sweden, Stockholm, Sweden, 1990.

[26] Drela, M. and Giles, M. B., "Viscous-Inviscid Analysis of Transonic and Low Reynolds Number Airfoils," AIAA Journal, Vol. 25, No. 10, 1987, pp. $1347-$ 1355.

[27] Timmer, W. A. and van Rooij, R. P. J. O. M., "Summary of the Delft University Wind Turbine Dedicated Airfoils," AIAA Paper 2003-0352, 2003.

[28] van Rooij, R., "Modification of the Boundary Layer Calculation in RFOIL for Improved Airfoil Stall Prediction," IW-96087R, Delft University of Technology, Delft, Netherlands, 1996.

[29] Fuglsang, P. and Bak, C., "Development of the Ris $\varnothing$ Wind Turbine Airfoils," Wind Energy, Vol. 7, 2004, pp. 145-162.

[30] Fuglsang, P., Bak, C., Gaunaa, M., and Antoniou, I., "Design and Verification of the Risø-B1 Airfoil Family for Wind Turbines," ASME Journal of Solar Energy Engineering, Vol. 126, 2004, pp. 1002-1010.

[31] Dryden, H. L., "Review of Published Data on the Effect of Roughness on Transition from Laminar to Turbulent Flow," Journal of the Aeronautical Sciences, Vol. 20, No. 7, 1953, pp. 477-482. 
[32] Smith, A. M. O. and Clutter, D. W., "The Smallest Height of Roughness Capable of Affecting Boundary-Layer Transition," Journal of Aerospace Sciences, Vol. 26, No. 4, 1959, pp. 229-245.

[33] Schiller, L., "Strömung in Rohren," Handbuch der Experimentalphysik, Vol. 4, 1932, pp. 189-192.

[34] von Doenhoff, A. E. and Braslow, A. L., "The Effect of Distributed Surface Roughness on Laminar Flow," Boundary Layer and Flow Control, Vol. 2, 1961, pp. 657-681.

[35] Tani, I., "Boundary-Layer Transition," Annual Review of Fluid Mechanics, Vol. 1, 1969, pp. 169-196.

[36] Klebanoff, P. S., Schubauer, G. B., and Tidstrom, K. D., "Measurements of the Effect of Two-Dimensional and Three-Dimensional Roughness Elements on Boundary-Layer Transition," Journal of the Aeronautical Sciences: Readers' Forum, Vol. 22, No. 11, 1955, pp. 803-804.

[37] Downs, III, R. S., White, E. B., and Denissen, N. A., "Transient Growth and Transition Induced by Random Distributed Roughness," AIAA Journal, Vol. 46, No. 2, 2008, pp. 451-462.

[38] Ergin, F. G. and White, E. B., "Unsteady and Transitional Flows Behind Roughness Elements," AIAA Journal, Vol. 44, No. 11, 2006, pp. 2504-2514.

[39] Hidore, J. P., Investigation of Data Quality for Wind Tunnel Internal Balance Testing, Master's thesis, Texas A\&M University, College Station, Texas, 2013. 
[40] Abbott, I. H. and von Doenhoff, A. E., Theory of Wing Sections, Dover Publications, Mineola, New York, 1959.

[41] Selig, M. S., "UIUC Airfoil Coordinates Database-Version 2.0," , Department of Aerospace Engineering, University of Illinois at Urbana-Champaign, Urbana, Illinois, 61801, 2006.

[42] Wilcox, B. J. and White, E. B., "Computational Analysis of Insect Impingement on Wind Turbine Blades," Wind Energy, In preparation, 2015.

[43] Wright, W. B., "User Manual for the NASA Glenn Ice Accretion Code LEWICE: Version 2.0," NASA/CR-1999-209409, NASA Glenn Research Center, Cleveland, Ohio, 1999.

[44] Barlow, J. B., Rae, Jr., W. H., and Pope, A., Low-Speed Wind Tunnel Testing, John Wiley \& Sons, Inc., New York City, New York, 3rd ed., 1999.

[45] Freels, J. R., An Examination of Configurations for Using Infrared to Measure Boundary Layer Transition, Master's thesis, Texas A\&M University, College Station, Texas, 2012.

[46] Crawford, B. K., Duncan, G. T., West, D. E., and Saric, W. S., "LaminarTurbulent Boundary Layer Transition Imaging Using IR Thermography," Optics and Photonics Journal, Vol. 3, 2013, pp. 233-239.

[47] Anderson, J. D., Fundamentals of Aerodynamics, McGraw-Hill, New York City, New York, 4th ed., 2007. 
[48] Press, W. H., Teukolsky, S. A., Vetterling, W. T., and Flannery, B. P., Numerical Recipes in C: The Art of Scientific Computing, Cambridge University Press, New York City, New York, 2nd ed., 1992.

[49] Sheldahl, R. E. and Klimas, P. C., "Aerodynamic Characteristics of Seven Symmetrical Airfoil Sections Through 180-Degree Angle of Attack for Use in Aerodynamic Analysis of Vertical Axis Wind Turbines," SAND80-2114, Sandia National Laboratories, Albuquerque, New Mexico, 1981.

[50] Beer, F. P., Johnston, E., and DeWolf, J. T., Mechanics of Materials, McGrawHill, New York City, New York, 4th ed., 2006.

[51] Fransson, J. H. M., Matsubara, M., and Alfredsson, P. H., "Transition Induced by Free-Stream Turbulence," Journal of Fluid Mechanics, Vol. 527, 2005, pp. 125.

[52] Jonkman, J., Butterfield, W., Musial, W., and Scott, G., "Definition of a 5-MW Reference Wind Turbine for Offshore System Development," NREL/TP-50038060, NREL, Golden, Colorado, 2009.

[53] Elliott, D. and Schwartz, M., "Development and Validation of High-Resolution State Wind Resource Maps for the United States," NREL/TP-500-38127, NREL, Golden, Colorado, 2005.

[54] Platt, A. D. and Buhl, Jr., M. L., WT_PERF User Guide for Version 3.05.00, NREL, Golden, Colorado, Nov. 2012. 
[55] van Rooij, R. P. J. O. M. and Timmer, W. A., "Roughness Sensitivity Considerations for Thick Rotor Blade Airfoils," Journal of Solar Energy Engineering, Vol. 125, Nov. 2003, pp. 468-478.

[56] Somers, D. M., "Effects of Airfoil Thickness and Maximum Lift Coefficient on Roughness Sensitivity," , NREL/SR-500-36336, Airfoils, Inc., Port Matilda, Pennsylvania, 2005.

[57] von Doenhoff, A. E. and Abbott, Jr., F. T., "The Langley Two-Dimensional Low-Turbulence Pressure Tunnel," NACA-TN-1283, NACA, Langley Field, Virginia, 1947.

[58] Smith, A. M. O. and Gamberoni, N., "Transition, Pressure Gradient, and Stability Theory," Douglas Aircraft Company, Report ES 26388, El Segundo, California, 1956.

[59] van Ingen, J. L., "A Suggested Semi-empirical Method for the Calculation of the Bounday Layer Transition Region," Report VTH-74, Delft University of Technology, Delft, Netherlands, 1956.

[60] Gürün, A. M., Interactions of Tollmien-Schlichting Waves and Stationary Transient Disturbances, Ph.D. thesis, Case Western Reserve University, Cleveland, Ohio, 2006. 
APPENDIX A

\section{AIRFOIL COORDINATES}

Table A.1. Interpolated NACA $63_{3}-418$ coordinates.

\begin{tabular}{cccccc}
\hline \hline$x / c$ & $y / c$ & $x / c$ & $y / c$ & $x / c$ & $y / c$ \\
\hline 1.0000 & 0.0012 & 0.1494 & 0.0864 & 0.2904 & -0.0694 \\
0.9800 & 0.0044 & 0.1197 & 0.0785 & 0.3183 & -0.0698 \\
0.9544 & 0.0090 & 0.0854 & 0.0672 & 0.3461 & -0.0695 \\
0.9395 & 0.0120 & 0.0666 & 0.0596 & 0.3739 & -0.0686 \\
0.9093 & 0.0183 & 0.0498 & 0.0517 & 0.4017 & -0.0670 \\
0.8792 & 0.0249 & 0.0351 & 0.0437 & 0.4295 & -0.0649 \\
0.8492 & 0.0317 & 0.0228 & 0.0355 & 0.4572 & -0.0622 \\
0.8191 & 0.0386 & 0.0147 & 0.0292 & 0.4849 & -0.0592 \\
0.7891 & 0.0456 & 0.0085 & 0.0230 & 0.5125 & -0.0558 \\
0.7591 & 0.0526 & 0.0042 & 0.0174 & 0.5401 & -0.0520 \\
0.7290 & 0.0595 & 0.0018 & 0.0130 & 0.5676 & -0.0480 \\
0.6989 & 0.0662 & 0.0003 & 0.0087 & 0.5952 & -0.0438 \\
0.6688 & 0.0726 & -0.0003 & 0.0033 & 0.6226 & -0.0394 \\
0.6386 & 0.0788 & 0.0000 & 0.0000 & 0.6501 & -0.0349 \\
0.6083 & 0.0846 & 0.0012 & -0.0040 & 0.6776 & -0.0303 \\
0.5779 & 0.0900 & 0.0047 & -0.0098 & 0.7050 & -0.0257 \\
0.5475 & 0.0949 & 0.0099 & -0.0153 & 0.7325 & -0.0212 \\
0.5170 & 0.0993 & 0.0165 & -0.0205 & 0.7600 & -0.0168 \\
0.4864 & 0.1031 & 0.0244 & -0.0250 & 0.7942 & -0.0116 \\
0.4557 & 0.1062 & 0.0397 & -0.0319 & 0.8302 & -0.0067 \\
0.4250 & 0.1085 & 0.0573 & -0.0382 & 0.8678 & -0.0023 \\
0.3942 & 0.1100 & 0.0768 & -0.0438 & 0.8970 & 0.0003 \\
0.3634 & 0.1106 & 0.0969 & -0.0486 & 0.9161 & 0.0017 \\
0.3325 & 0.1102 & 0.1243 & -0.0540 & 0.9339 & 0.0025 \\
0.3017 & 0.1088 & 0.1518 & -0.0584 & 0.9502 & 0.0028 \\
0.2710 & 0.1064 & 0.1794 & -0.0619 & 0.9675 & 0.0021 \\
0.2404 & 0.1030 & 0.2071 & -0.0648 & 0.9800 & 0.0011 \\
0.2099 & 0.0986 & 0.2348 & -0.0670 & 0.9904 & 0.0000 \\
0.1795 & 0.0931 & 0.2626 & -0.0685 & 1.0000 & -0.0012 \\
\hline \hline & & & & &
\end{tabular}




\section{APPENDIX B}

\section{AIRFOIL PRESSURE PORTS}

Table B.1. Pressure port locations, with $z / c$ of zero at midspan. Upper ordinates are on the left and lower ordinates are on the right.

\begin{tabular}{cccccc}
\hline \hline$x / c$ & $y / c$ & $z / c$ & $x / c$ & $y / c$ & $z / c$ \\
\hline 0.95 & 0.0098 & -0.3281 & 0 & 0 & 0 \\
0.9147 & 0.0172 & -0.3164 & 0.0013 & -0.0040 & 0.0117 \\
0.8604 & 0.0292 & -0.3047 & 0.005 & -0.0102 & 0.0234 \\
0.8061 & 0.0417 & -0.293 & 0.0113 & -0.0165 & 0.0352 \\
0.7517 & 0.0543 & -0.2813 & 0.02 & -0.0227 & 0.0469 \\
0.6974 & 0.0665 & -0.2695 & 0.0313 & -0.0283 & 0.0586 \\
0.6431 & 0.0779 & -0.2578 & 0.045 & -0.0339 & 0.0703 \\
0.5888 & 0.0881 & -0.2461 & 0.0613 & -0.0394 & 0.082 \\
0.5345 & 0.0947 & -0.2344 & 0.08 & -0.0446 & 0.0938 \\
0.4802 & 0.1038 & -0.2227 & 0.1013 & -0.0496 & 0.1055 \\
0.4259 & 0.1085 & -0.2109 & 0.125 & -0.0541 & 0.1172 \\
0.3716 & 0.1106 & -0.1992 & 0.1586 & -0.0592 & 0.1289 \\
0.3172 & 0.1097 & -0.1875 & 0.2173 & -0.0657 & 0.1406 \\
0.2629 & 0.1056 & -0.1758 & 0.2759 & -0.0690 & 0.1523 \\
0.2086 & 0.0984 & -0.1641 & 0.3345 & -0.0697 & 0.1641 \\
0.1543 & 0.0881 & -0.1523 & 0.3931 & -0.0675 & 0.1758 \\
0.125 & 0.0800 & -0.1406 & 0.4517 & -0.0628 & 0.1875 \\
0.1013 & 0.0727 & -0.1289 & 0.5104 & -0.0571 & 0.1992 \\
0.08 & 0.0651 & -0.1172 & 0.569 & -0.0478 & 0.2109 \\
0.0613 & 0.0572 & -0.1055 & 0.6276 & -0.0386 & 0.2227 \\
0.045 & 0.0493 & -0.0938 & 0.6862 & -0.0289 & 0.2344 \\
0.0313 & 0.0413 & -0.082 & 0.7449 & -0.0192 & 0.2461 \\
0.02 & 0.0335 & -0.0703 & 0.8035 & -0.0103 & 0.2578 \\
0.0113 & 0.0260 & -0.0586 & 0.8621 & -0.0029 & 0.2695 \\
0.005 & 0.0185 & -0.0469 & 0.9207 & 0.0004 & 0.2813 \\
0.0013 & 0.0117 & -0.0352 & & & \\
0 & 0.0072 & -0.0234 & & & \\
-0.0003 & 0.0035 & -0.0117 & & & \\
\hline \hline & & & & & \\
0.04
\end{tabular}




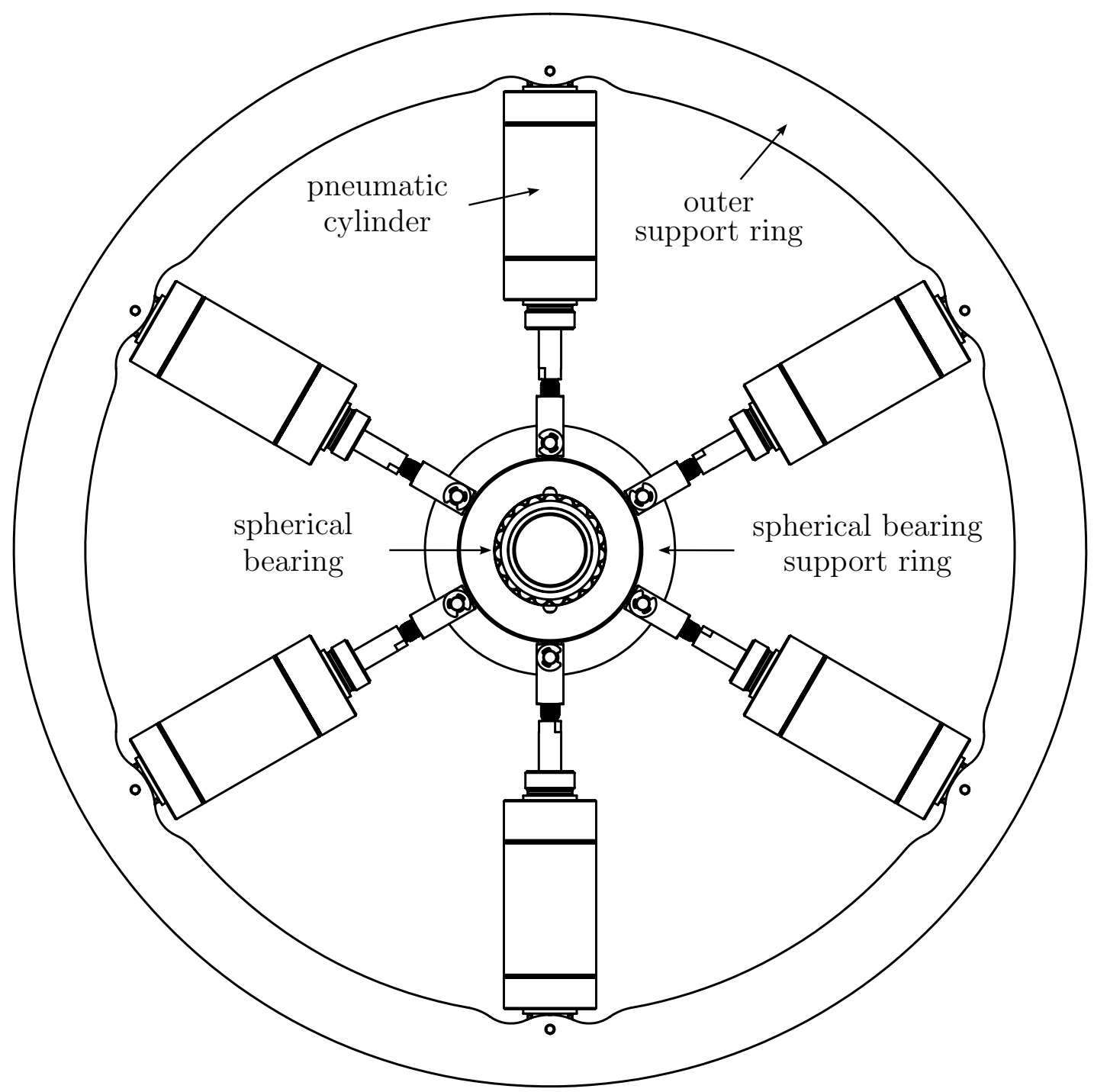

Figure C.1. Drawing of the compliant ceiling mount. The pneumatic cylinders permit planar motions, while the spherical bearing allows rotational compliance. The outer support ring optionally mounts to a balance. 


\section{APPENDIX D}

\section{WAKE RAKE PITOT LOCATIONS}

Table D.1. Wake rake Pitot pressure locations, with $z / c$ of zero at midspan.

\begin{tabular}{c}
\hline \hline$z / c$ \\
\hline-0.3094 \\
-0.2531 \\
-0.1969 \\
-0.1688 \\
-0.1406 \\
-0.1125 \\
-0.0844 \\
-0.0703 \\
-0.0563 \\
-0.0422 \\
-0.0281 \\
-0.0141 \\
0.0000 \\
0.0141 \\
0.0281 \\
0.0422 \\
0.0563 \\
0.0703 \\
0.0844 \\
0.1125 \\
0.1406 \\
0.1688 \\
0.1969 \\
0.2531 \\
0.3094 \\
\hline \hline
\end{tabular}




\section{APPENDIX E}

\section{BOUNDARY LAYER RAKE POSITIONS}

Table E.1. Relative positions of the Pitot boundary layer rake probes. The wall is at $y=0$.

\begin{tabular}{c}
\hline \hline$y$ inch $]$ \\
\hline 0.019 \\
0.031 \\
0.042 \\
0.054 \\
0.070 \\
0.073 \\
0.089 \\
0.099 \\
0.116 \\
0.151 \\
0.157 \\
0.358 \\
0.548 \\
0.737 \\
1.142 \\
1.347 \\
1.551 \\
1.751 \\
1.952 \\
\hline \hline
\end{tabular}




\section{APPENDIX F}

\section{HOTFILM SENSOR LOCATIONS}

Table F.1. Hotfilm sensor locations.

\begin{tabular}{c}
\hline \hline$x / c$ \\
\hline 0.04 \\
0.08 \\
0.12 \\
0.16 \\
0.200 \\
0.231 \\
0.254 \\
0.285 \\
0.316 \\
0.348 \\
0.380 \\
0.410 \\
0.48 \\
0.56 \\
\hline \hline
\end{tabular}




\section{APPENDIX G}

\section{AIRFOIL PERFORMANCE SUMMARY}

Table G.1. Airfoil performance summary at $\boldsymbol{R e}_{c}=1.6 \times 10^{6}$.

\begin{tabular}{cccc}
\hline \hline Configuration & $\Delta d c_{l} / d \alpha[\%]$ & $\Delta c_{l \max }[\%]$ & $\Delta L / D_{\max }[\%]$ \\
\hline clean & $6.761 \pm 0.039 \mathrm{rad}^{-1}$ & $1.306 \pm 0.007$ & $147 \pm 16$ \\
WFF & -0.4 & 0.9 & -2.4 \\
trip & -6.6 & -10.8 & -57.9 \\
$100-03$ & -0.5 & -2.1 & -20.4 \\
$100-09$ & -0.5 & -1.3 & -18.0 \\
$100-15$ & -0.8 & -4.2 & -31.1 \\
$140-03$ & -2.6 & -5.3 & -29.2 \\
$140-03 \mathrm{E}$ & -3.5 & -5.2 & -31.2 \\
$140-06$ & -3.7 & -6.3 & - \\
$140-09$ & -4.5 & -6.9 & -31.5 \\
$140-12$ & -5.4 & -7.5 & -43.0 \\
$140-15$ & -5.6 & -6.5 & -43.5 \\
$200-03$ & -5.9 & -6.0 & -45.8 \\
\hline \hline
\end{tabular}


Table G.2. Airfoil performance summary at $R e_{c}=2.4 \times 10^{6}$.

\begin{tabular}{cccc}
\hline \hline Configuration & $\Delta d c_{l} / d \alpha[\%]$ & $\Delta c_{l \max }[\%]$ & $\Delta L / D_{\max }[\%]$ \\
\hline clean & $6.730 \pm 0.017 \mathrm{rad}^{-1}$ & $1.324 \pm 0.003$ & $107 \pm 5$ \\
WFF & 0.1 & -0.6 & -5.5 \\
trip & -4.9 & -10.8 & -49.1 \\
$100-03$ & -0.1 & -1.6 & -0.8 \\
$100-09$ & -0.5 & -2.1 & -1.7 \\
$100-15$ & -1.6 & -4.0 & -13.2 \\
$140-03$ & -4.8 & -3.1 & -32.8 \\
$140-03 \mathrm{E}$ & -4.9 & -4.4 & -34.8 \\
$140-06$ & -4.7 & -3.7 & -31.0 \\
$140-09$ & -5.8 & -6.6 & -36.3 \\
$140-12$ & -6.1 & -6.7 & -39.1 \\
$140-15$ & -5.8 & -7.2 & -40.1 \\
$200-03$ & -5.7 & -1.4 & -35.7 \\
\hline \hline
\end{tabular}

Table G.3. Airfoil performance summary at $R e_{c}=3.2 \times 10^{6}$.

\begin{tabular}{cccc}
\hline Configuration & $\Delta d c_{l} / d \alpha[\%]$ & $\Delta c_{l \max }[\%]$ & $\Delta L / D_{\max }[\%]$ \\
\hline clean & $6.725 \pm 0.010 \mathrm{rad}^{-1}$ & $1.368 \pm 0.002$ & $106 \pm 5$ \\
WFF & -0.5 & -0.1 & -5.8 \\
trip & -4.7 & -12.4 & -45.2 \\
$100-03$ & -0.3 & -3.4 & -18.2 \\
$100-09$ & -1.6 & -4.8 & -23.7 \\
$100-15$ & -3.1 & -6.0 & -31.6 \\
$140-03$ & -3.4 & -4.0 & -35.4 \\
$140-03 \mathrm{E}$ & -2.8 & -5.6 & -37.1 \\
$140-06$ & -3.7 & -5.6 & -37.1 \\
$140-09$ & -3.6 & -7.4 & -39.1 \\
$140-12$ & -3.6 & -7.8 & -40.2 \\
$140-15$ & -3.7 & -8.7 & -40.8 \\
$200-03$ & -2.4 & -1.3 & -36.8 \\
\hline \hline
\end{tabular}


Table G.4. Airfoil performance summary at $R e_{c}=4.0 \times 10^{6}$.

\begin{tabular}{cccc}
\hline \hline Configuration & $\Delta d c_{l} / d \alpha[\%]$ & $\Delta c_{l \max }[\%]$ & $\Delta L / D_{\max }[\%]$ \\
\hline clean & $6.798 \pm 0.008 \mathrm{rad}^{-1}$ & - & $103 \pm 4$ \\
WFF & - & - & - \\
trip & - & - & - \\
$100-03$ & -2.5 & - & -23.3 \\
$100-09$ & -2.6 & - & -29.7 \\
$100-15$ & -3.3 & - & -32.5 \\
$140-03$ & -2.3 & - & -32.0 \\
$140-03 \mathrm{E}$ & -2.4 & - & -32.6 \\
$140-06$ & -2.3 & - & -32.7 \\
$140-09$ & -2.2 & - & -35.4 \\
$140-12$ & -3.1 & - & -33.8 \\
$140-15$ & -2.5 & - & -36.3 \\
$200-03$ & -3.1 & - & -35.1 \\
\hline \hline
\end{tabular}




\section{APPENDIX H}

INFRARED THERMOGRAPHY SUMMARY

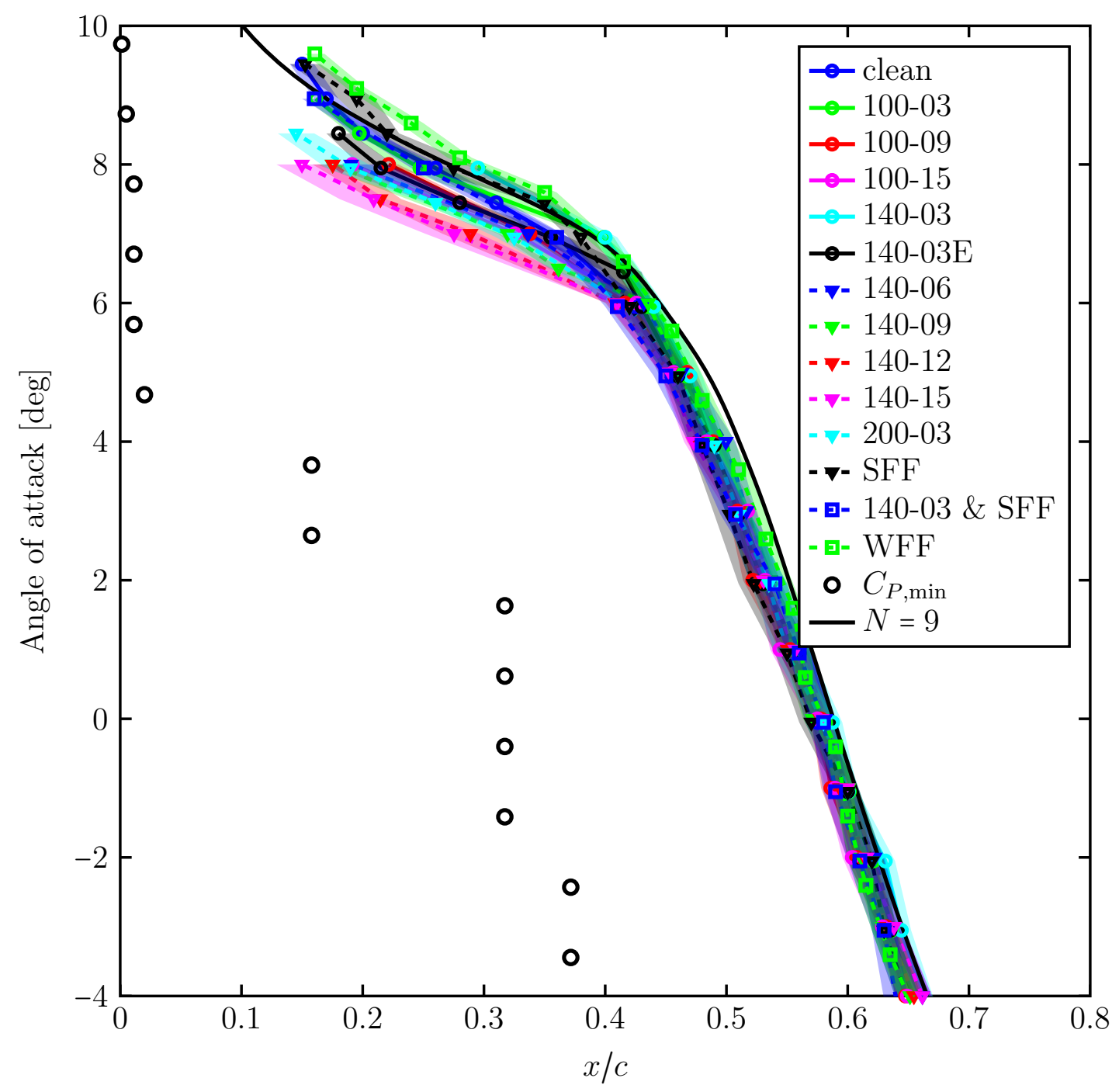

Figure H.1. IR boundary-layer transition at $R e_{c}=0.8 \times 10^{6}$. 


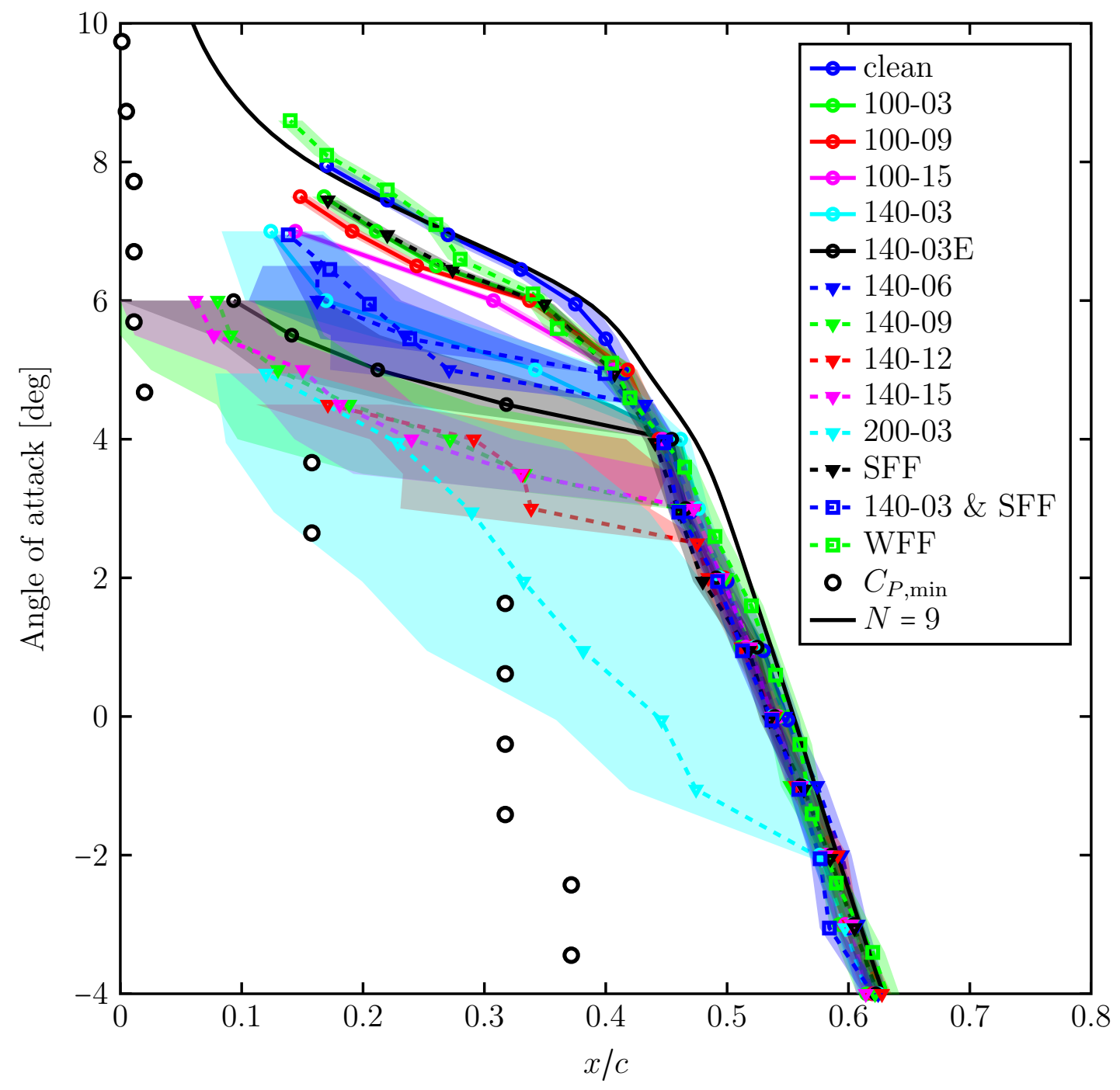

Figure H.2. IR boundary-layer transition at $R e_{c}=1.6 \times 10^{6}$. 


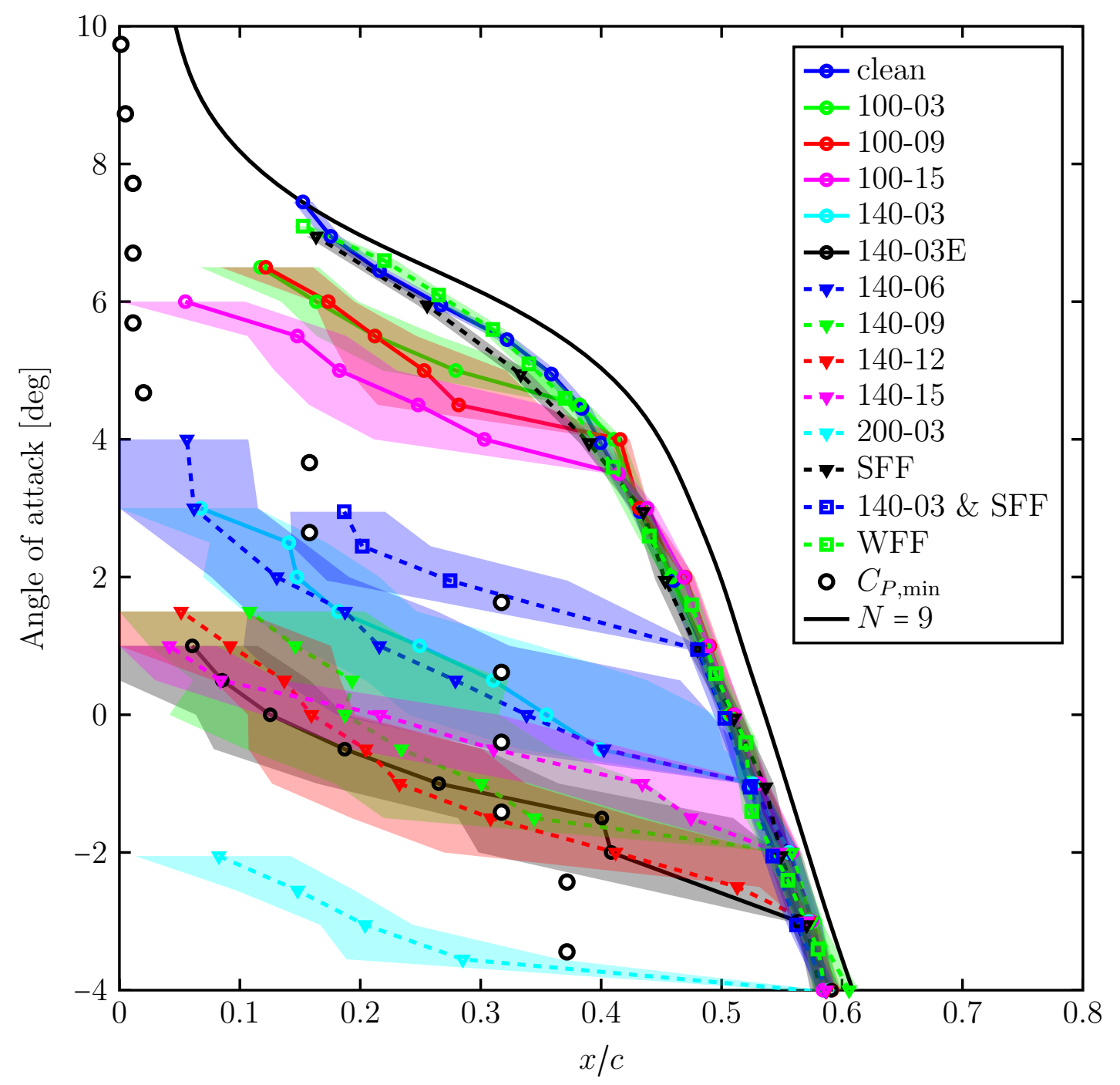

Figure H.3. IR boundary-layer transition at $R e_{c}=2.4 \times 10^{6}$. 


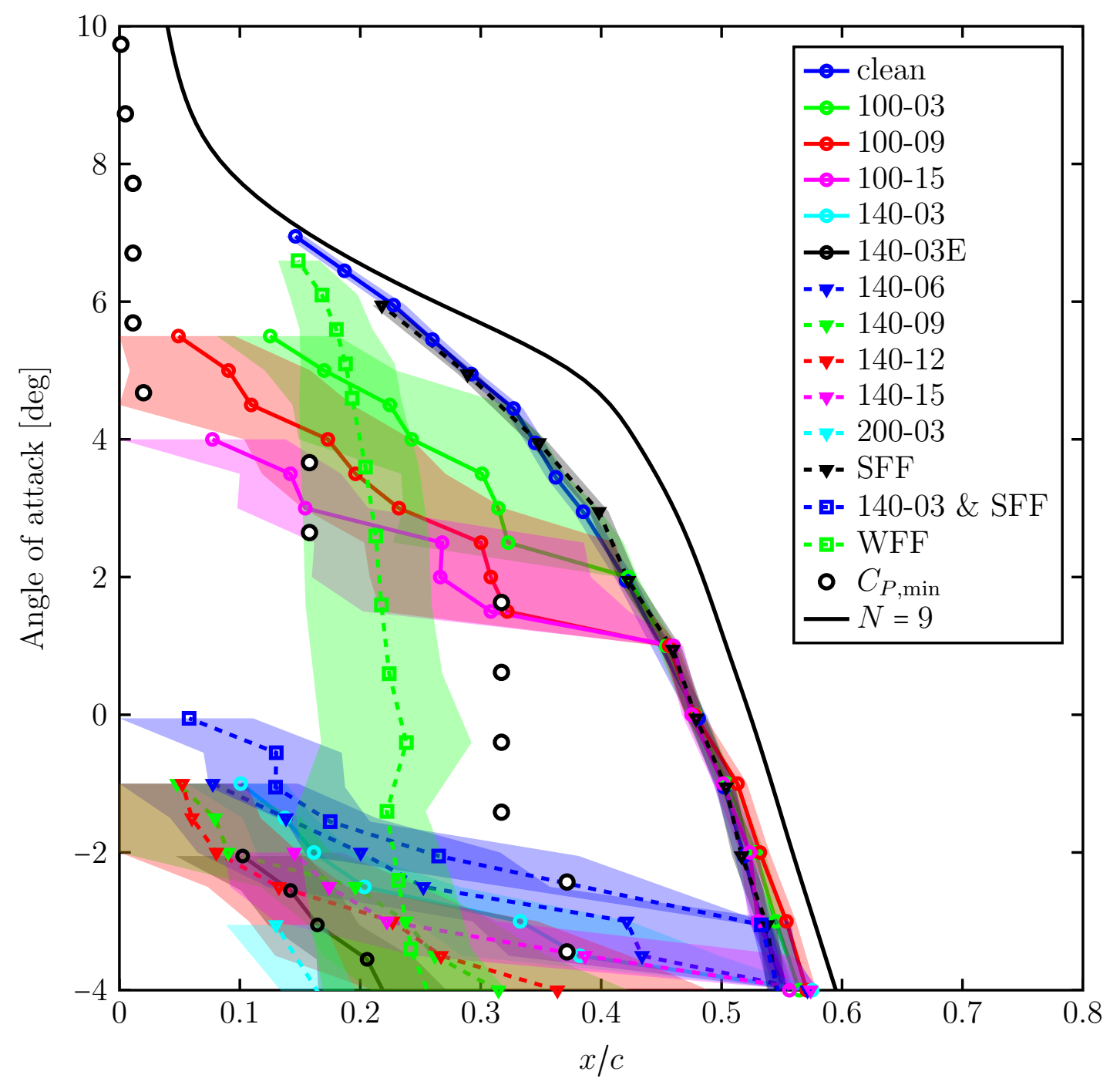

Figure H.4. IR boundary-layer transition at $R e_{c}=3.2 \times 10^{6}$. 


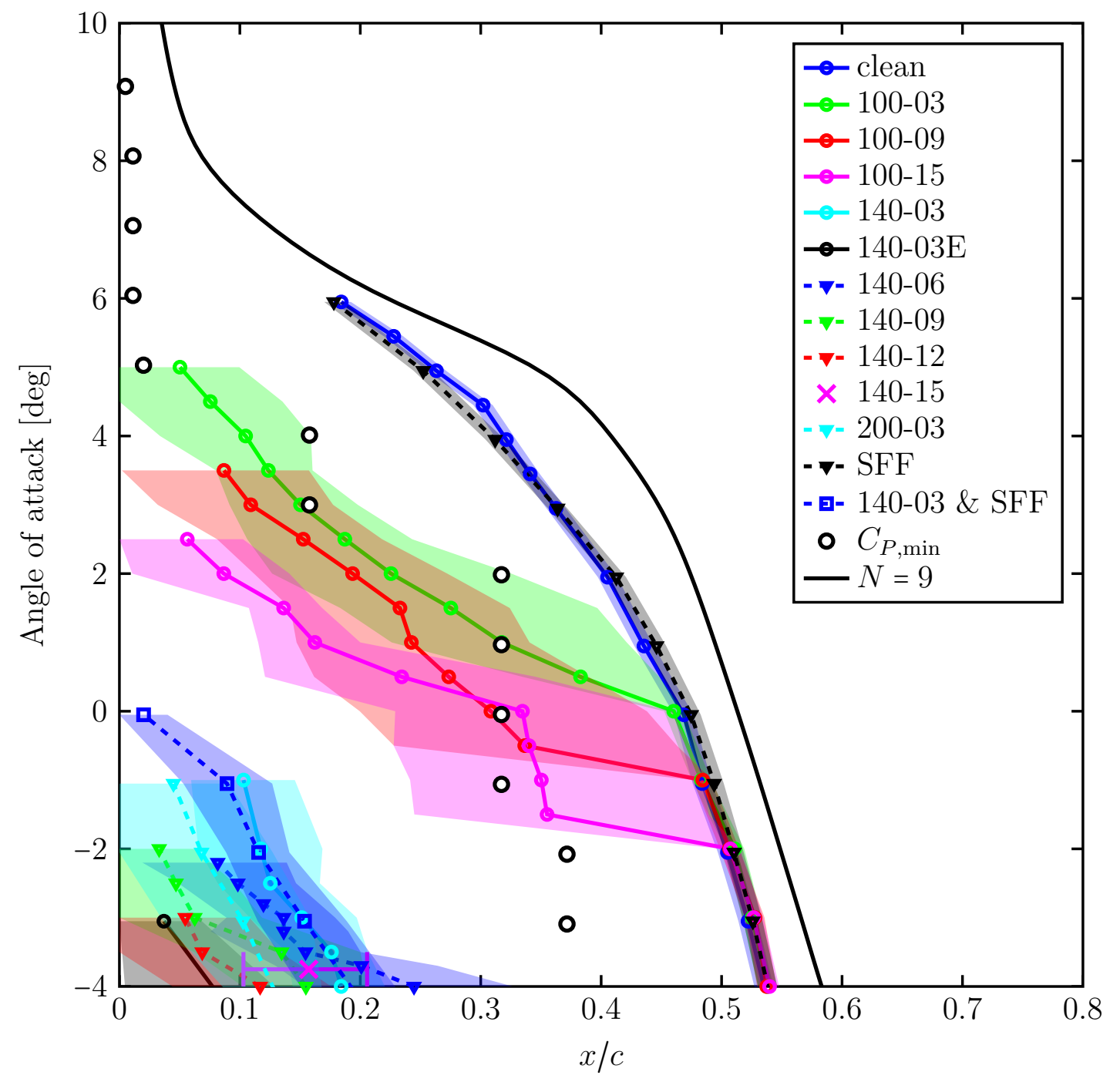

Figure H.5. IR boundary-layer transition at $R e_{c}=4.0 \times 10^{6}$. 


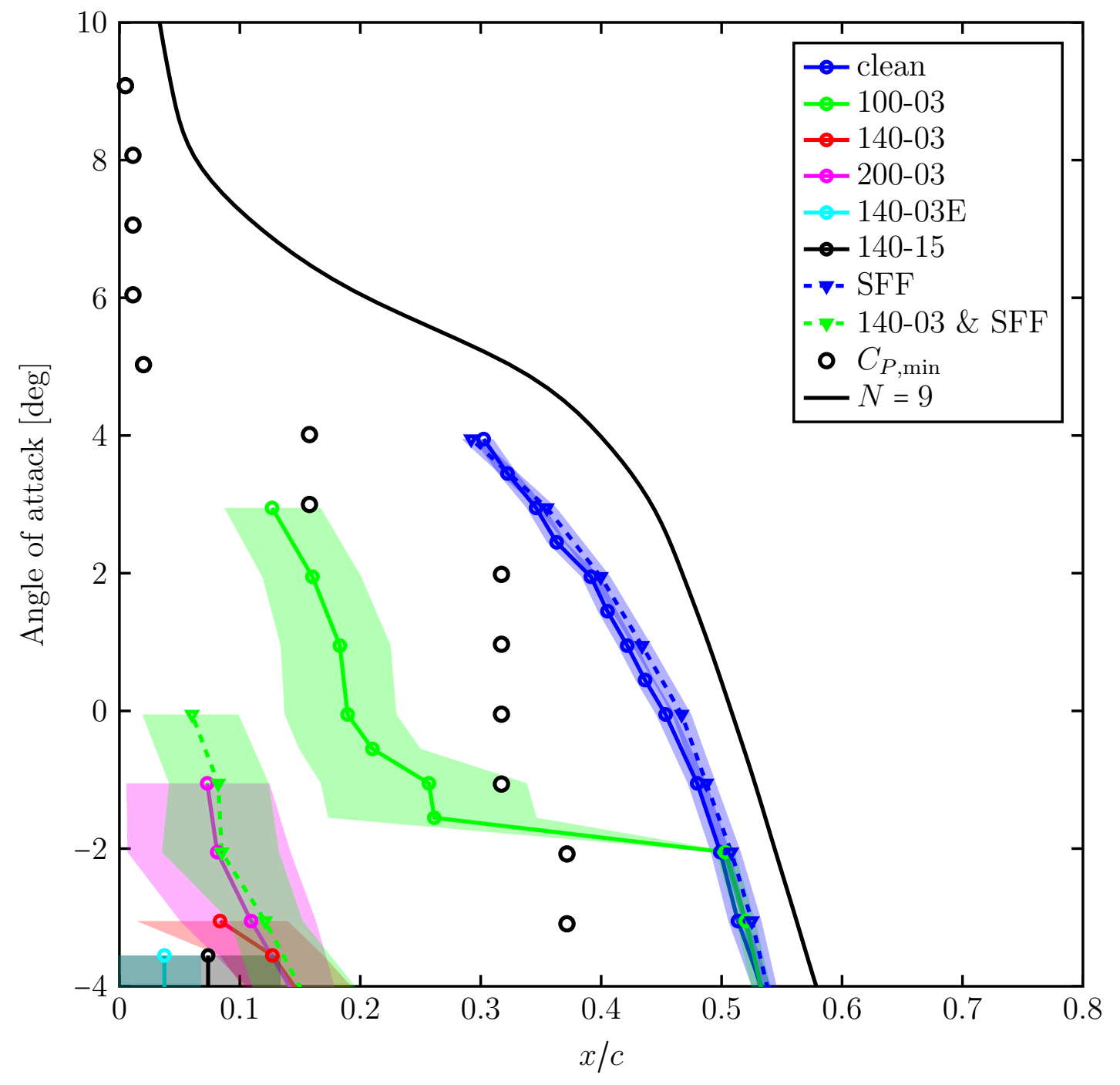

Figure H.6. IR boundary-layer transition at $R e_{c}=4.4 \times 10^{6}$. 


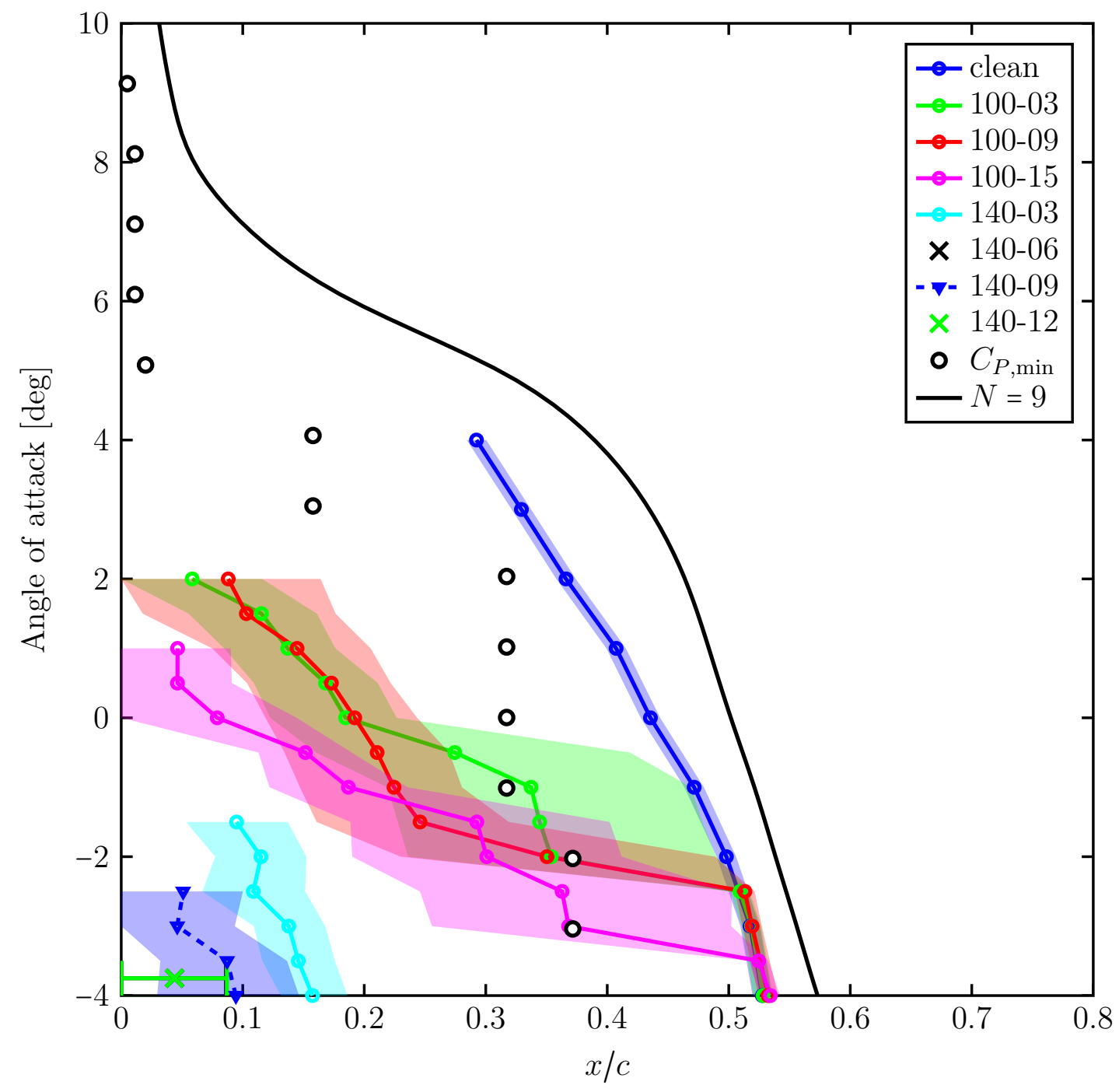

Figure H.7. IR boundary-layer transition at $R e_{c}=4.8 \times 10^{6}$. 


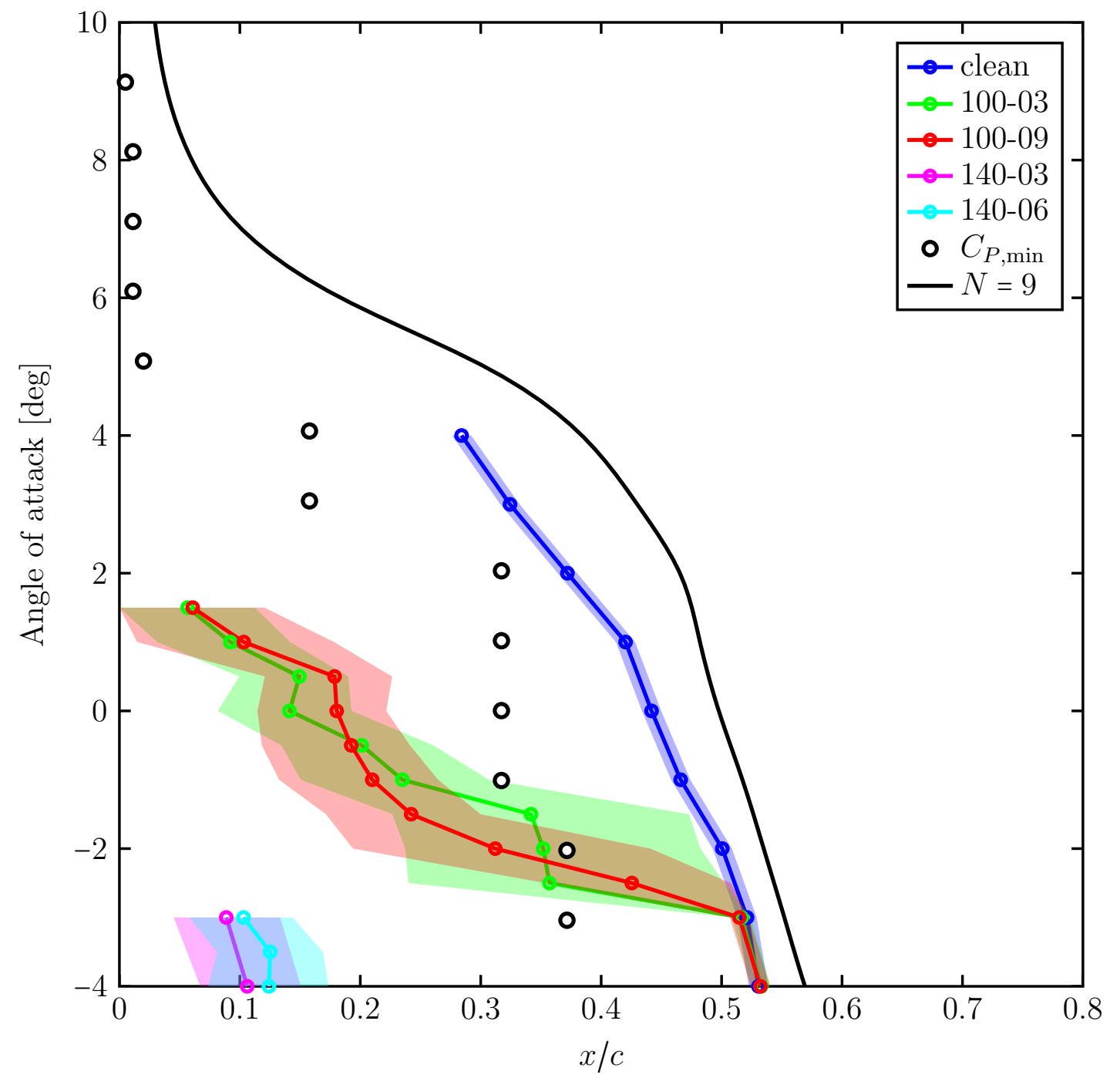

Figure H.8. IR boundary-layer transition at $R e_{c}=5.0 \times 10^{6}$. 